\title{
Assessment Report on the Kinetics of Radionuclide Adsorption on Yucca Mountain Tuff
}

\author{
R. S. Rundberg
}

LA- -11026-MS

DE88 006031

\section{DISCLAIMER}

This report was prepared as an account of work sponsored by an agency of the United States Government Neither the United States Government nor any agency thereof, nor any of their employees, makes any warranty, express or implied, or assumes any legal liability or responsibility for the accuracy, completeness, or usefulness of any information, apparatus, product, or process disclosed, or represents that its use would not infringe privately owned rights. Reference herein to any specific commercial product, process, or service by trade name, trademark, manufacturer, or otherwise does not necessarily constitute or imply its endorsement, recommendation, or favoring by the United States Government or any agency thereof. The views and opinions of authors expressed herein do not necessarily state or reflect those of the United States Government or any agency ther zof.
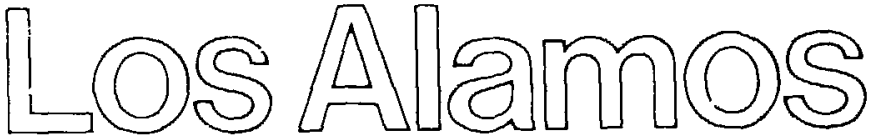


\section{Contents}

ABSTRACT . . . . . . . . . . . . . . . . . . . .

I. INTRODLCTION . . . . . . . . . . . . . . . . . . . . . . 1

11. ELITION CLRVE SPREADING IN CRLSHED-TLFF COLCMNS . . . . . 3

A. The Theory of Column Chromatography . . . . . . . . . . . . . . . . 4

B. Experiment Results . . . . . . . . . . . . . . . . . . . . . . . . 5

C. Conclusions . . . . . . . . . . . . . . . 8

III. THE LPTAKE OF (ATIONS ON TLFF WAFERS . . . . . . . . 8

A. Experiment . . . . . . . . . . . . . 11

B. Results and Discussion . . . . . . . . . . . . . . . . . . . 11

C. Conclusions . . . . . . . . . . . . . . . 17

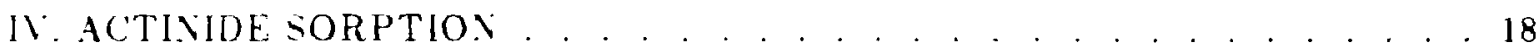

A. Time Dependence of Actinide jorption in Batch Measurements . . . . . . 18

B. Conclusions . . . . . . . . . . . . . . . 23

V. WATER VELOCITY LIMITS FOR APPLYING SORPTION RATIOS . . . . . 24

A. The Thomas Solution . . . . . . . . . . . . . . . . . . . . . . . . 24

B. Calculated Limits . . . . . . . . . . . . . . . . . . . . . . 28

V1. SIMMARY AND CONCLLSIONS . . . . . . . . . . 31

REFERENCES . . . . . . . . . . . . . . . . 34

APPEYDIX A. Fits of Column Elution to Mass Transfer Solution . . . . . . . . 37

APPENIIX B. Fits of Wafer Liptake to Kinetic Model . . . . . . . . . . . . . 84 


\title{
ASSESSMENT REPORT ON THE KINETIC'S OF RADIONITLIDE ADSORPTION ON YICOA MOUNTAIN TUTF \\ R. S. Rundberg
}

\begin{abstract}
ABSTRAC'T
The kinetics of sorption was measured by observing the uptake of radionuclides by tuff wafers and crushed tuff as a function of time. In addition. the broadening of breakthrough curves for cations eluted through crushed-tuff colnmms was interpreted in terms of adsorption kinetics. The results of these measurements are consistent with a diffusion-limited adsorption mechanism for simple cations. such as strontium. cesium, and barium. The adsorption kinetics for these simple cations is sufficiently fast so that equilibrium can be assumed for the retardation of these chemical species in the groundwater velocities that would be reasonable for must release scenarios. The actinides. in particular plutonium. exhibited a slow time dependence for adsorption. The lack of reproducibility in sorption neasurements for actinides makes the interpretation of those results tenuous. The further study of actinide sorption kinetics is. therefore. recommended.
\end{abstract}

\section{INTRODIT:TION}

The minerals present in the tuff underlying Yucca Mountain. Nevada. provide a natural barrier to the movement of radionuclides. ${ }^{1}$ This geochemical barrier is under study by the Vevada Nuclear Naste Storage Investigations Project, which is examining the suitability of the Yucra Mountain site as a potential high-level nuclear waste repository. This geochemical barrier is generally due to the adsorption of radionuclides on the internal and external surfaces of aluminosilicate and. to a lesser extent, metal oxide minerals. The result is a stowing or retardation of the radionuclides with respect to the velocity of the water: analogous liquid chromatography studies ran be performed in the laboratory. The overall proces; of moving solutes through chromatographic columns. which includes ad- 
vertion, diffusion. dispersion, and adsorplion. in called masis transfer. The performatere of a chromatographic column is measured in cerms of the mumber of theoretical plates or

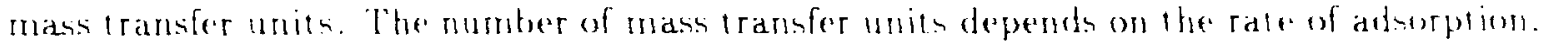
among other things. The commonly used formula that relates the retardation fartor to the sorption ratio assumes a large number of mass transfer units. An excessively low mumber of mass transfer units an lead to earlier breakthrough than predicted.

The rate of adsorption of radionuclides on tuff mat be limited by diffusion. reaction between chemical species. or reaction with the solid phase. The study of adsorption kinetics can provide a basis for a lundamental understanding of the adsorption process. In addition to surface absorption. a mechanism that has extremely slow kinetics and that may provide a barrier to radionuclide migration is the dissolution and subsequent recrystallizalion of minerals. Some radionuclides can be incorporated into the newly formed mineral crystats and become permanenty immobilized. The time scale required to examine this phenomena under the conditions experted in the field is not feasible for laboratory study.

linderstanding the kinetics of adsorption is important for the correct interpretation of laboratory radionuclide migration experimerlts because some radionuclides, for whatever reason. exhibit changes in adsorption ratios with time (for example, plutonium and americium ${ }^{2}$ ) and also because some transport experiments involve relatively high water velocities (for example. experiments involving transport by fracture flow). The interpretation of some phenomena is ambiguous unless sorption kinetics are conridered. For instance. some radionuclides elute rapidly through a crushed-tuff column because of kinetics. uncharged or negatively charged species. or colloids. To interpret these results, supporting evidence will be required from several independent experiments.

Rate constants for the kinetics of adsorption are necessary to establish firm limits on water velocities for which equilibrium sorption mechanisms can be assumed. This will be irmportant in the assessinent of repository performance under scenarios that involve increased water velocities above those used in the laboratory colurns studies. If the velocities considered in the scenarios are above these limits, we retardation factors will have to be adjusted accordingly. A series of limits based on the Thomas solution are provided in tier. $V$ of this report.

Reaction rates and rate laws have been widely used in chenical research to elucidate the mechanism of reaction. The order of the dependence of the reaction rate on the reactiant concentrations can be used to infer the identity of an intermediate species in the reaction mechanism. The magnitude rate constants or activation energy for reaction can also be used to infer a reaction mechanism. For example. the exchange of ions on a surface would likely have essentially no errgy barrier and the rate should only be diffusion limited. 
The effect of sorption kinetics can be observed in several ways. The shape of tracer elutions through crushed-tuff columns can provide an estimate of the rate of reaction. In column chromatography studies. usually the theoretical plate height increases, and therefore. the peak width increases at very low fluid velocity where longitudinal diffusion is significant. As the fluid velocity in a chromatographic column increases, the plate height will decrease until reaction kinetics prevents the solute from completely equilibrating with the solid phase. at which point the plate height is minimized with respect to fluid velocity and increases with increasing velocity. Column chromatography has been well described using solutions to the mass transfer equations developed for linear reactions. The uptake of solutes in crushed tuff or tuff wafers will yield reaction rates if the rate of reaction is slower than the rate of diffusion into the tuff particles or wafers. If the reaction is much sower than cifrusion into the particles, the reaction sate law can be determined directly. If the rate of diffusion and reaction are nearly equal, interpretation is more complex but can be carried mul using the method described in Sec. 111.

The purpose of this report is to (1) present the known rate constants for the adsorption of cations on tuff, (2) provide velocity limits for which measured sorption ratios for tuff are valid, (3) discuss the anomalous behavior of actinides in terms of kinetics, (4) assess what impart kinetics could have on the transport of actinides, and (5) provide data that can be used to validate transport models involving nonequilibrium sorption.

\section{I. ELUTION CURVE SPREADING IN CRUSHED-TUFF COLUMNS}

Strontium, cesium, barium, and other simple cations should interact with zeolites and clays in geologic media by means of an ion exchange mechanism. Erickson's sorption experiments with argillite show that the rate of sorption is diffusion conirolled. ${ }^{3}$ Sorption of strontium, cesium, and barium have been shown to correlate with the mineralogy of tuff from Yucca Mountain." The Freundlich isotherms ${ }^{4,5}$ determined for tuffs are also consistent with an ion exchange mechanism. To further test this mechanism, the results of experiments with crushed-rock columns were compared with what would be expected from conventioral ion exchange liquid chromatography.

The absorption bcharine of the actinides with tuff appears to be more complex. Complete clution curves for actinides in crushed tuff as a function of water velocity are not yet available. and thus. the effect of rmass transfer kinetics on actinide elution curves cannot be addressed at this tine. The kinetics of adsorption will be addressed in the context of other experiments in sier. Il. 


\section{A. The Theory of Column Chromatography}

The sharpness of a column breakthrough curve depends on the number of mass transfer units or the number of theoretical plates. This is illustrated in the solution to the mass transport equation derived by Thomas (discussed in detail in Sec. V). The larger the number of mass transfer units or theoretical plates, the sharper the breakthrough curve. Vote that chemists prefer to use theoretical plates, chemical engineers prefer mass transfer units, and hydrologists prefer the Peclet number. Because various disciplines use a solution nearly identical to the Thomas solution (fo: large values of $\mathbf{N}$ ), the parameters are similar or at least proportional to each other However, the Peclet number does not include the chemical processes included in the mass transfer number. The number of theoretical plates for a given column is equal to the iength of the column divided by the theoretical plate height. Thus, the sharpness of the breakthrough curve is inversely proportional to the plate height. The following discussion is not a rigorous theoretical treatment, but it accounts for the general performance of chromatographic columns.

The theoretical plate height, $\mathrm{H}$, in column chromatography is the sum of at least four factors and can be represented by the following equation. ${ }^{6}$

$$
H=H_{p}+H_{d}+H_{s}+H_{m},
$$

where

$H_{V}$ is due to dispersion,

$H_{t}=$ is due to molecular diffusion,

$H_{s} \quad$ is due to mass transfer, sorption-desorption kinetics, and

$H_{r n}$ is due to mass transfer, zone spreading.

The first term, which is due to dispersion, has no velocity dependence and can be represented by the equation

$$
H_{I}, \quad 2 \lambda d_{\eta}, \quad,
$$

where $\lambda$ is a constant that depends on the packing and $d_{F}$ is the particle diameter. This contribution to the plate height results in broadening of the chromatographic peak caused by the distribution of flow velocities and flow paths. Nonuniform packing of the column will result in a wider distribution of flow velocities and, therefore. broader peaks.

The second term. the molecular diffusion term, is inversely proportional to fluid velocity and. therefore becomes dominant at slow fluid velocities. This relationship is represented by the equation

$$
H_{d}=2 \gamma D D_{n}, l .
$$


where

$$
\begin{aligned}
& \quad \text { tortuosity factor. } \\
& \mathrm{D}_{m} \quad=\text { diffusion coefficient in the mobile phase, and } \\
& i \quad=\text { average fluid velocity. }
\end{aligned}
$$

The tortuosity factor is actually inversely proportional to the tortuosity of the flow paths. spherical beads yield a tortuosity factor of $\sim 0.6$ (Ref. 7 ).

The last two terms are due to the kinetics of sorption and desorption. Because the rate of ion exchange is normally diffusion controlled, these relationships are expressed in terms of the diffusion coefficients of the ions and the geometry of the exchange particles. Both these terms are directly proportional to the fluid velocity. and they are represented as

$$
H_{s} \therefore \operatorname{qrd}^{2} v_{s},
$$

where

$q$ - configuration factor,

$r \quad \because$ constant dependent on the relative migration rate,

$d=$ thickness of the stationary phase, and

$\mathrm{D}_{z}=$ diffusion coefficient in the stationary phase:

and

$$
H_{m}-\mathcal{L} d_{p}^{2} v: D_{m}
$$

where 2 is another configuration factor. These equations show that at low fluid velocilies the plate height is determined by molecular longitudinal diffusion and at high fluid velocities by the rate of mass transfer.

\section{B. Experiment Results}

The fluid ielocities used in most of the crushed-rock column experiments are low enough for the theoretical plate height to be estimated on the basis of longitudinal diffusion in the mobile phase. A small set of crushed-rock columns were chosen to illustrate this.

The diffusion coefficients can be calculated from ionic conductivities using Vernst.'s equation for single-ion diffusion coefficients at infinite dilution.

$$
\begin{aligned}
& \begin{array}{l}
I_{i}^{2}, \quad F T \Lambda_{1} \\
F-Z_{1}
\end{array} \\
& 8.931+101 . T \Lambda_{1} .
\end{aligned}
$$


TABLE 1

DIFFUSION COEFFICIENTS

\begin{tabular}{lcr} 
Cation & Ionic Concuctivity & \multicolumn{1}{c}{$\mathrm{D}_{0}^{2}$} \\
$\left\langle\mathrm{~cm}^{2} / \mathrm{s}\right\}$
\end{tabular}

where

$\mathrm{T}$ - temperature in degrees Kelvin,

$\Lambda_{2}=$ ionic conductivity, and

$\mathrm{Z}_{1}=$ ionic charge.

The single-ion diffusion coefficients were thus calculated from the ionic conductivities ${ }^{9}$ and are given in Table I. The theoretical plate heights were then calculated using $\gamma=0.6$ for the YM-54-1 tuff column. As can be seen in Table II, the resulting plate heights are too large. The plate heights were also calculated with $\gamma$ adjusted to give a best fit to the actual plate heights. The calculated theoretical plate heights are large enough to demonstrate that no unusually slow mechanism for sorption is necessary to explain the data in these cases. The calculated plate heights shown in Table II can be compared with those in Table III. Except for the case of column CS-5-2, which was run at a high flow rate, the peak shapes are adequately described by diffusional broadening.

The performance of chromatographic columns is sometimes expressed in terms of the reduced plate height, $h$, and the reduced fluid velocity, $n$ :

$$
\begin{aligned}
& h=H / d_{p} \text { and } \\
& n=d_{p} r / D_{m} .
\end{aligned}
$$

Surprisingly close agreement was obtained when the reduced plate heights for the two CS-5 (Climax Stock granite) crushed-rock columns were compared with the theoretical values for a typically efficient chromatographic column. ${ }^{1 "}$ Assuming a particle cliameter of $70 \mu \mathrm{m}$ (median of the sieve fraction), the reduced plate height for column CS-5-1 is 11.0 and the reduced velocity is 0.09 . The reduced plate height for column CS5-2 is 8.0 and the reduced velocity is 8.0 . These results are within $10 \%$ of the theoretical values. ${ }^{11}$ 
TABLE II

THEORETICAL PLATE HEIGHTS CALCLLATED ON THE

BASIS OF MOLECILAR DIFFISIONONLY

\begin{tabular}{|c|c|c|c|c|c|c|}
\hline Cation & $\begin{array}{l}Y M-54-1 \\
(7-0.6)\end{array}$ & $\begin{array}{l}Y \mathrm{M}-54-1 \\
(7-0.17)\end{array}$ & $\begin{array}{l}(\mathrm{M}-54-3 \\
(y=0.21)\end{array}$ & $\begin{array}{l}Y M-22 B \\
(\gamma=0.35)\end{array}$ & $\begin{array}{c}(C S-5-1 \\
(y-0.40)\end{array}$ & $\begin{array}{c}(C S-5-2 \\
(y-0.10)\end{array}$ \\
\hline$S r^{2-}$ & 0.14 & 0.040 & 0.046 & 0.032 & 0.064 & 0.001 \\
\hline $\mathrm{Cs}^{-}$ & 0.37 & 0.104 & 0.121 & 0.083 & -- & \\
\hline$B \mathrm{a}^{2-}$ & 0.15 & 0.043 & 0.050 & 0.034 & 0.068 & 0.001 \\
\hline
\end{tabular}

TABLE III

CRLSHED-ROCK COLLMN PERFORMA.VCE

\begin{tabular}{|c|c|c|c|c|c|c|}
\hline Column & $\begin{array}{l}\text { Velocity } \\
\text { (crm s) }\end{array}$ & Cation & FWHM $\mathrm{t}_{0}{ }^{1{ }^{2}}$ & $N_{T}{ }^{a}$ & $N_{\text {rntu }}{ }^{a}$ & $H$ \\
\hline \multirow[t]{3}{*}{ YM-22B } & $1.7: 10^{-4}$ & $\mathrm{Sr}^{2-}$ & 0.57 & 49 & 34 & 0.039 \\
\hline & & $\mathrm{Cs}^{-}$ & 0.56 & 51 & 35 & 0.037 \\
\hline & & $\mathrm{Ba}^{2-}$ & 0.72 & 31 & 21 & 0.061 \\
\hline \multirow[t]{3}{*}{ YM-.54-1 } & $6.6 \times 10^{-5}$ & $S r^{2-}$ & 0.64 & 39 & 27 & 0.038 \\
\hline & & $\mathrm{Cs}^{-}$ & 1.0 & 16 & 11 & 0.094 \\
\hline & & $\mathrm{Ba}^{2-}$ & 0.86 & 22 & 15 & 0.069 \\
\hline \multirow[t]{3}{*}{$Y M-54-3$} & $7.0 \cdot 10=$ & $8 r^{2-}$ & 0.55 & 53 & 37 & 0.049 \\
\hline & & $\mathrm{Cs}^{-}$ & 0.79 & 26 & 18 & 0.100 \\
\hline & & $\mathrm{Ba}^{2}-$ & 0.69 & 34 & 24 & 0.076 \\
\hline \multirow{2}{*}{$\mathrm{CS}-5-1$} & $9.7 \cdot 10^{5}$ & $\mathrm{Sr}^{2}-$ & 0.75 & 28 & 19 & 0.077 \\
\hline & & $\mathrm{Ba}^{2-}$ & 0.65 & 38 & 26 & 0.057 \\
\hline \multirow[t]{2}{*}{$(C,-5-3-2$} & $8.8 \cdot 10^{3}$ & $s r^{2-}$ & 0.50 & 64 & 44 & 0.056 \\
\hline & & $\mathrm{Ba}^{2}=$ & 0.38 & 110 & 76 & 0.033 \\
\hline
\end{tabular}

$N_{T}$ is the number of theoretical plates and $N_{m t u}$ the number of mass transfer units. 
The complete set of crushed-tuff elution data ${ }^{11}$ was fit to the error function solution for mass transport, and the results are shown in Table $I V$. Strontium behaves as expected on the basis of the previous discussion and sharpens dramatically as the velocity is increased to $1.84,10^{2} \mathrm{~cm} / \mathrm{s}$. However, cesium and barium show significant broadening in the faster flowing columns. Unfortunately, the data set is too sparse to make solid inferences as to the cause of this behavior. It has been noted, however, that cesium sorbs irreversibly on certain clay minerals. This process would undoubtedly be slower than simple ion exchange and wouid broaden the elution curve.

\section{Conclusion}

The spread of elution curves for strontium, cesium, and barium was studied in the context of chromatographic theory. The spreading at water velocities below $10^{-4} \mathrm{~cm} / \mathrm{s}$ was controlled largely by the longitudinal diffusion of the cations in solution. There appears to be a sharpening of the elution curve at velocities from $10^{-4} \mathrm{~cm} / \mathrm{s}$ to $10^{-2} \mathrm{~cm} / \mathrm{s}$ for strontium. Cesium did not appear to elute more sharply at higher velocities, and barium appeared to sharpen with some exceptions. In none of the crushed-tuff column experiments did the shape of the curves indicate excessively slow mass transfer kinetics.

The crushed-tuff elutions were fit to the error funcrion solution of the transport equations, and they adecuately reproduced the data in the majority of cases. The elution curves with the best fit calculated curves are showil in the figures contained in App. A. The curves were all fit using the Oak Ridge Generalized Least Squares code, ORGLS. The erzor function deviated from the observed results in the tails of many of the elutions; however, this discrepancy was small and because the mass of the radionuclide will arrive earlier, it can be neglected.

\section{THE UPTAKE OF CATIONS ON TUFF WAFERS}

The elution curves discussed in the previous section indicate rapid sorption kinetics on crushed-tuff columns. Sorption experiments were also performed on thin tuff wafers. When a diffusion model with instantaneous equilibrium was applied to the data, it could not be fit by adjusting the diffusivity or the distribution coefficient. The data can, however, be fit by using a diffusion model with reversible reaction. The rate constants for uptake on $t, u f f$ are consistent with a model of sorption that is diffusion limited but where diffusion occurs in two stages. First, cations diffuse into the rock through the water-filled pore space. Vext, the cations diffuse into the murh narrower channels within the aluminosilicate crystals. After they are within the zeolite framework or between the clay layers, the cations may rapidly sorb on the negatively charged surfaces. 
MASS TRANSFER UNITS FOR CRUSHED-TUFF COLUMNS (DETERMINED BY LEAST SQUARES FITTING OF CURVE SHAPES)

\begin{tabular}{|c|c|c|c|c|c|c|c|}
\hline Sample & Isot & pe/Feed & $\mathrm{N}_{m t n}$ & $\begin{array}{c}\text { Peak } \\
\text { Volume } \\
(1 / \mathrm{B})\end{array}$ & $\begin{array}{c}\text { Column } \\
\text { Length } \\
(\mathrm{cm}) \\
\end{array}$ & $\begin{array}{l}\text { Velocity } \\
(\mathrm{cm} / \mathrm{s})\end{array}$ & $f$ \\
\hline G-1-2334 B & $\mathrm{I}^{-}$ & $\operatorname{cont}^{a}$ & 30. & 0.620 & 4.90 & $5.88 \times 10^{-3}$ & 0.643 \\
\hline & $\mathrm{Tc}$ & cont. & 41. & 0.571 & 4.90 & $5.88 \times 10^{-3}$ & 0.643 \\
\hline & $\mathrm{Tc}$ & spike & 38. & 0.528 & 4.90 & $5.88 \times 10^{-3}$ & 0.643 \\
\hline & Sr & spike & 14. & 63.8 & 4.90 & $5.88 \times 10^{-3}$ & 0.643 \\
\hline & $\mathrm{Ba}$ & spike & 69. & 731 & 4.90 & $5.88 \times 10^{-3}$ & 0.643 \\
\hline & Cs & spike & 52. & 1010 & 4.90 & $5.88 \times 10^{-3}$ & 0.643 \\
\hline G-1-2334 C & $\mathrm{I}^{-}$ & $\operatorname{con} t$. & 32. & 0.470 & 5.00 & $1.418 \times 10^{-3}$ & 0.479 \\
\hline & $\mathrm{Tc}$ & cont. & 37. & 0.463 & 5.00 & $1.418 \times 10^{-3}$ & 0.479 \\
\hline G-1-1883 & I & cont. & 46. & 0.376 & 5.00 & $1.418 \times 10^{-3}$ & 0.479 \\
\hline & I & cont & 33. & 0.366 & 5.00 & $1.418 \times 10^{-3}$ & 0.479 \\
\hline & $\mathrm{Tc}$ & cont. & 35. & 0.368 & 5.00 & $1.418 \times 10^{-3}$ & 0.479 \\
\hline G-1-1883 R & I & cont. & 68. & 0.407 & 5.00 & $0.31 \mathrm{~m} \ell / h r$ & 0.479 \\
\hline & $\mathrm{Tc}$ & cont. & 75. & 0.403 & 5.00 & $0.31 \mathrm{m \ell} / \mathrm{hr}$ & 0.479 \\
\hline $\mathrm{G}-1-1883$ & I & cont. & 84. & 0.589 & 5.0 & $0.31 \mathrm{ml} / \mathrm{hr}$ & 0.479 \\
\hline & $\mathrm{Tc}$ & cont. & 92. & 0.586 & 5.0 & $0.31 \mathrm{~m} \ell / \mathrm{hr}$ & 0.479 \\
\hline YM-5 & $\mathrm{Sr}$ & spike & 19. & 157 & 4.90 & $1.64 \times 10^{-4}$ & 0.500 \\
\hline$Y M-22$ & $S r$ & spike & 27. & 10.1 & 1.90 & $2.01 \times 10^{-4}$ & 0.540 \\
\hline & Cs & spike & 23. & 146 & 1.90 & $2.01 \times 10^{-4}$ & 0.540 \\
\hline & $\overline{B a}$ & spike & 31. & 53.7 & 1.90 & $2.01 \times 10^{-4}$ & 0.540 \\
\hline$Y M_{1}-38-3$ & $\mathrm{Cs}$ & spike & 8. & 7160 & 2.45 & $2.45 \times 10^{-2}$ & 0.377 \\
\hline YM-54-1 & $\mathrm{Sr}$ & spile & 26. & 13.1 & 1.50 & $8.11 \times 10^{-5}$ & 0.644 \\
\hline & $\mathrm{Cs}$ & spike & 10. & 31.5 & 1.50 & $8.11 \times 10^{-5}$ & 0.644 \\
\hline & $\mathrm{Ba}$ & spike & 18. & 38.1 & 1.50 & $8.11 \times 10^{-5}$ & 0.644 \\
\hline
\end{tabular}

${ }^{a}$ Cortinuous feed. 
TABLE IV (cont)

Peak Column

Volume Length Velocity

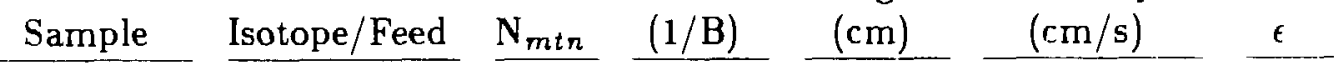

$\begin{array}{lllllll}\text { YM-54-2 Cs } & \text { cont. } & 29 . & 21.5 & 1.49 & 1.34 \times 10^{-4} & 0.706\end{array}$

$\begin{array}{llllllll}\text { YM-54-3 } & \mathrm{Sr} & \text { spikt } & 42 . & 22.4 & 2.60 & 7.16 \times 10^{-5} & 0.652\end{array}$

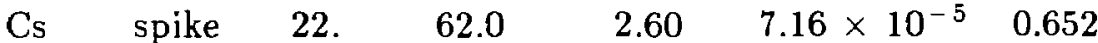

Ba spike 29. $66.6 \quad 2.60 \quad 7.16 \times 10^{-5} \quad 0.652$

$\begin{array}{lllllll}\text { JA-3c-1 Sr } & \text { spike } & 66 . & 41.1 & 4.40 & 3.41 \times 10^{-4} & 0.566\end{array}$

$\begin{array}{llllllll}\text { JA-32-3 Sr } & \text { spike } & 18 . & 13.4 & 1.85 & 1.94 \times 10^{-4} & 0.598\end{array}$

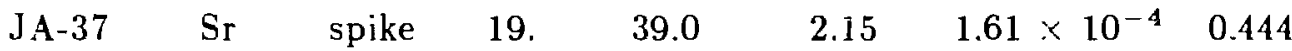

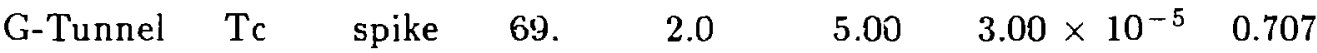

$\begin{array}{llllllll}\text { G-1-1292 } & \mathrm{Sr} & \text { spike } & 5 . & 69.6 & 2.95 & 7.73 \times 10^{-5} & 0.769\end{array}$

G-1-1436 HTO cont. $31 . \quad 1.33 \quad 8.00 \quad 3.44 \times 10^{-5} \quad 0.700$

$\begin{array}{llllllll}\text { G-1-1883-1 } & \text { Sr } & \text { spike } & 19 . & 5.45 & 2.14 & 1.27 \times 10^{-4} & 0.677\end{array}$

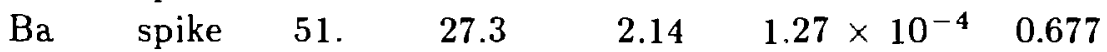

$\begin{array}{llllllll}\text { G-1-1883-2 } & \mathrm{Sr} & \text { spike } & 30 . & 54.9 & 4.35 & 6.72 \times 10^{-5} & 0.614\end{array}$

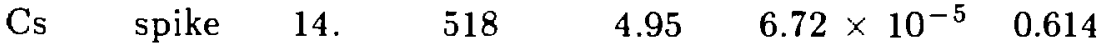

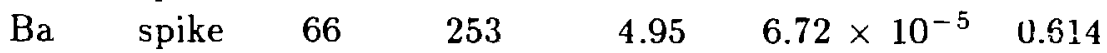

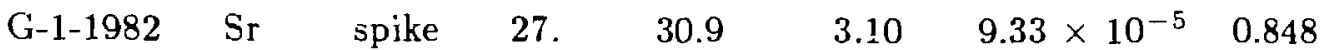

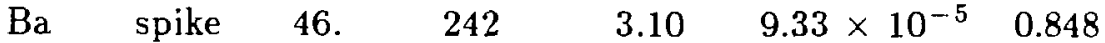

$\begin{array}{llllllll}\text { G-1-2363 } & \text { Sr } & \text { spike } & 101 . & 67.5 & 4.85 & 1.80 \times 10^{-4} & 0.579\end{array}$

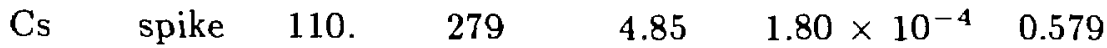

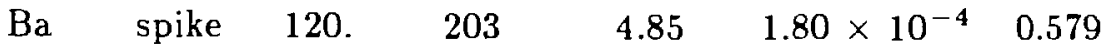

$\begin{array}{llllllll}\text { G-1-2410 } & \mathrm{Sr} & \text { spike } & 159 . & 50.9 & 4.85 & 4.29 \times 10^{-4} & 0.561\end{array}$

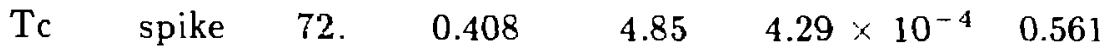




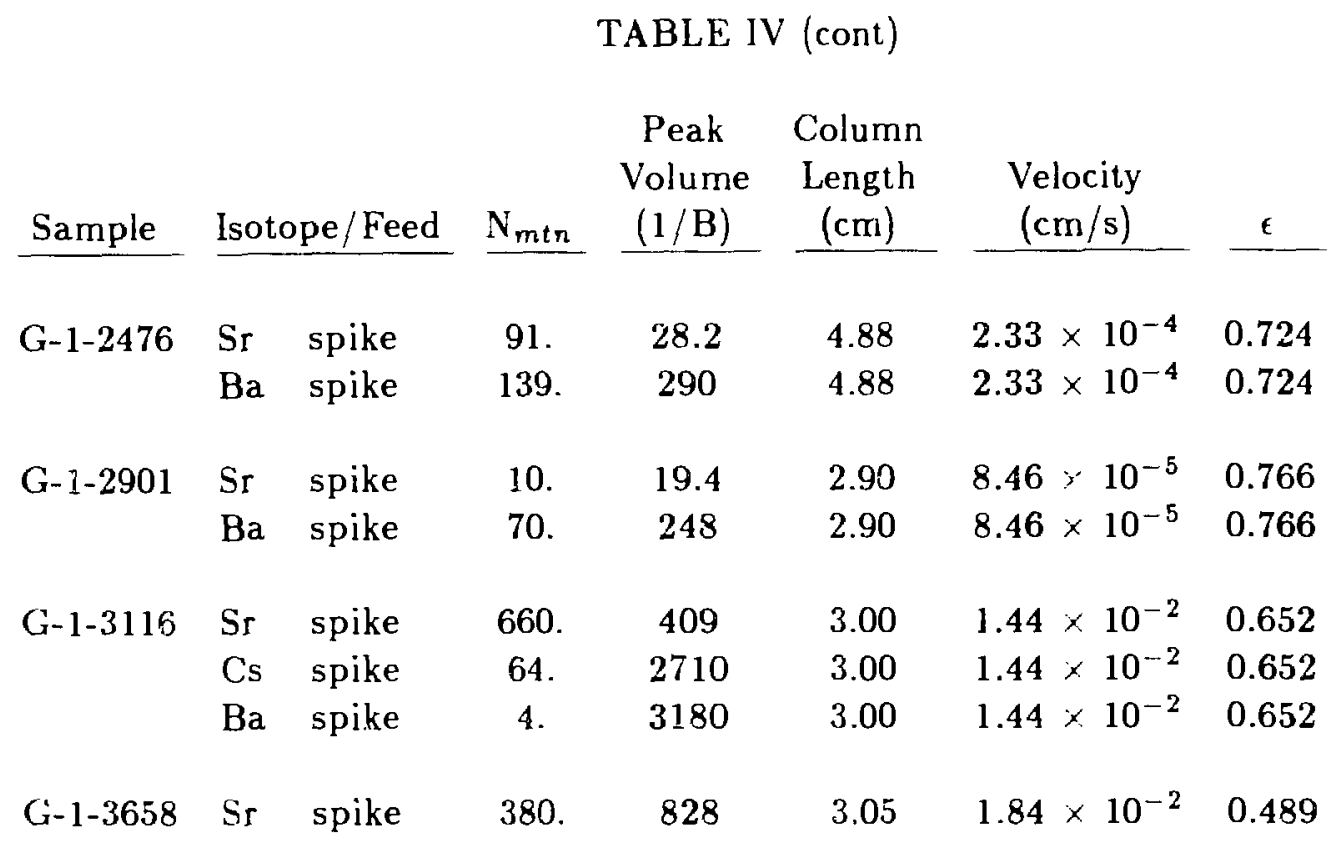

\section{A. Experiment}

Pretreated groundwater samples containing a radioactive tracer, ${ }^{137} \mathrm{Cs}$, ${ }^{193} \mathrm{Ba}$, or ${ }^{85} \mathrm{Sr}^{m}$, were contacted with 2 -mm-thick tuff disks with $2.54-\mathrm{cm}$ diameter. The tuff disks, supported by a teflon tnread, were immersea ir. the traced solution and agitated on an orbital shaker. The water was sampled periodically and analyzed to determine radionuclide uptake as a function of time. Samples were taken from as early as 5 min after the introduction of tracer to as long as 4 weeks afterward.

The tuff samples were obtained from Drill Hole USW G-1 at Yucca Mountain, Nevada. The samples were G-1-1436, a highly zeolizized ash-fall tuff from the Calico Hills unit, G-1-1883, a partially welded devitrified tuff from the Prow Pass unit, and G-1-1982, another partially welded devitrified tuff from the Prow Pass unit. ${ }^{12,13}$ The radionuclides were absorbed on the zeolite minerals, and smectite clays are contained in the tuff matrix. The mineralogic analyses of these samples are given in Table V.

\section{B. Results and Discussion}

The results of these experiments were compared with the analytic equation for diffusion into a plane sheet from a solution of limited volume. The equation (equilibrium sorotion and matrix diffusion) is plotted in Fig. 1. This plot has a log-log scale because 


\section{TABLE V}

PERCENT OF MINERALOGIC CONTENT IN DRILL HOLE SAMPLES

\section{AS DETERMINED BY X-RAY DIFFRACTION}

\begin{tabular}{|c|c|c|c|c|c|c|}
\hline Tuff Sample & Smectite & $\begin{array}{c}\text { Illite- } \\
\text { Muscovite }\end{array}$ & $\begin{array}{l}\text { Clinoptil- } \\
\text { olite }\end{array}$ & Quartz & $\begin{array}{l}\text { Cristob- } \\
\text { alite }\end{array}$ & $\begin{array}{c}\text { Alkali } \\
\text { Feldspar }\end{array}$ \\
\hline G-1-1436 & $<5$ & $<5$ & $75-90$ & $5-10$ & - & 5 \\
\hline G-1-1883 & $2-5$ & $<5$ & - & $20-40$ & $0-10$ & $40-60$ \\
\hline G-1-1982 & $5-20$ & $<5$ & - & - & $30-60$ & $20-60$ \\
\hline
\end{tabular}

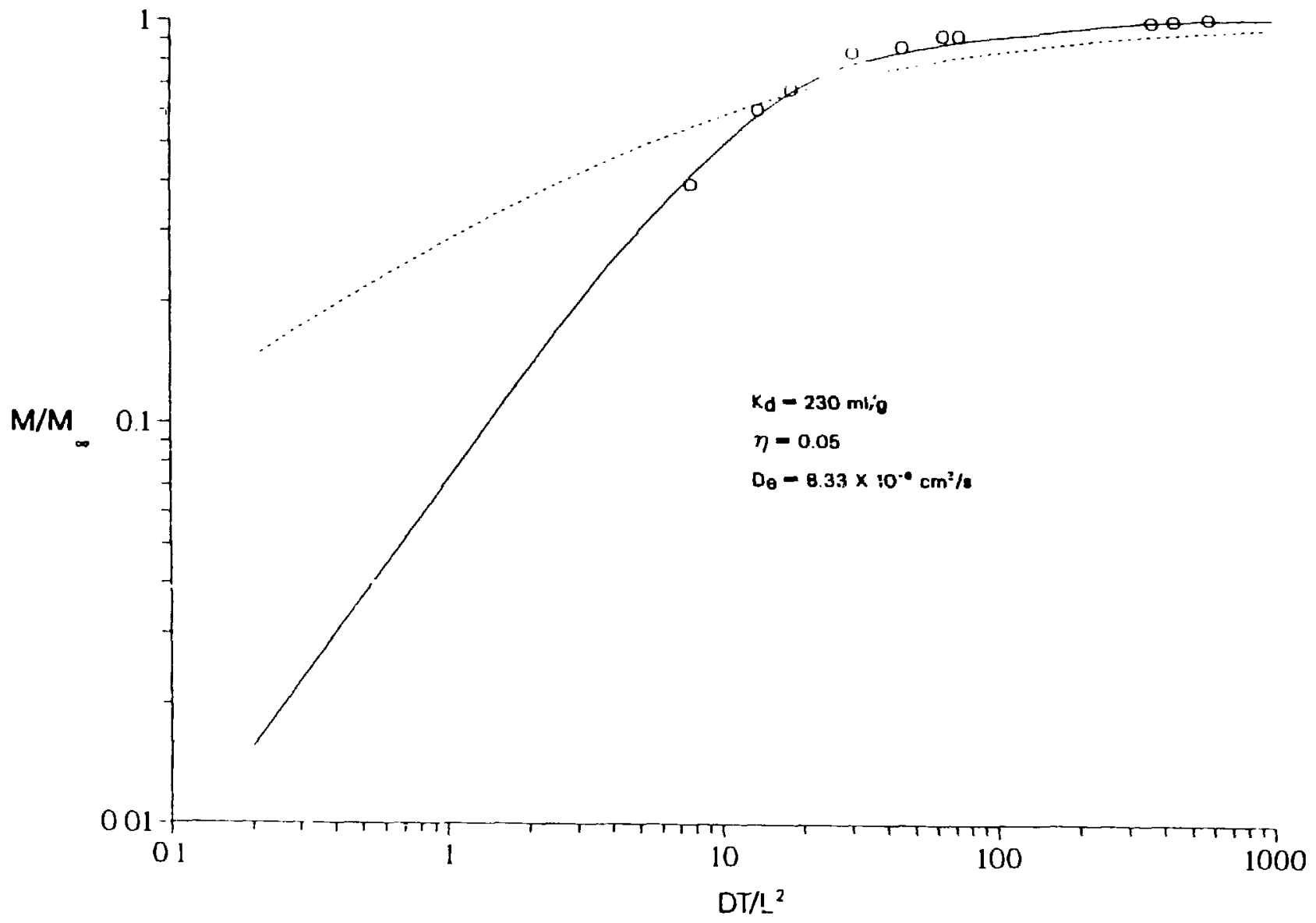

Fig. 1. Comparison of matrix diffusion with slow mass transfer kinetics to matrix diffusion with equilibrium sorption. 
in dimensionless form the data should be fit by simply translating the curve; that is, scaling the diffusion coefficient. It is clear that all the data cannot be fit using this model, particularly the early points.

One of the assumptions inherent in this formalism, which could affect the time dependence of uptake, is that the diffusing species is partitioned between the solid and liquid phases in a manner that is constant with time, that is, a linear adsorption isotherm. The latter assumption is valid in highly zeolitized tuff and generally in tuffs having high sorption ratios. ${ }^{14}$ At the concentration levels used in these experiments, the isotherm is expected to be linear for the other devitrified tuffs as well, with the possible exception of cesium isotherms (they can be nonlinear as a result of multiple high-affinity sorption sites). Therefore, in this paper only the effect of sorption kinetics on the uptake radionuclides by tuff wafers will be discussed.

The data were next fit to the one-dimensional diffusion equation for a plane sheet coupled to a linear reversible reaction with the solid phase, as defined below.

The diffusion is governed by the equation

$$
\frac{\delta c}{\delta t}=D \frac{\delta^{2} c}{\delta x^{2}}-\frac{\delta s}{\delta t}
$$

with the simultaneous reaction of the type

$$
\frac{\delta s}{\delta t}-k_{1} c-k_{2} s
$$

where

$$
\begin{aligned}
& c \quad-\text { concentration of the solute free to diffuse within the sheet, } \\
& s \quad=\text { concentration of the inmobilized solute, } \\
& D \quad-\text { diffusion coefficient, } \\
& r \quad=\text { position in the disk, } \\
& t \quad \text { the time, and } \\
& k_{1} \cdot k_{2} \quad \text { the rate constants of forward and backward reactions, respectively. }
\end{aligned}
$$

The solution to these equations is given by Crank: ${ }^{15}$

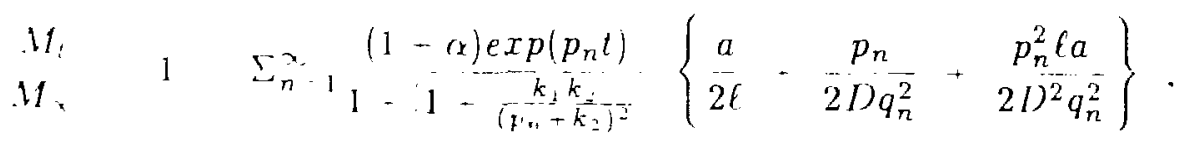

where $p_{n}$ and $q_{n}$ are the norizero roots of

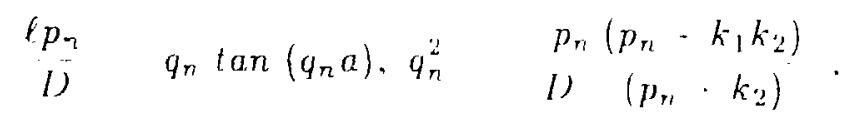


and where $\alpha=\ell /(R+1) a, M_{\infty}=\ell c_{o} /(1+\alpha)$, and

$$
\begin{aligned}
& c_{0}=\text { the initial concentration of tracer, } \\
& a=\text { the thickness of the sheet, } \\
& \ell=\text { the effective length of the solution, } \\
& M_{t}=\text { the total amount of solute taken up by the sheet at time } \mathrm{t}, \\
& M_{\infty}=\text { the amount of uptake at injection time, and } \\
& R=\mathrm{k}_{1} / \mathrm{k}_{2} .
\end{aligned}
$$

This solution is plotted in Fig. 1 as a solid line. An excellent fit to the data is obtained with diffusion coefficients that are close to those expected for matrix diffusion. All the uptake results for the three tracers on the three tuff samples show good fits with the kinetic model. The rate constants and diffusivities are given in Table VI. Diffusion coefficients for these cations are fairly close to the free ionic diffusion coefficients. This similarity indicates that the diffusion path is not very tortuous. However, this may not be true for the larger sample where dead-end pores would have more effect on diffusion. Another inieresting observation is that whereas the sorption rate constants vary by many orders of magnitude, the desorption rate constants vary only slightly (less than a factor of 2) for similar tuffs and less than a factor of $\mathbf{4}$ for dissimilar tuffs, for a given cation.

The sorption ratios for samples of tuffs G-1-1883 and G-1-1982 were determined after 4 weeks by using the distribution of radionuclides between the tuff wafer and the solution. The errors in mass balance of trace: between the solution and the tuff wafer for the G-11436 sample were too large to yield a meaningful sorption ratio. A desorption experiment was performed on this sample and the sorption ratios after 3 weeks were determined for cesium and strontium. The results of these experiments are shown in Table VII with corresponding measurements from crushed-tuff (batch) experiments. ${ }^{14}$ The agreement is excellent, differing by much less than a factor of 2 in all cases. 
TABLE VI

SORPTION RATE CONSTANTS FOR NEVADA TEST SITE TUFF

\begin{tabular}{|c|c|c|c|c|c|}
\hline $\begin{array}{l}\text { Tuff } \\
\text { Sample }\end{array}$ & $\begin{array}{l}\text { Radio- } \\
\text { nuclide }\end{array}$ & $\begin{array}{c}\mathrm{K}_{d} \\
(\mathrm{~m} \ell / \mathrm{g}) \\
\end{array}$ & $\begin{array}{c}k_{1} \\
\left(s^{-1}\right)\end{array}$ & $\begin{array}{c}k_{2} \\
\left(s^{-1}\right) \\
\end{array}$ & $\begin{array}{c}\mathrm{D} \\
\left(\mathrm{cm}^{2} / \mathrm{s}\right) \\
\end{array}$ \\
\hline \multirow[t]{3}{*}{$G-1-1436$} & $\mathrm{Cs}$ & 7790 & $6.3 \times 100$ & $1.4 \times 10^{-4}$ & $2.78 \times 10^{-6}$ \\
\hline & $\mathrm{S}_{\Gamma}$ & 36300 & $3.5 \times 100$ & $2.0 \times 10^{-5}$ & $2.11 \times 10^{-6}$ \\
\hline & $\mathrm{Ba}$ & 148000 & $1.2 \times 101$ & $1.7 \times 10^{-5}$ & $3.38 \times 10^{-7}$ \\
\hline \multirow[t]{3}{*}{ G-1-1883 } & $\mathrm{Cs}$ & 230 & $5.9 \times 10^{-2}$ & $4.2 \times 10^{-5}$ & $8.33 \times 10^{-6}$ \\
\hline & $\mathrm{S}_{\mathrm{r}}$ & 27 & $1.1 \times 10^{-3}$ & $6.7 \times 10^{-6}$ & $1.33 \times 10^{-5}$ \\
\hline & $\mathrm{Ba}$ & 210 & $5.7 \times 10^{-2}$ & $4.4 \times 10^{-5}$ & $8.89 \times 10^{-6}$ \\
\hline \multirow[t]{3}{*}{$\mathrm{G}-1-1982$} & Cs & 1000 & $4.0 \times 10^{-1}$ & $4.7 \times 10^{-5}$ & $9.44 \times 10^{-6}$ \\
\hline & $S_{r}$ & 88 & $9.5 \times 10^{-3}$ & $1.4 \times 10^{-5}$ & $1.37 \times 10^{-5}$ \\
\hline & $\mathrm{Ba}$ & 800 & $2.6 \times 10^{-1}$ & $4.4 \times 10^{-5}$ & $8.89 \times 10^{-6}$ \\
\hline
\end{tabular}

TABLE VII

$\mathrm{K}_{\mathrm{d}}$ COMPARISON: TUFF WAFERS vs CRUSHED TUFF

\begin{tabular}{|c|c|c|c|}
\hline Tuff Sample & Element & $\begin{array}{r}\mathrm{K}_{\mathrm{d}}(\text { Wafer }) \\
(\mathrm{m} \ell / \mathrm{g}) \\
\end{array}$ & $\begin{array}{r}\mathrm{K}_{\mathrm{d}}(\mathrm{Batch}) \\
(\mathrm{m} \ell / \mathrm{g}) \\
\end{array}$ \\
\hline \multirow[t]{3}{*}{ G-1-1883 } & $\mathrm{Sr}$ & 27 & 22 \\
\hline & Cs & 230 & 190 \\
\hline & $\mathrm{Ba}$ & 210 & 180 \\
\hline \multirow[t]{3}{*}{$G-1-1982$} & $\mathrm{Sr}$ & 80 & 62 \\
\hline & $\mathrm{Cs}$ & 1000 & 1200 \\
\hline & $\mathrm{Ba}$ & 800 & 800 \\
\hline \multirow[t]{2}{*}{ G-1-1436 (desorption) } & $\mathrm{Sr}$ & $95 \check{500}$ & 87000 \\
\hline & Cs & 14900 & 2400 \\
\hline
\end{tabular}


If the :ate of sorption of radionuclides is controlled mainly by diffusion into zeolite and clay crystals, the rate constants $k_{1}$ and $k_{2}$ can be related to the diffusion coefficient by the equations for mass transfer in ion exchange particles. ${ }^{16,17}$ The uptake of cations by a mineial is expressed as

$$
\begin{aligned}
\frac{\delta s}{\delta t} & \left.=\frac{60 D_{e f f}}{r^{2}} \mid s_{\imath}-s\right\} \\
& =\frac{60 D_{e f f}}{r^{2}}\left(\left(\epsilon+K_{d} \rho\right) c_{m}-s\right],
\end{aligned}
$$

so that

$$
\begin{aligned}
& k_{1}=60 i \epsilon+K_{d} \rho j \frac{D_{e f j}}{r^{2}}, \quad \text { and } \\
& k_{2}=60 \frac{D_{e f f}}{r^{2}}
\end{aligned}
$$

where

$$
\begin{aligned}
& \mathrm{c}_{m}=\text { concentration in the pore fluid, } \\
& \mathrm{s}_{\imath}=\text { concentration in the solid phase at the interface, } \\
& \mathrm{r} \quad=\text { the crystal diameter } \\
& \mathrm{D}_{e f f}=\text { effective diffusion coefficient, } \\
& \mathrm{K}_{d}=\text { distribution coefficient } \\
& \rho \quad=1 \text { ry bulk density, and } \\
& \epsilon \quad=\text { porosity. }
\end{aligned}
$$

This enables one to estimate a diffusion coefficient for an ion inside the zeolite or clay crystal, assuming the film resistance on the crystal is the same for ion exchange resin. Samples of the tuffs used in these experiments have been examined under a scanning electron microscope. The zeolite and clay crystals appear to be equal to or smaller than $1 \mu \mathrm{m}$ in diameter." This allows one to calculate an upper limit for the intracrystalline diffusion coefficient. Table VIII reports these estimates and the diffusion coefficients determined for two pure nature ztolites, chabazite and mordenite. The diffusivities in these zeolites are many orders of magnitude smaller than the free ionic diffusivities. This difference is a result of the narrow channels within the zeolite crystal structure through which the ions must migrate. The kinetic diameter of chabazite is $4.3 \AA$ (Ref. 18), and that of mordenite is

- From information received from David T. Vaniman, Los Alamos National Laboratory (October 1983). 


\begin{tabular}{|c|c|c|}
\hline Sample & Ion & $\begin{array}{c}\mathrm{D}_{2} \\
\left(\mathrm{~cm}^{2} / \mathrm{s}\right)\end{array}$ \\
\hline \multirow[t]{3}{*}{ Chabazite 19] } & $\mathrm{Cs}^{+}$ & $4.9 \times 10^{-13}$ \\
\hline & $\mathrm{Sr}^{2+}$ & $1.3 \times 10^{-16}$ \\
\hline & $\mathrm{Ba}^{2}$ & $1.3 \times 10^{-13}$ \\
\hline \multirow[t]{3}{*}{ Mordenite 20} & $\mathrm{Cs}^{+}$ & $5 \times 10^{-15}$ \\
\hline & $\mathrm{Sr}^{2+}$ & $1.5 \times 10^{-16}$ \\
\hline & $\mathrm{Ba}^{2}$ & $4.5 \times 10^{-16}$ \\
\hline \multirow[t]{3}{*}{ G-1-1436 } & $\mathrm{Cs}^{+}$ & $\mathrm{F} 2.3 \times 10^{-14}$ \\
\hline & $\mathrm{Sr}^{2+}$ & F $3.3 \times 10^{-15}$ \\
\hline & $\mathrm{Ba}^{2}$ & $\mathrm{~F} 2.8 \times 10^{-14}$ \\
\hline \multirow[t]{3}{*}{ G-1-1883 } & $\mathrm{Cs}^{+}$ & $\mathrm{F} 6.7: 10^{-13}$ \\
\hline & $\mathrm{Sr}^{2+}$ & F1.1 $\times 10^{-15}$ \\
\hline & $\mathrm{Ba}^{2}$ & $\mathrm{~F} 7.3 \times 10^{-15}$ \\
\hline \multirow[t]{3}{*}{ G-1-1952 } & $\mathrm{Cs}^{+}$ & F $7.8 \times 10^{-15}$ \\
\hline & $\begin{array}{c}\mathrm{Sr}^{2+} \\
\mathrm{Ba}^{2}\end{array}$ & $\begin{array}{l}F 2.3 \times 10^{-15} \\
F 73 \times 10^{-15}\end{array}$ \\
\hline & $B a^{2}$ & $5 . .3$ \\
\hline
\end{tabular}

$3.9 \AA$ (Ref. 19). The kinetic diameter for the zeolite clinoptilolite, which is present in the tuff of the Calico Hills member of Yucca Mountain tuff G-1-1436, is $3.5 \AA$ (Ref. 20). The channel opening in a fully hydrated montmorillonite clay (the principle adsorbing mineral in G-1-1883 and G-1-1952 tuff) is approximately 5.6 (Ref. 20); therefore, a larger diffusivity is expected for montmorillonite. Until more complete crystal size distributions are measured in these tuffs, this difference cannot be observed. The estimated diffusivities show that the mass transfer rates observed for cesium, strontium, and barium sorption on Yucca Mountain tuff are consistent with a diffusion-limited ion exchange mechanism.

\section{Conclusions}

The sorptive properties of Yucca Mountain tuff for the simple cations of strontium, cesium. and barium are consistent with a simple ion exchange mechanism. The uptake of these radionuclides by intact samples of tuff can be described by matrix diffusion accompanied by a reversible adsorption reaction. The mass transfer kinetics is also consistent with diffucion-limited ion exchange, where the rate-determining step is diffusion in to the 
channels within crystals of zeolites and clays. The sorption ratios for these cations on intact tuff are in excellent agreement with the sorption ratios that were determined for crushed tuff during batch-technique experiments. This agreement is primarily the result of the small crystal size observed in the tuffs; that is, the crushed-and intact-tuff samples have similar grain sizes.

\section{ACTINIDE SORPTION}

Any discussion of the kinetics of sorption for the actinides is difficult because the mechanism of sorption is not known nor is the chemical form of plutonium or americium in neutral pH solutions known with any certainty. However, there are some trends exhibited in the actinide sorption data that allow inferences to be drawn. One of these is the lack of a consistent increase in the sorptiun of actinides on tuff sumples containing progressively greater composition of minerals with abundant cation exchange sites; that is, zeolites and clays. This observation suggests that either the predominant species of plutonium or americium is not a cation or that the predominant cationic species is too large to be adsorbed on the intracrystalline sites. In Sec. Il and III, the adsorption of cations was shown to be diffusion limited. Therefore, the kinetics of actinide sorption could be expected to be slow only if the reaction from the predominant species to form an adsorbing species is slow. Another trend is found in the desorption of actinides. The actinides generally desorb with a $K_{d}$ equal to or greater than 10 times the adsorption $K_{d}$. This observation could indicate slow desorption kinetics. However, there are several alternate explanations; for instance, the higher desorption could also indicate precipitation or the saturation of a limited number of strongly binding adsorption sites.

\section{A. Time Dependence of Actinide Sorption in Batch Measurements}

The sorption ratios for radionuclides on Nevada Test Site tuff have been measured as a function of time for many elements and tuff samples. The simple cations in agreement with the diffusion-limited mechanism discussed earlier did not show significant changes in sorption ratios with time over 12 -week periods. Plutonium and, to a much lesser extent, americium have shown a change in $\mathrm{K}_{d}$ with time. although there is large scatter between replicate measurements. The data for plutonium and americium are summarized in Table IX. A number of paradoxes presented by the data should be noted: (1) americium $K_{\mathrm{C}} \mathrm{s}$ do not appear to increase with time, with the possible exception of the YM-49 experiment: (a) americium $K_{d}$ s appear to decrease with time in several experiments (the significance $n^{\prime}$ this observation is dubious in view of the large scatter in americium $K_{f}$ values); and (3) plutonium $K_{f}$ increase with time in several of the experiments: that is, in experiments 
TABLE IX

ACTINIDE KINETICS OF SORPTION

\begin{tabular}{|c|c|c|c|}
\hline \multicolumn{2}{|c|}{$\begin{array}{c}\text { Sample } \\
(\mu \mathrm{m})\end{array}$} & $\begin{array}{c}\text { Time } \\
\text { (weeks) }\end{array}$ & $K_{d}$ \\
\hline \multirow[t]{4}{*}{$\mathrm{Am}$} & 518 & 1 & 214 \\
\hline & & 2 & 198 \\
\hline & & 4 & 225 \\
\hline & & 8 & 82 \\
\hline \multirow[t]{4}{*}{$\mathrm{Pu}$} & JA-18 & 1 & 120 \\
\hline & & 2 & 110 \\
\hline & & 4 & 101 \\
\hline & & 8 & 144 \\
\hline \multirow[t]{4}{*}{ Am } & JA-32 & 1 & 110 \\
\hline & & 2 & 110 \\
\hline & & 4 & 185 \\
\hline & & 8 & 79 \\
\hline \multirow[t]{4}{*}{ Am } & JA -37 & 1 & 430 \\
\hline & & 2 & 370 \\
\hline & & 4 & 430 \\
\hline & & 8 & 640 \\
\hline \multirow[t]{3}{*}{$\mathrm{Am}$} & YM-22 & 3 & 1500 \\
\hline & & 6 & 1100 \\
\hline & & 12 & 1100 \\
\hline \multirow[t]{3}{*}{$\mathrm{Pu}$} & YM-22 & 3 & 37 \\
\hline & & 6 & 64 \\
\hline & & 12 & 100 \\
\hline \multirow[t]{3}{*}{$\mathrm{Pu}$} & YM-22 & 3 & 130 \\
\hline & & 6 & 120 \\
\hline & & 12 & 280 \\
\hline \multirow[t]{7}{*}{$\mathrm{Am}$} & Y.M-38 & & \\
\hline & -75 & 3 & 9500 \\
\hline & & 6 & 7300 \\
\hline & & 12 & 2600 \\
\hline & $75-.500$ & 3 & 6100 \\
\hline & & 6 & 5200 \\
\hline & & 12 & 2500 \\
\hline
\end{tabular}

Deviation from the mean of duplicate runs.

Estimated error. 
TABLE IX (cont)

\begin{tabular}{|c|c|c|c|c|}
\hline \multicolumn{2}{|c|}{$\begin{array}{c}\text { Sample } \\
(\mu \mathrm{m})\end{array}$} & \multirow[t]{2}{*}{$\begin{array}{c}\text { Time } \\
\text { (weeks) }\end{array}$} & \multirow[t]{2}{*}{$\mathrm{K}_{\mathrm{d}}$} & \multirow[t]{2}{*}{ Error $^{a}$} \\
\hline $\mathrm{Pu}$ & YM-38 & & & \\
\hline & $<75$ & 3 & 130 & \\
\hline & & 6 & 320 & \\
\hline & & 12 & 650 & \\
\hline & $75-2500$ & 3 & 58 & \\
\hline & & 6 & 120 & \\
\hline & & 12 & 240 & \\
\hline & & 3 & 6200 & \\
\hline
\end{tabular}

Am YM-49

$\begin{array}{cc}3 & 2900 \\ 6 & 2800 \\ 12 & 7100\end{array}$

$\mathrm{Pu} \quad \mathrm{YM}-49$

$\begin{array}{cl}3 & 145 \\ 6 & 180 \\ 12 & 210-820\end{array}$

$\begin{array}{llcl}\text { Am } & \text { YM-54 } & & \\ & <75 & 3 & 900 \\ & & 6 & 1300 \\ & & 12 & 900 \\ & 75-2500 & 3 & 150 \\ & & 6 & 150 \\ \text { Pu } & \text { YM-54 } & & \\ & <75 & 3 & 66 \\ & & 6 & 64 \\ & 75-500 & 12 & 76 \\ & & 3 & 52 \\ & & 6 & 81 \\ \text { Am } & \text { G-1-188.3 } & 3 & 160 \\ & & 6 & 4200 \\ & & 12 & 5300 \\ \text { Pu } & \text { G-1-1883 } & 3 & 51 \\ & & 6 & 71 \\ & & 12 & 94\end{array}$

a Deviation from the mean of duplicate runs. 
with YM-22, YM-38, YM-49, YM-54, and G-1-1883. The data in Table IX are all listed in terms of $K_{d}$ so that they more easily convert to concentration in sclution for the following useful relations. The $\mathrm{K}_{\mathrm{d}}$ is equal to the concentration in the solid, $q$ (moles/g), over the aqueous concentration, $c$ (moles; $\mathrm{m} \ell$ ),

$$
K_{\mathrm{d}}=\frac{?}{c} .
$$

All the batch measurements were performed with $1 \mathrm{~g}$ of solid $/ 20 \mathrm{~m} \ell$ of solution so that by mass balance the solid phase concentration is

$$
q=\frac{20 c o}{1}-\frac{20 c}{1}
$$

where $c o$ is the initial concentration. Thus,

$$
\frac{c}{c o}=\frac{20}{\left(20-K_{d}\right)}
$$

A plot of YM-22 plutonium sc:ption in terms of $c / c 0$ is shown in Fig. 2. The accompanying curve is a fit to the daia using a linear reversible rate law. If we assume linear concentration dependence, the rate of change in solution concentration is

$$
\frac{d c}{a t}=-k_{1} c+k_{2}[20 c o-20 c] \text {, }
$$

the solution to which is

$$
\frac{c}{c o}=1-\frac{20 k_{2}}{k_{1}+20 k_{2}} e^{-k_{1}-20 k_{2} i t}+\frac{20 k_{2}}{k_{1}+20 k_{2}} .
$$

This rate law fits the data in Fig. 2 reasonably well. However, the rate constant $k_{1}=6.37$ $\times 10^{-7} \mathrm{~s}^{-1}$ is very small as compared with the $6.3 \times 10^{-6}$ to $1.1 \times 10^{-3} \mathrm{~s}^{-1}$ observed for simple cations, and $\mathrm{k}_{2}=6.37 \times 10^{-9}$ is small compared with $6.7 \times 10^{-6}$ to $1.4 \times 10^{-4}$ $\mathrm{s}^{-1}$. For the desorption experiment, the rate law is

$$
\frac{d q}{d t}=k_{1} c-k_{2} q
$$

and the solution analogous to Eq. (1) is

$$
\frac{q}{q o}=1-\frac{k_{1}}{k_{1}+20 k_{2}} e^{-\frac{k_{1}}{20}-k_{2} t}+\frac{k_{1}}{k_{1}+20 k_{2}} .
$$

The $K_{d}$ can be calculated as a function of time using

$$
K_{d}=\frac{20 /(q / q o)}{1-(q / q o)} .
$$




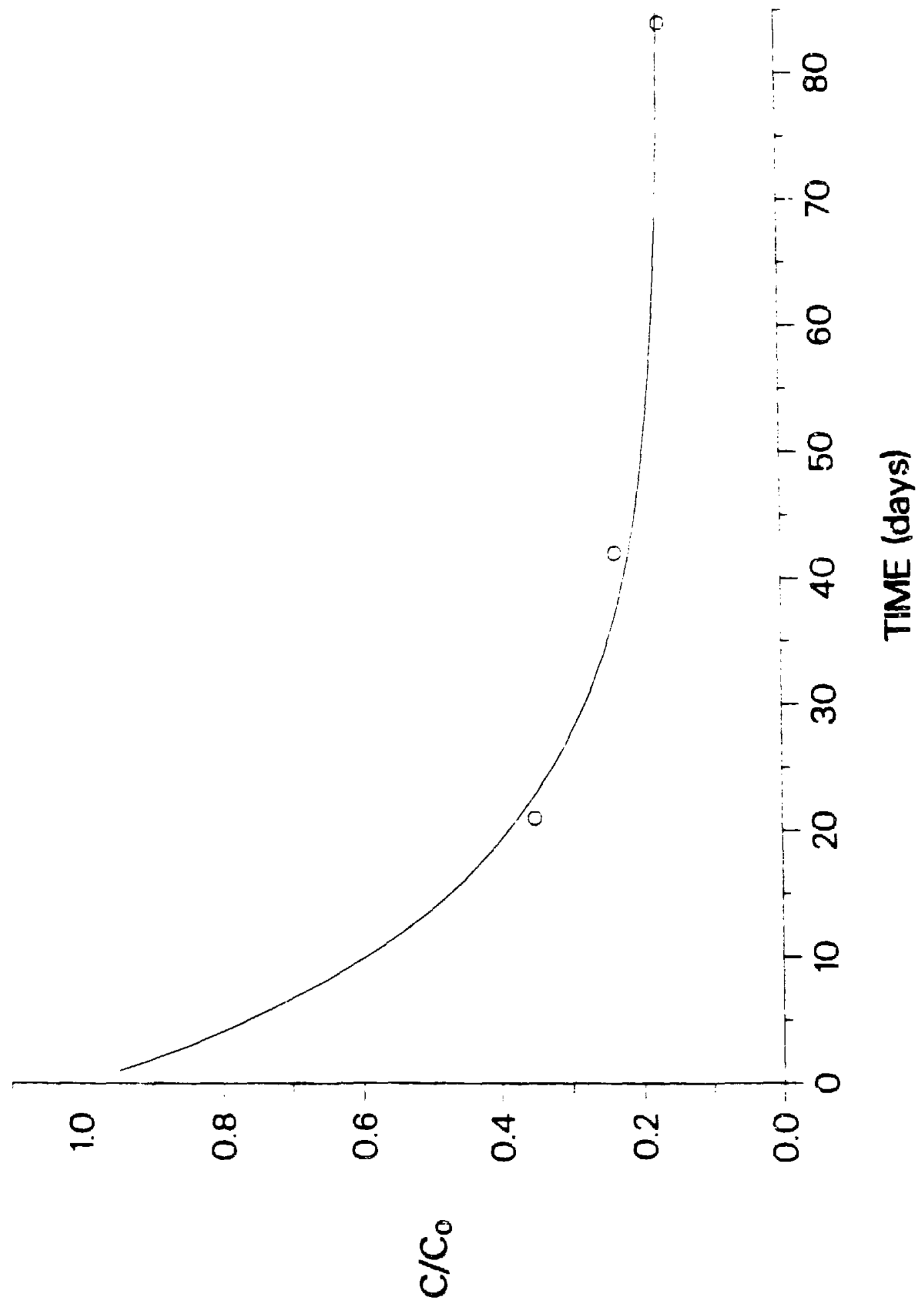

Fig. 2. The c co as a function of time for plutonium sorption on $Y \mathrm{M}-22(\mathrm{Tpt})$ tuff. 
The resulting sorption and desorption values are shown in Table $\mathrm{X}$. The fit to the sorption data appears to be quite good and the desorption values are at least of the correct order of magnitude. Until experiments exhibiting a kinetic effect are run cver smaller time increments, an order of magnitude fic is all that can be expected and deviations from the linear rate law cannot be measured.

\section{B. Conclusions}

The phenomenon of actinide sorption is still not well understood. The reproducibility of batch sorvtion experimerts on actinides is poor. The plutonium feed solutions have contained a mixture of oxidation states from IV to VI. The thermodynamic data base for actinide solubility is too poor to accurately predict the solubilities in Drill Hole J-13 water. Th:1s, the effects of precipitation, which would yield an apparent sorption ratio, cannot be ruled out in the batch measurements. Furthermore, there is no sensitivity to cationadsorbing minerals such as clays and zeolites. This leaves the mechanism for "sorption" in do:ıbt.

The kinetics of sorption are apparently slow for plutonium in a number of cases although time dependence is not observed in every series of batch measurements. However, to be conservative, the slow sorption observed in a few cases can be used as a baseline for sorption kinetics. The kinetic constants established in the preceding section will be used in Sec. $V$ for establishing groundwater velocity limits for which the $K_{d}$ or equilibrium sorption constants aro still valid. The uncertainty in the rate constants and velocity limits is difficult to estimate because the mechanism is so poorly understood.

TABLE X

SORPTION/DESORPTION RESULTS FOR SAMPLE YM-22

\begin{tabular}{|c|c|c|c|c|}
\hline \multirow{2}{*}{$\begin{array}{c}\text { Time } \\
\text { (wepks) }\end{array}$} & \multicolumn{2}{|c|}{$\begin{array}{c}\text { Experimental } \\
\mathrm{K}_{d} \\
(\mathrm{~m} l \cdot \mathrm{g})\end{array}$} & \multicolumn{2}{|c|}{$\begin{array}{c}\text { Calculated } \\
\mathrm{K}_{d} \\
(\mathrm{~m} \ell / \mathrm{g}) \\
\end{array}$} \\
\hline & Sorption & Desorption & Sorption & Desorption \\
\hline$?$ & 37 & 1400 & 33 & 1770 \\
\hline 6 & 64 & 1300 & 71 & 906 \\
\hline 12 & 100 & 1300 & 99 & 475 \\
\hline
\end{tabular}


Further experimentation with the actinides is necessary to improve confidence in predicting the retardation of these elements. As plutonium in defined oxidation states becomes available, more meaningful sorption studies can be performed. Experiments of this nature have already been initiated at Los Alamos and progress can be expected soon. In addition, it is desirable to study the interaction of single species with pure minerais. This research is also planned for the future.

\section{WATER VELOCITY LIMITS FOR APPLYING SORPTION RATIOS}

The kinetics of sorption will increase spreading in the breakthrough curve as fluid velocity increases. If the fluid velocity increases sufficiently, premature breakthrough will occur. The velocity at which this premature breakthrough occurs is the limit to which the equilibrium treatment of sorption is valid. The velocity limits can be determined for a porous medium using Thomas's formulation.

\section{A. The Thomas Solution}

Most calculations of sorption breakthrough curves for elution of ionic tracers from a chromatographic column employ some form of the Rosen solution. ${ }^{21}$ However, the more general treatment by Thomas ${ }^{22}$ takes into account the curved shape of the equilibrium relationship, that is, the Langmuir Isotherm. In many cases, a favorable equilibrium could compensate for the lowering of the apparent $K_{d}$ by using a column at high fluid velocities. This effect may be especially important in the near-field situation where the radionuclide concentration may be high. Thomas assumed that the rate of adsorptisil can be represented by an expression for a monovalent ion exchange reaction such as

$$
\begin{aligned}
C s^{+}+N a-R & =C s-R-N a+ \\
(c) \cdot\left(q_{m}-q\right) & =(q) \times\left(c_{o}-c\right),
\end{aligned}
$$

where

$$
\begin{aligned}
N a-R \text { and } C s-R & =\text { sorbed ions, } \\
c, q_{m}-q, q, \text { and } c_{o}-c & =\text { concentrations of the species in the above equilibrium, } \\
q_{m} & =\text { sorption capacity, and } \\
c_{o} & =\text { carrier ion concentration. }
\end{aligned}
$$

The kinetic expression for the forward reaction in the above equlibrium is

$$
\rho_{B} \frac{\partial q}{\delta t}=\kappa a c\left(1-\frac{q}{q_{m}}\right)-\frac{1}{K}\left(c_{n} \quad c\right) \frac{q}{q_{m}}
$$

where 
$\rho_{B}=$ the bulk density,

$\kappa=$ the kinetic coefficient,

$a$ - interfacial area per unit volume of bed, and

$K=$ equilibrium cunstant.

Solving this equation coupled to the mass balance relationship

$$
\frac{\rho_{B}}{\epsilon} \frac{\delta q}{\delta t}+v \frac{\delta c}{\delta x}=0,
$$

where

$$
\begin{aligned}
& \epsilon=\text { porosity and } \\
& v=\text { fluid velocity }
\end{aligned}
$$

and substituting

$$
t=t-\frac{x}{v}
$$

where $x$ is the column length, and using the appropriate boundary conditions for continuous feed yields the following solutions:

$$
\begin{aligned}
\frac{c}{c_{0}} & =\frac{J(n / K, n T)}{J(n / K, n T)+1-J(n, n T / K) \mid \exp [1-(K-1)(n-n T)]} \text { and } \\
\frac{q}{q_{m}}= & \frac{1-J(n T, n / K)}{J(n / K, n T)+1-J(n, n T / K) \mid \exp [1-(K-1)(n, n T)]},
\end{aligned}
$$

where

$$
\begin{aligned}
n & =\frac{\kappa a x}{\nu \epsilon}=\text { dimensionless distance or number of transfer units to position } \mathrm{x}, \\
T & =\frac{\nu \epsilon c_{0} t}{q_{m} \rho_{B} x} \\
n T & =\frac{\kappa a c_{o} t}{q_{m} \rho_{B}}=\text { dimensionless time, } \\
J(\alpha, \beta) & =1-e^{-\beta} \int_{0}^{\alpha} e^{-\xi} I_{o}(2 \sqrt{\beta \xi}) d \xi, \text { and } \\
I_{0} & =\text { the zero-order modified Bessel function. }
\end{aligned}
$$

The computer program THOMAS was written to calculate breakthrough curves. The J functions were evaluated numerically using Gaussian quadrature; 16-point Gaussian quadrature reproduced exactly the published table of Vermeulen. ${ }^{17}$ Figures 3 to 6 show the resulting curves for 2 to 25 mass units; they were calculated with equilibrium constants of 1,10 . and 100. It should be noted that when the breakthrough $\left(c / c_{n}=0.5\right)$ occurs at $\mathrm{T}=1.0$, the following relationship holds:

$$
R_{j}=\frac{K_{d} \rho_{B}}{\epsilon}+1,
$$




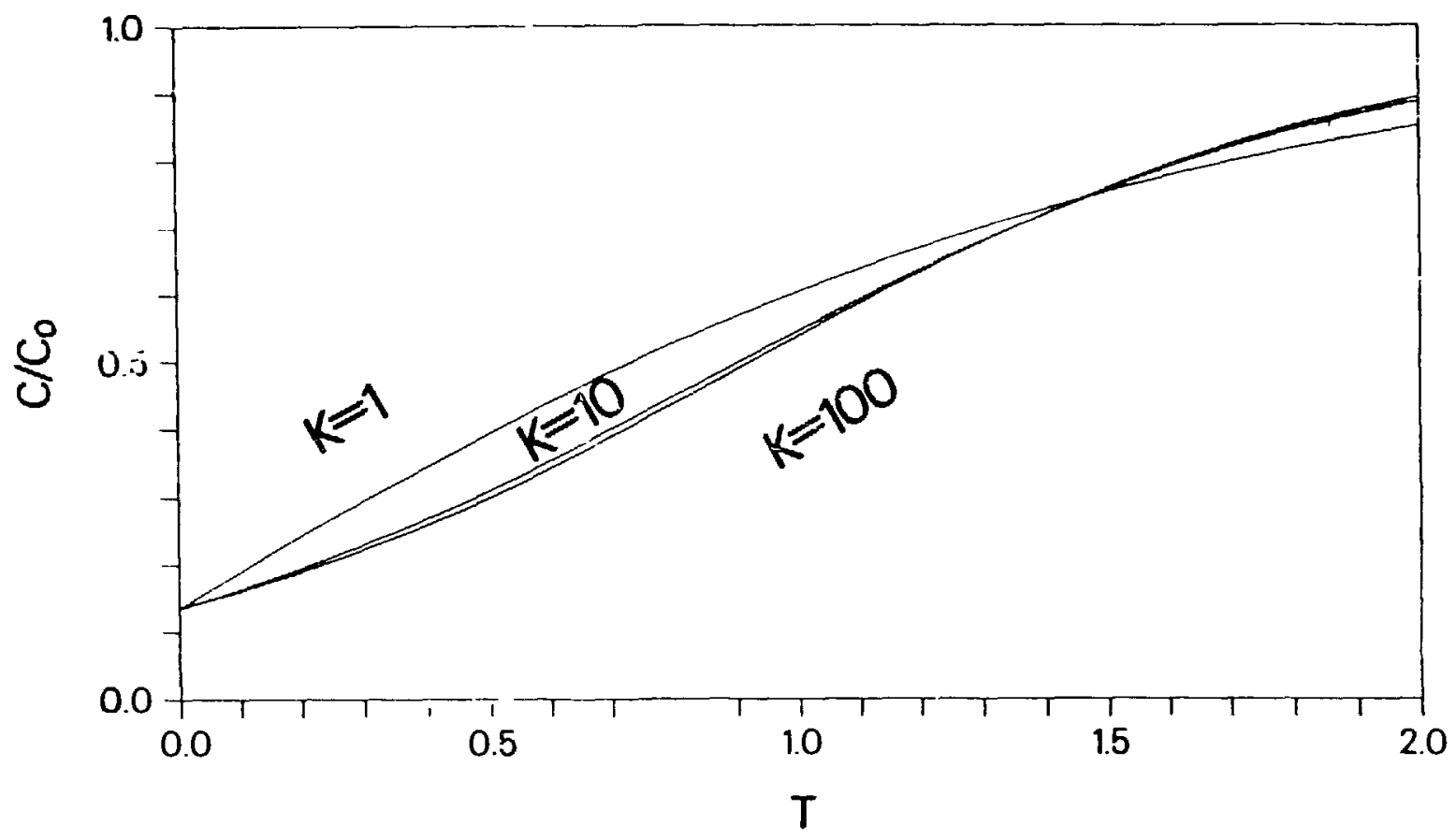

Fig. 3. Thomas solution breakthrough curves calculated by using 2 MTUS.

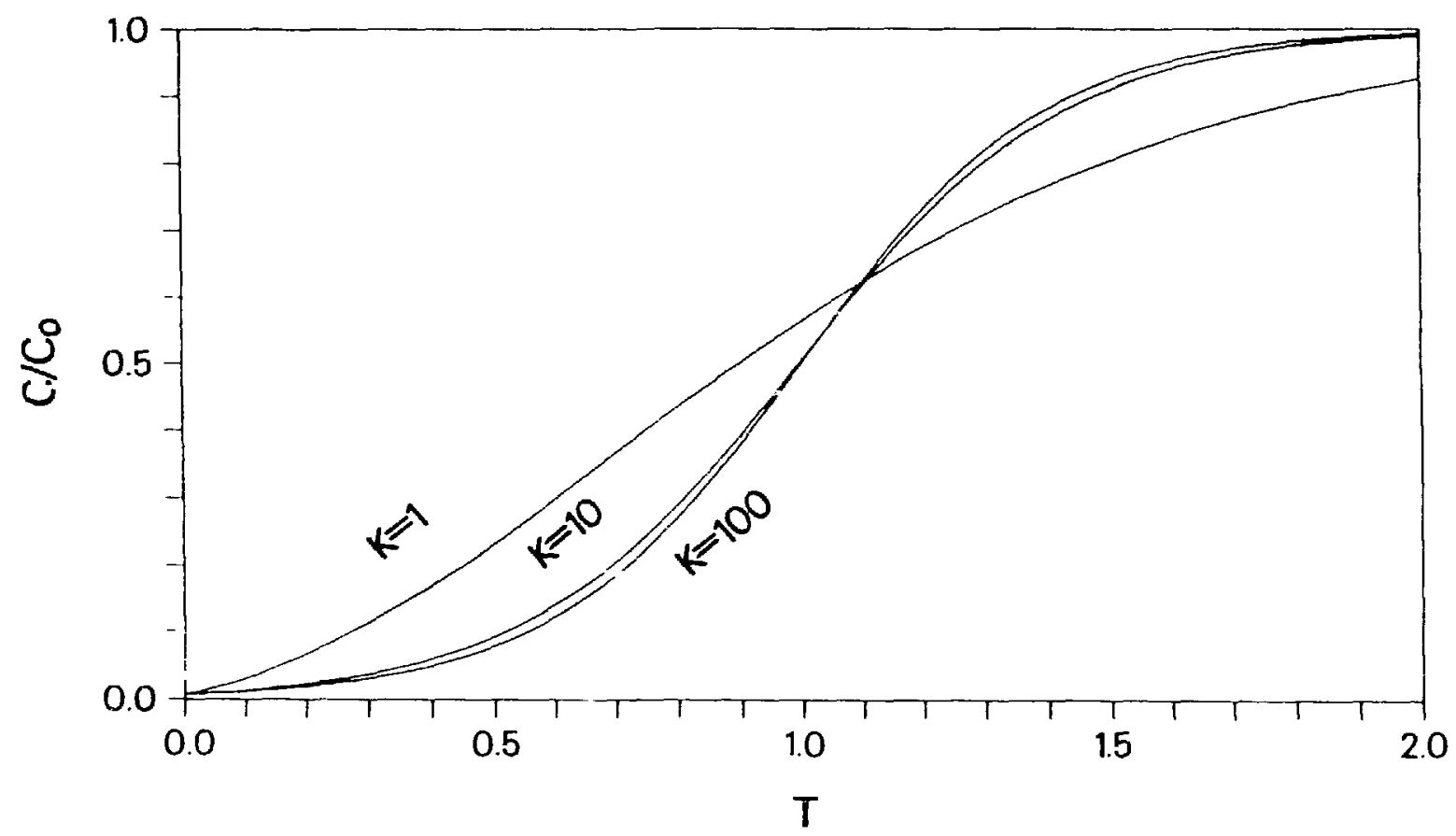

Fig. 4. Breakthrough mirves calculated by the Thomas solution using 5 MTLS. 


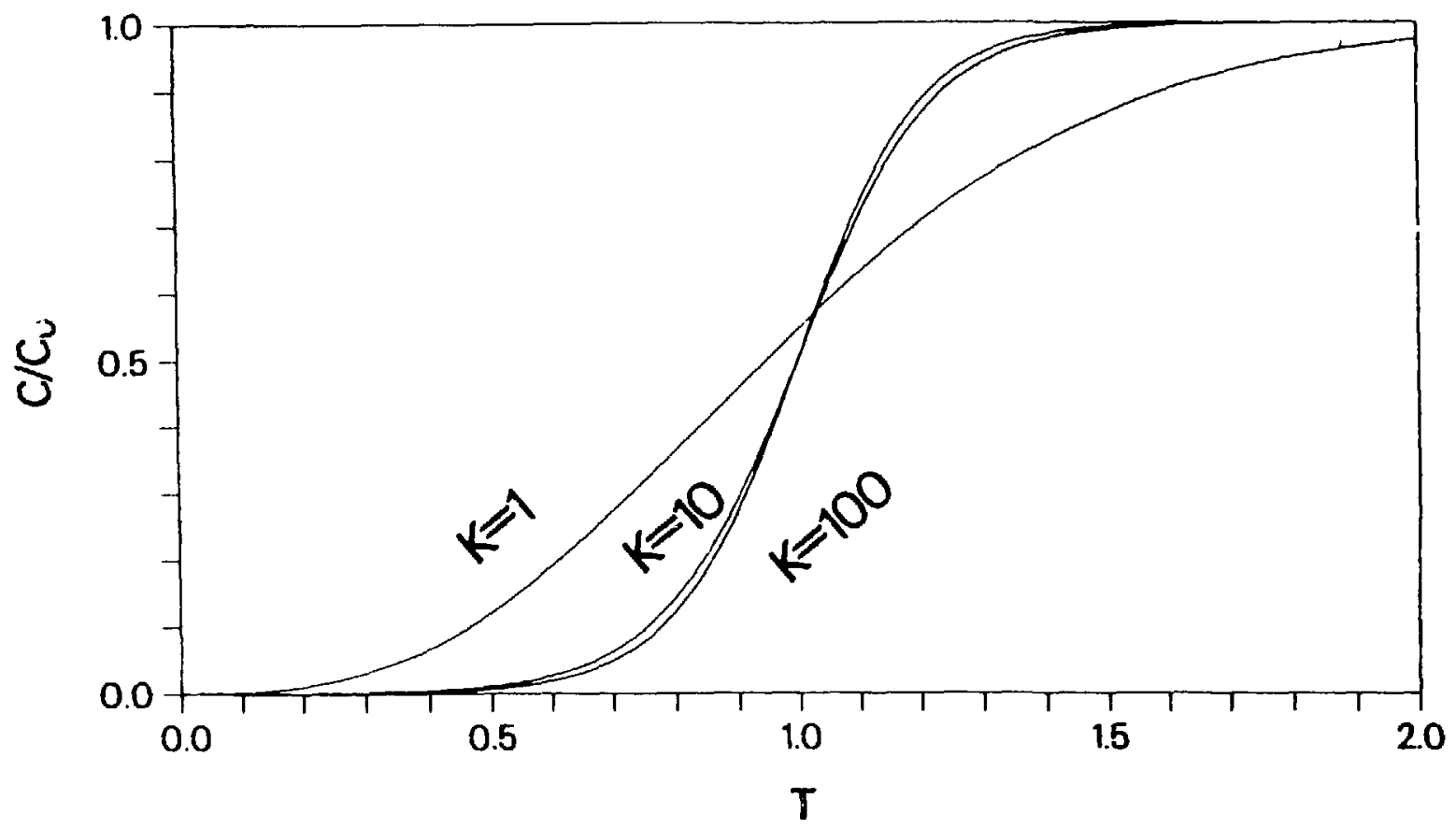

Fig. 5. Thomas solution breakthrough curves using 10 MTUS.

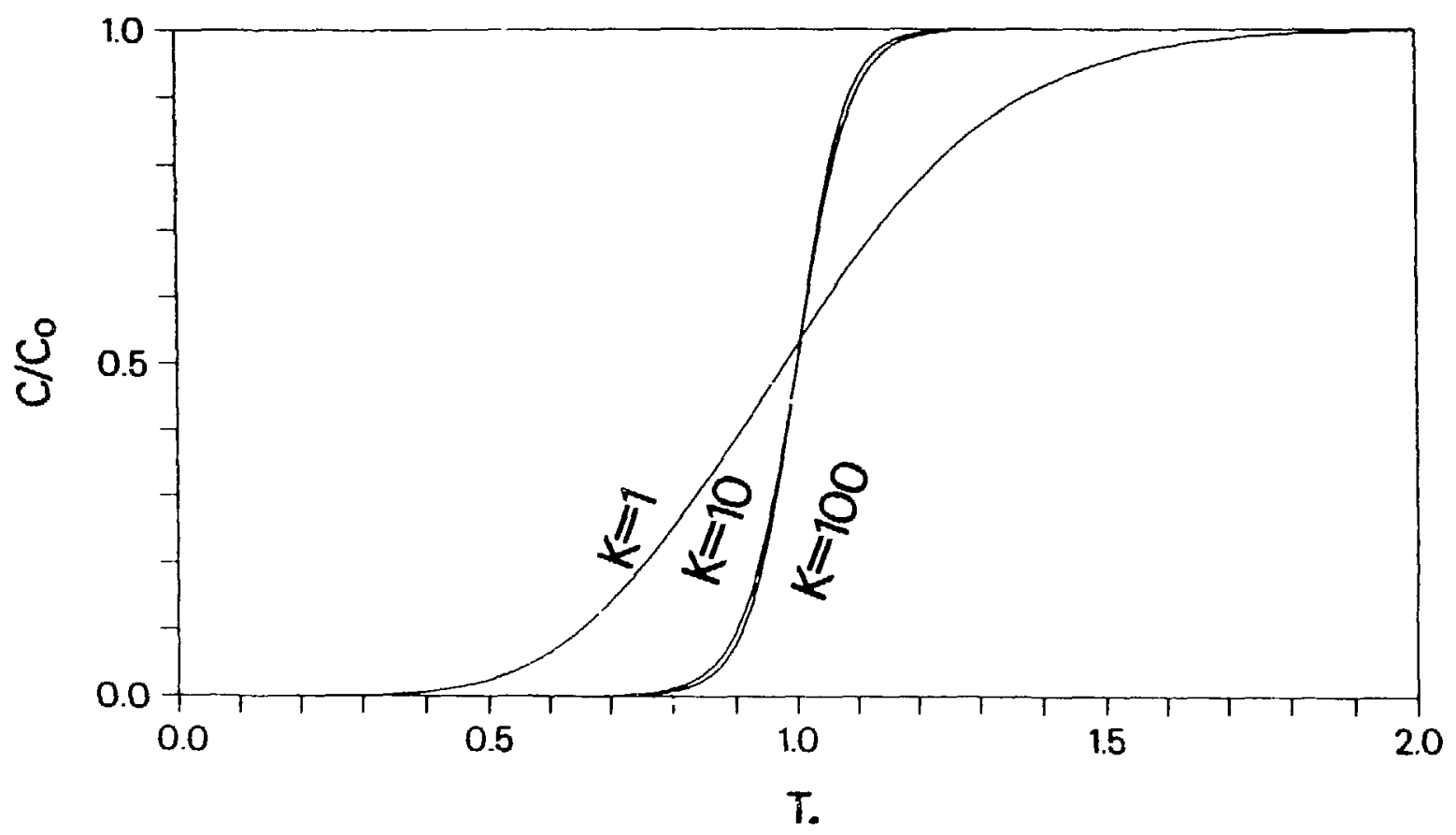

Fig. 6. Thomas solution breakthrough curves using 25 MTUS. 
where

$$
\begin{aligned}
& R_{f}=\text { retardation factor, } \\
& K_{d}=\text { distribution coefficient }, \\
& \rho_{B}=\text { bulk density, and } \\
& \epsilon \quad=\text { porosity. }
\end{aligned}
$$

If $\mathrm{T}$ is less than 1.0 at $\mathrm{c} / \mathrm{c}_{o}=0.5$, the following relationship holds:

$$
R_{f}=\frac{T K_{d} \rho_{B}}{\epsilon}+1 .
$$

The calculations show that for $K=1$, the breakthrough begins to arrive early by a few percent at 25 mass transfer units. However, with $\mathrm{K}=10$, the breakthrough does not begin to arrive significantly early until the number of mass transfer units is less than five. It is also interesting that increasing the equilibrium constant from 1 to 100 does not significantly improve column performance. A favorable equilibrium, $\mathrm{K}>1$, also sharpens the breakthrough curve, giving an effectively higher number of mass transfer units. This effect could be important in many cases. For example, for YM-22 tuff, the results for sorption capacities, groundwater analyses, and $\mathrm{K}_{\mathrm{d}}$ values ${ }^{5}$ give an equilibrium constant of about 20 for cesium. Also, isotherm data ${ }^{2}$ at high concentrations indicate an equilibrium constant of about 17 for cesium of YM-22 tuff. The equilibrium constant, $\mathrm{K}$, for cesium calculated from the sorption capacity, $K_{\mathrm{d}}$ value, and data from groundwater analyses for JA-18 tuff is about 120 . This may be an important effect for many radionuclides in the near field and, therefore, more measurements of isotherms at high concentrations could prove useful. However, for most simple cations, extremely high fluid velocities are required to lower the number of mass transfer units to a level where this effect is important.

\section{B. Calculated Limits}

The velocity limits for which chromatographic theory and retardation factors are valid can be determined from the minimum number of mass transfer units established in the previous section. However, there are two bases that can be used to relate mass transfer units to groundwater velocity: (1) the measured mass transfer units from column experiments and (2) the calculated mass transfer units from kinetic rate constants. The use of measured mass transfer units is not the most conservative because the overali mass transfer coefficient depends on. among other things, the hydrodynamic dispersion, which in turn depends on the flow path and/or pore structure along the flow path in Yucca Mountain. 
The adsorption-rate-limited mass transfer coefficient depends on fluid-side kinetics at lower water velocities, and at higher velocities the mass transfer coefficient is dominated by particle-side kinetics. This relationship is demonstrated in the following equation: ${ }^{23}$

$$
\frac{1}{\kappa}=\frac{1}{b}\left[\frac{1}{3.45\left(\frac{D_{f}}{d_{v^{\prime}}}\right) \sqrt{d_{p} \epsilon v /\left(6(1-\epsilon) D_{f}\right)}}\right]+\frac{1}{K_{d} \rho k_{p} a},
$$

where

$$
\begin{aligned}
& \kappa=\text { mass transfer coefficient, } \\
& D_{f}=\text { ion diffusivity in the fluid, } \\
& d_{p}=\text { particle diameter, } \\
& \epsilon \quad=\text { porosity, } \\
& v \quad=\text { water velocity, } \\
& K_{d}=\text { distribution coefficient } \\
& \rho \quad=\text { the dry bulk density, and } \\
& k_{p} a=\text { particle-side rate constant. }
\end{aligned}
$$

The first term, the fluid-side kinetics, is inversely proportional to the velocity. The second term, particle-side kinetics, is independent of velocity. Thus, at high velocity the overall mass transfer coefficient, $\kappa$, is equal to the particle-side kinetics. Also, this equation has a maximum for the mass transfer coefficient at a velocity determined by the relative kinetic parameters for the fluid- and particle-side kinetics.

Table XI compares the observed mass transfer coefficients with those expected on the basis of the adsorption kinetics observed in Sec. II. The mass transfer unit numbers were measured in the crushed-tuff columns that were run at the fastest water velocities, and the expected mass transfer coefficients were based on fluid- and particle-side rates. These numbers were calculated using the following formula:

$$
n=\kappa a x / v \epsilon,
$$

where

$$
\begin{aligned}
& a \quad \text { the interfacial area of the solid phase per unit volume of bed and } \\
& x=\text { length of the column. }
\end{aligned}
$$

The interfacial area, $a$, was assumed to be approximately $200 \mathrm{~cm}^{-1}$ and the average particle size. about $100 \mu \mathrm{m}$. Because the sorption rate constants for the actual mineral assemblages in the tuff studied by the column method were not always available, the average desorption rate constant of $4.8 \times 10^{5}$ was used. The desorption rates did not 
TABLE XI

MASS TRANSFER UNITS FOR CRUSHED-TUFF COLUMNS

\begin{tabular}{|c|c|c|c|c|c|}
\hline \multirow[b]{2}{*}{ Sample } & \multirow[b]{2}{*}{$(\mathrm{cm} / \mathrm{s})$} & \multirow[b]{2}{*}{ Element } & \multirow[b]{2}{*}{ Measured } & \multicolumn{2}{|c|}{ N Mass Transfer Units } \\
\hline & & & & $\begin{array}{c}\text { Calculated From } \\
\text { Fluid Side }\end{array}$ & $\begin{array}{c}\text { Calculated From } \\
\text { Particle Side }\end{array}$ \\
\hline \multirow[t]{3}{*}{ G-1-3116 } & $1.4 \times 10^{-2}$ & $\mathrm{Sr}$ & 660 & 220 & 20 \\
\hline & & $\mathrm{Cs}$ & 64 & 250 & 120 \\
\hline & & $\mathrm{Ba}$ & 4 & 86 & 650 \\
\hline G-1-3658 & $1.8 \times 10^{-2}$ & $\mathrm{Sr}$ & 380 & 200 & 40 \\
\hline $\mathrm{YM}-38$ & $2.45 \times 10^{-2}$ & Cs & 8 & 160 & 550 \\
\hline \multirow[t]{3}{*}{ G-1-2331 } & $5.9 \times 10^{-3}$ & $\mathrm{Sr}$ & 140 & 340 & 4.4 \\
\hline & & Cs & 52 & 390 & 43 \\
\hline & & $\mathrm{Ba}$ & 69 & 130 & 16 \\
\hline
\end{tabular}

vary more than an order of magnitude for very different mineral systems described in Sec. III.

In some cases, the agreement between experimental results and the theoretical calculations is poorer than 1 order of magnitude. This may be due to one of several errors. (1) The kinetics of the tuff samples run at high velocity have not been determined independently by other means, such as tuff wafers. (2) Nonfickian dispersion or channeling was not accounted for. (3) There may be irreversible interactions, particularly for cesium.

When elements are adsorbed with a large $K_{d}$ (greater than $100 \mathrm{~m} / \mathrm{g}$ ), the kinetic rate constants appear to give a number of mass transfer units that is larger than observed. Therefore, it would seem that the most conservative approach would be to use measured velocities as upper limits when the $K_{d}$ is greater than 100 and calculated mass transfer units to establish velocity limits when the $K_{d}$ is smaller than 100 . The threshold velocity is the velocity above which the number of mass transfer units is less than five. Table XII lists the threshold velocities as a function of ion and $\mathrm{K}_{\mathrm{d}}$ for a 100 -m-long column with a porosity of 0.3 .

There are no limits listed for americium because the $K_{d}$ s are generally larger than 100 , there is no firm evidence for sorption kinetics, and crushed-tuff columns have not yet been run as a function of velocity. Likewise, tuff columns have not been run for plutonium with tuffs having a $K_{d}$ much greater than 100 . The limits listed in Table XII cannot be 
TABLE XII

VELOCITY LIMITS FOR THE APPLICABILITY OF $\mathrm{K}_{\mathrm{d}} \mathrm{S}$

\begin{tabular}{|c|c|c|c|}
\hline Element & $\begin{array}{c}\mathrm{K}_{\mathrm{H}} \\
(\mathrm{m} \ell / \mathrm{g})\end{array}$ & $\begin{array}{l}\text { Maximum Velocity } \\
(\mathrm{cm} / \mathrm{s})\end{array}$ & $\begin{array}{l}\text { Maximum Velocity } \\
(\mathrm{m} / \mathrm{y})\end{array}$ \\
\hline $\mathrm{Sr}$ & $\begin{array}{r}10 \\
100 \\
1000\end{array}$ & $\begin{array}{l}5.6 \cdot 10^{11} \\
5.6 \times 10^{1} \\
1.3 \times 10^{2}\end{array}$ & $\begin{array}{l}1.8 \times 10^{6} \\
1.8 \times 10^{7} \\
4.1 \times 10^{7}\end{array}$ \\
\hline $\mathrm{Cs}$ & $\begin{array}{r}10 \\
100 \\
1000\end{array}$ & $\begin{array}{l}5.6 \times 10^{0} \\
5.6 \times 10^{1} \\
1.0 \times 10^{2}\end{array}$ & $\begin{array}{l}1.8 \times 10^{6} \\
1.8 \times 10^{7} \\
3.1 \times 10^{7}\end{array}$ \\
\hline $\mathrm{Ba}$ & $\begin{array}{r}10 \\
100 \\
1000 \\
10000\end{array}$ & $\begin{array}{l}2.6 \times 10^{-1} \\
2.6 \times 10^{\prime \prime} \\
2.6 \times 10^{1} \\
9.7 \times 10^{1}\end{array}$ & $\begin{array}{l}8.2 \times 10^{4} \\
8.2 \times 10^{5} \\
8.2 \times 10^{6} \\
3.1 \times 10^{7}\end{array}$ \\
\hline $\mathrm{Pu}$ & $\begin{array}{r}10 \\
100\end{array}$ & $\begin{array}{l}7.5 \times 10^{-4} \\
7.5 \times 10^{-3}\end{array}$ & $\begin{array}{l}2.35 \times 10^{2} \\
2.35 \times 10^{3}\end{array}$ \\
\hline
\end{tabular}

used in any absolute sense--only as guidelines. If, in the performance assessment of the Yucca Mountain site, scenarios are introduced in which water velocities approach these limits, further study (inciuding field tests) will be necessary to obtain a more consistent data base and fuily evaluate the effect of dispersion.

\section{SUMMARY AND CONCLUSIONS}

Simple cations, such as strontium, cesium, and barium, adsorb on Yucca Mountain tuff with high distribution coefficients and rapid sorption kinetics. The crushed-tuff column elutions with simple cations have shapes, which at low water velocities (less than $10^{-3}$ $\mathrm{cm} / \mathrm{s}$ ) were consistent with the logitudinal diffusivity of the cations. Thus, the mass transfer was much faster than the self-diffusion in water. However, when uptake of these cations was studied using 2 -mm thin wafers of intact tuff, the uptake as a function of time did not fit instantaneous adsorption kinetics. These data fit quite well with a linear reversible adsorption mechanism coupled to diffusion into the water. The rate constants thus determined were high and suggested a two-step diffusional model, where the diffusion inside the intracrystalline channels of zeolites and clays proceeds much more slowly than 
does diffusion in the intercrystalline pore space; however, the adsorption process at the surface was very fast. The rate constants determined by the water technique were applied to the prediction of elution curve shapes from crushed-tuff columns run at high water velocities-about $10^{-2} \mathrm{~cm} / \mathrm{s}$. The agreement between the predictions and the measured results was poor in some cases (a 2-order-of-magnitude discrepancy). This was expected because the rate constants used to predict the behavior in the crushed-tuff columns had not been determined for the tuff sample used in the column. Additionally, there are known irreversible processes for the sorption of cesium on many minerals; these processes would tend to distort the shape of elution curves without producing a nonconservative retardation factor.

An estimate of the velocity limit for which adsorption kinetics would be a concern was determined using the more conservative of the predicted mass transfer coefficients or the lowest mass transfer coefficient observed in the crushed-tuff column elutions. This calculation was performed for a $100-\mathrm{m}$ tuff column with: a porosity of $30 \%$, which would approximate transit through the bedded tuff of the Calico Hills tuff formation at Yucca Mountain. The finding of this exercise was that the kinetics of adsorption for the simple cations is fast enough to provide a sufficiently ample safety factor in the velocity limit so that adsorption kinetics in porous flow scenarios can be neglected. However, if one considers the kinetic rates calculated from batch sorption measurements, this was not the case for plutonium. The maximum velocity of $230 \mathrm{~m}$ per year, although well above the expected norrinal water infiltration rate, does not provide a sufficient safety factor to allow the neglect of kinetics in all scenarios, particularly in view of discrepancies as high as 2 orders of magnitude between results from crushed-tuff columns and those calculated in a similar manner.

The observation summarized above provides a basis for future research in sorption kinetics. The recommendations for future research on adsorption kinetics in Yucca Mountain tuff are given below.

(1) The adsorption of simple cations can be considered diffusion limited and further study of their kinetics does not appear to be necessary for performance assessment of any future repository at this site or evaluation of the transport of simple cations in Yucca Mountain.

(2) Sensitivity analyses should be performed to verify that the conclusions leading to recommendation (1) are valid for fracture flow scenarios.

(3) The kinetics of actinide adsorption on Yucca Mountain tuff should be studied in more detail. 
(4) The effect of nonlinear isotherms on the transport of radionuclides should be examined in sensitivity studies to determine if these isotherms will aggravate the effects of mass transfer kinetics. 


\section{REFERENCES}

1. D. L. Bish, D. T. Vaniman, R. S. Rundberg, K. Wolfsberg, W. R. Daniels, and D. E. Broxton, "Natural Sorptive Barriers in Yucca Mountain, Nevada, for LongTerm Isolation of High-Level Waste," in Radioactive Waste Management, Vol. 3 (International Atomic Energy Agency, Vienna, 1984), p. 415.

2. W. R. Daniels, K. Wolfsberg, R. S. Rundberg, A. E. Ogard, J. F. Kerrisk, C. J. Duffy, et al., "Summary Report on the Geochemistry of Yucca Mountain and Environs," Los Alamos National Laboratory report LA-9328-MS (December 1982).

3. K. L. Erickson, "A Fundamental Approach to the Analysis of Radionuclide Transport Resulting from Fluid Flow Through Jointed Media," Sandia National Laboratories report SAND80-0457 (1981).

4. E. N. Vine, B. P. Bayhurst, W. R. Daniels, S. J. DeVilliers, B. R. Erdal, F. O. Lawrence, and K. Wolfsberg, "Radionuclide Transport in Tuff," in Scientific Basis for Nuclear Waste Management, Vol. 3 (Plenum Press, New York, in press).

5. E. N. Vine, R. D. Aguilar, B. P. Bayhurst, W. R. Daniels, S. J. DeVilliers, B. R. Erdal, F. O. Lawrence, S. Maestas, P. Q. Oliver, J. L. Thompson, and K. Wolfsberg, "Sorption-Desorption Studies on Tuff. II. A Continuation of Studies with Samples from Jackass Flats, Nevada and Initial Studies with Samples from Yucca Mountain, Nevada," Los Alamos National Laboratory report LA-8110-MS (January 1980).

6. N. Hadden, F. Baumann, F. MacDonald, M. Munk, R. Stevenson, D. Gere. F. Zamaroni, and R. Majors, Basic Liquid Chromatography (Varian Aerograph, Walnut Creek, California, 1971).

7. J. H. Knox and L. McLaren, "A New Gas Chromatograph Method for Measuring Gaseous Diffusion Coefficients and Obstructive Factors," Anal. Chem. 36, 1477 (1964).

8. W. Vernst. "Zur Kinetic in der Los̈ung Befindlichen Kö̈per." Z. Physik. Chem. 2, $613(1888)$.

9. T. Vermeulen. (i. Klein, and N. Hiester, "Adsorption and Ion Exchange," in Chemical Engineers Handbook, 5th ed., R. H. Perry and C. H. Chilton, Eds. (McGraw-Hill, New York. 1973). Sec. 16. 
10. J. C. Giddings, Dynamics of Chromatography, Part I. Principles and Theory (Marcel Dekker, New York, 1965).

11. E. N. Treher and N. A. Raybold, "Elution of Radionuclides Through Columns of Crushed Rock from the Nevada Test Site," Los Alamos National Laboratory report LA-9329-MS (October 1982).

12. A. C. Waters and P. R. Carroll, Eds., "Preliminary Petrologic Characterization of Core Samples from LSW-G1, Yucca Mountain, Nevada," Los Alamos National Laboratory report LA-8840-MS (November 1981).

13. R. W. Spengler, F. M. Byers, Jr., and J. B. Warner, "Stratigraphy añd Structure of Volcanic Rocks in USW-G1. Yucca Mountain, Nye County, Nevada," CS Geol. Survey open-file report 81-1349 (1981).

14. K. Wolfsberg, R. D. Aguilar, B. P. Bayhurst, W. R. Daniels, S. J. DeVilliers, B. R. Erdal, F. O. Lawrence. S. Maestas, A. J. Mitchell, P. Q. Oliver, N. A. Raybold, R. S. Rundberg, J. L. Thompson. and E. N. Vine, "Sorption-Desorption Studies in Tuff. III. A Continuation of Studies with Samples from Jackass Flats and Yucca Mountain, Nevada," Los Alamos National Laboratory report LA-8747-MS (May 1981).

15. J. Crank, The Mathematics of Diffusion, 2nd ed. (Oxford Lniversity Press, London, 1975), p. 135 .

16. T. K. Sherwood, R. L. Pigford, and C. R. Wilke. Mass Transfer (McGraw-Hill, New York. 1975), p. 580.

17. T. Vermeulen. G. Klein. and N. K. Hiester, Chemical Engineers' Handbook, J. H. Perry, Ed. (McGraw-Hill, New York, 1973), Sec. 16.

18. R. M. Barrer. R. Bartholonew. and L. V. C. Rees, "Ion Exchange in Porous Crystals Part I. Self- and Exchange-Diffusion of Ions in Chabazite." J. Phys. Chem. Solids 24. $51-62(1963)$.

19. A. V. Rao and L. V. C. Rees, "Kinetics of Ion Exchange in Mordenite," Trans. Faraday ioc 62. 2505 (1966).

20. D. B. Breck, Zeolite Molecular Sieves (John Wiley \& sons, New York, 1974). 
21. J. B. Rosen, "Kinetics of a Fixed Bed System for Solid Diffusion into Spherical Particles," J. Chem. Phys. 20, 387 (1952).

22. H. Thomas, "Heterogeneous Ion Exchange in a Flowing System," J. Am. Chem. Soc. 66, 1664 (1944).

23. N. K. Heister, S. B. Radding, R. L. Nelson, and T. Vermeulen, "Empirical Correlation of Overall Mass-Transfer Resistance for Ion-Exchange Resin," A. I. ChE J. 2, 404 (1956). 
APPENDIX A

FITS OF COLUMN ELUTION TO MASS TRANSFER SOLUTION 


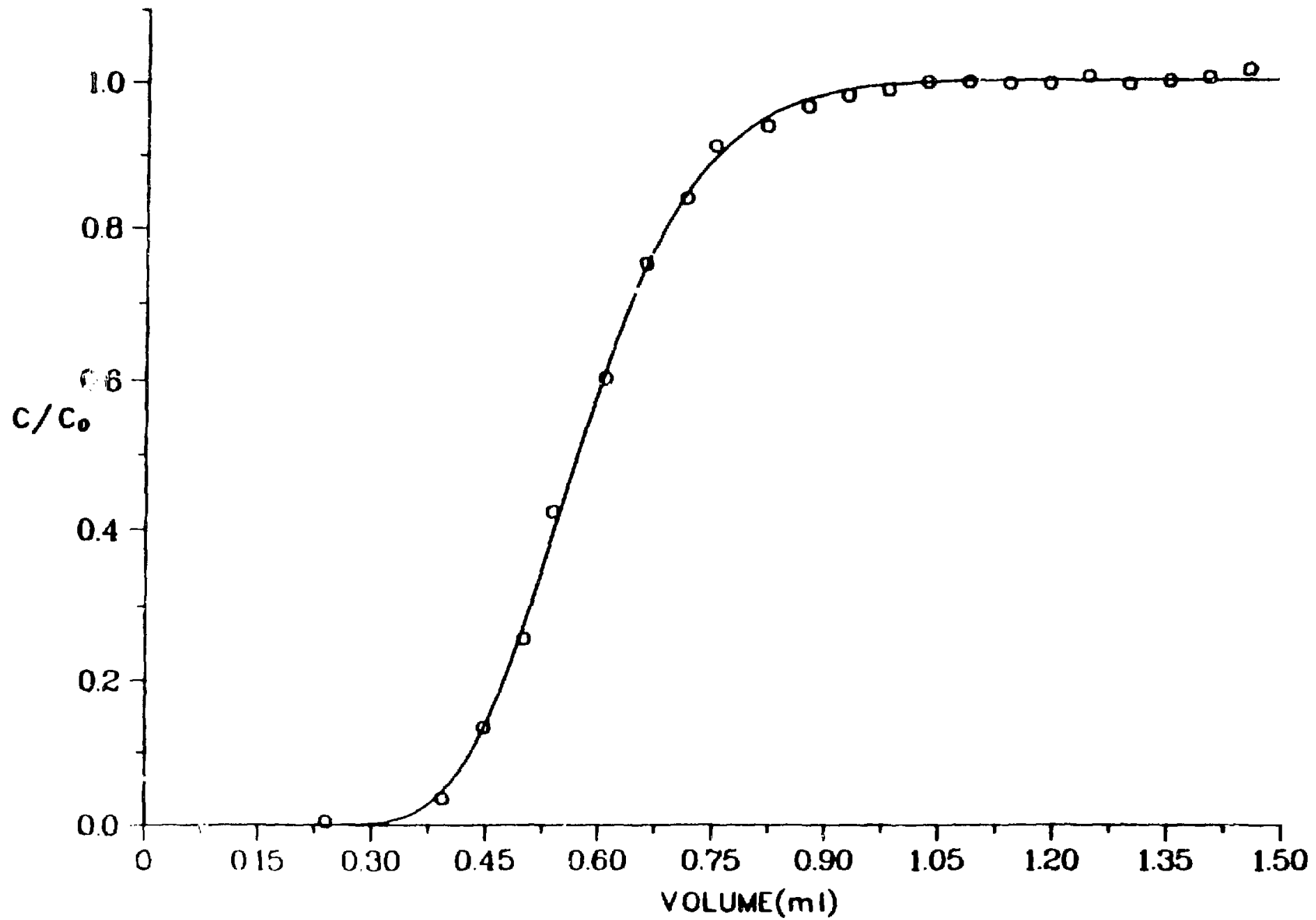

Fig. A-1. Sample G-1-2334B crushed-tuff column technetium elution, continuous feed. 


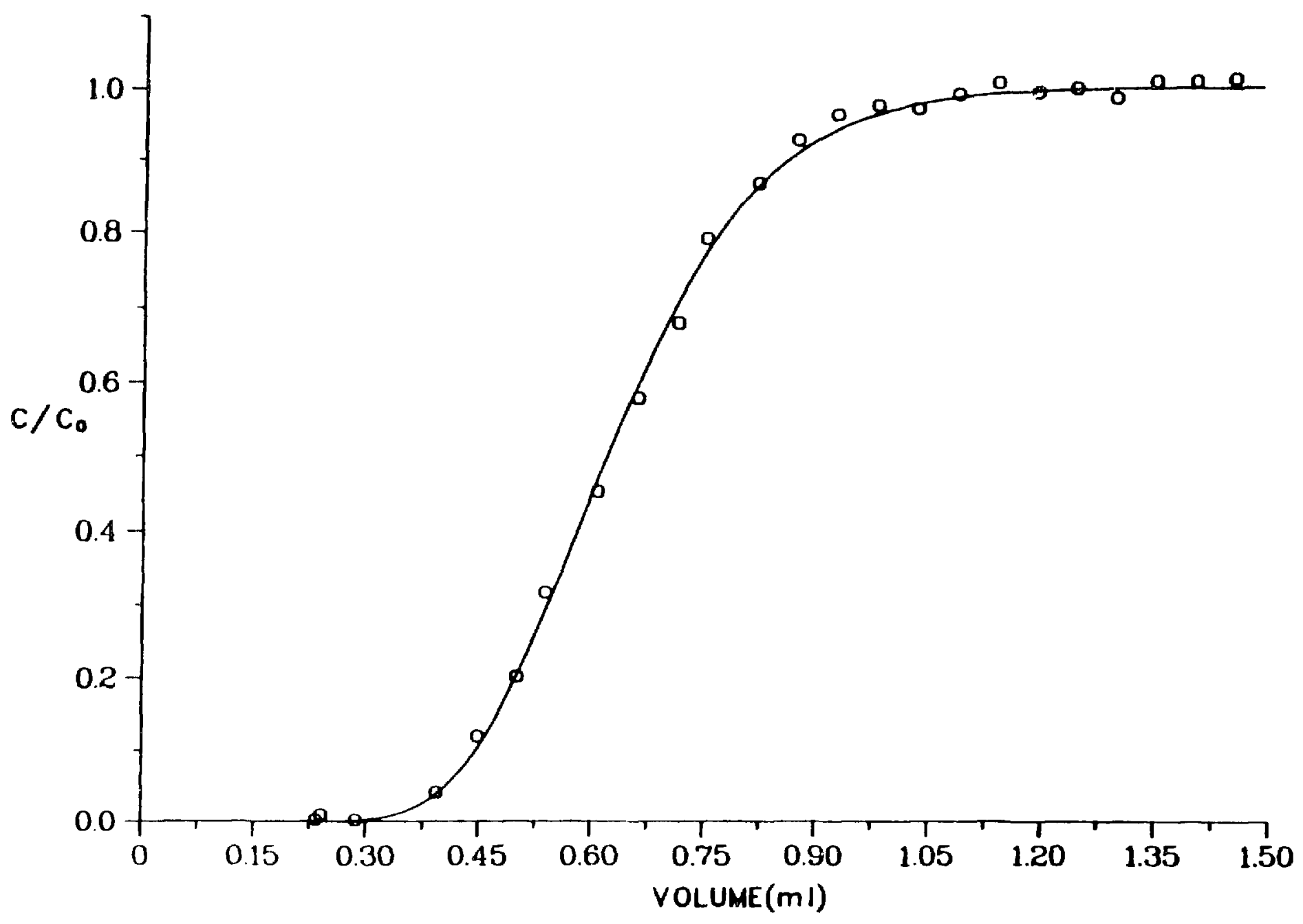




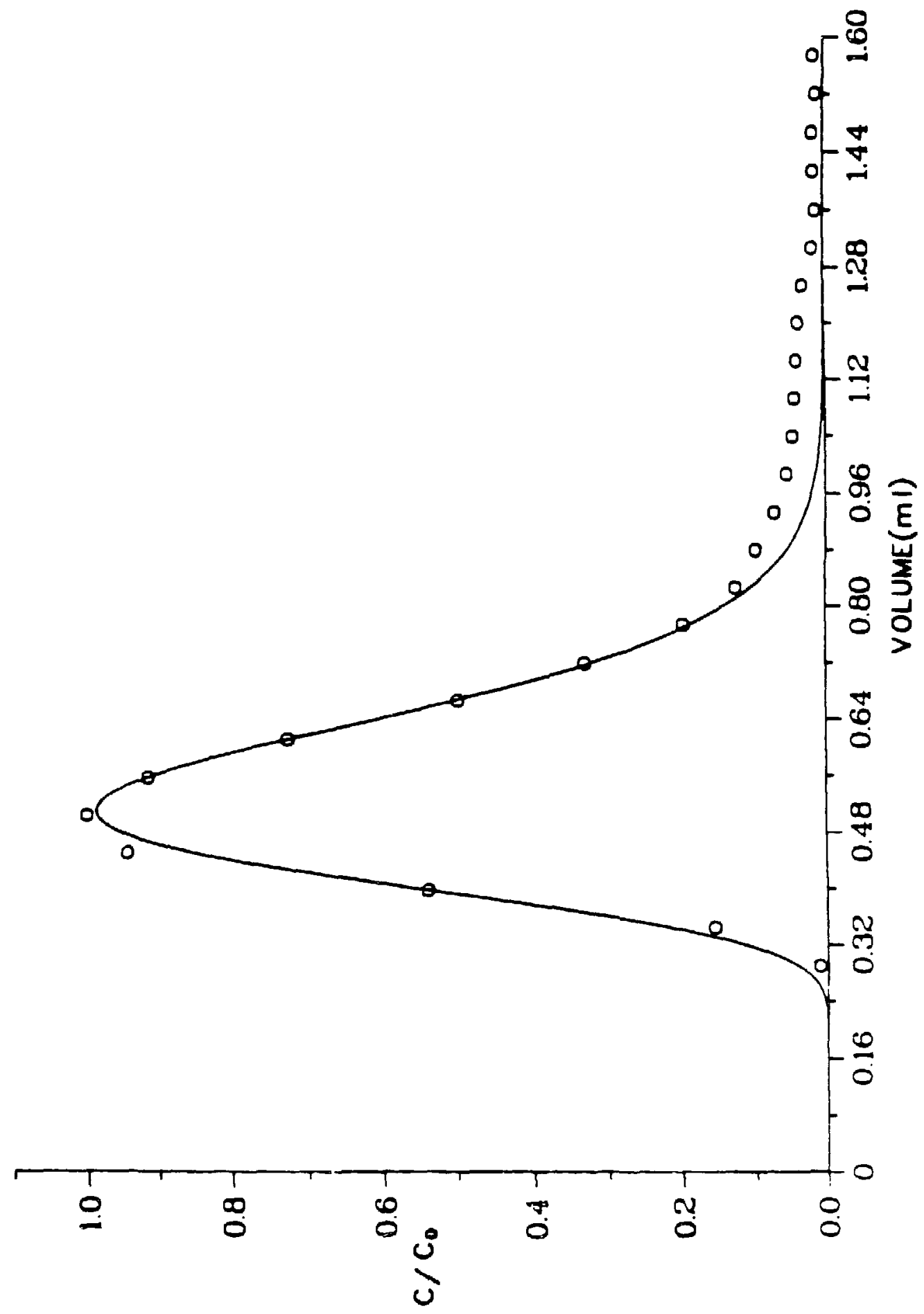



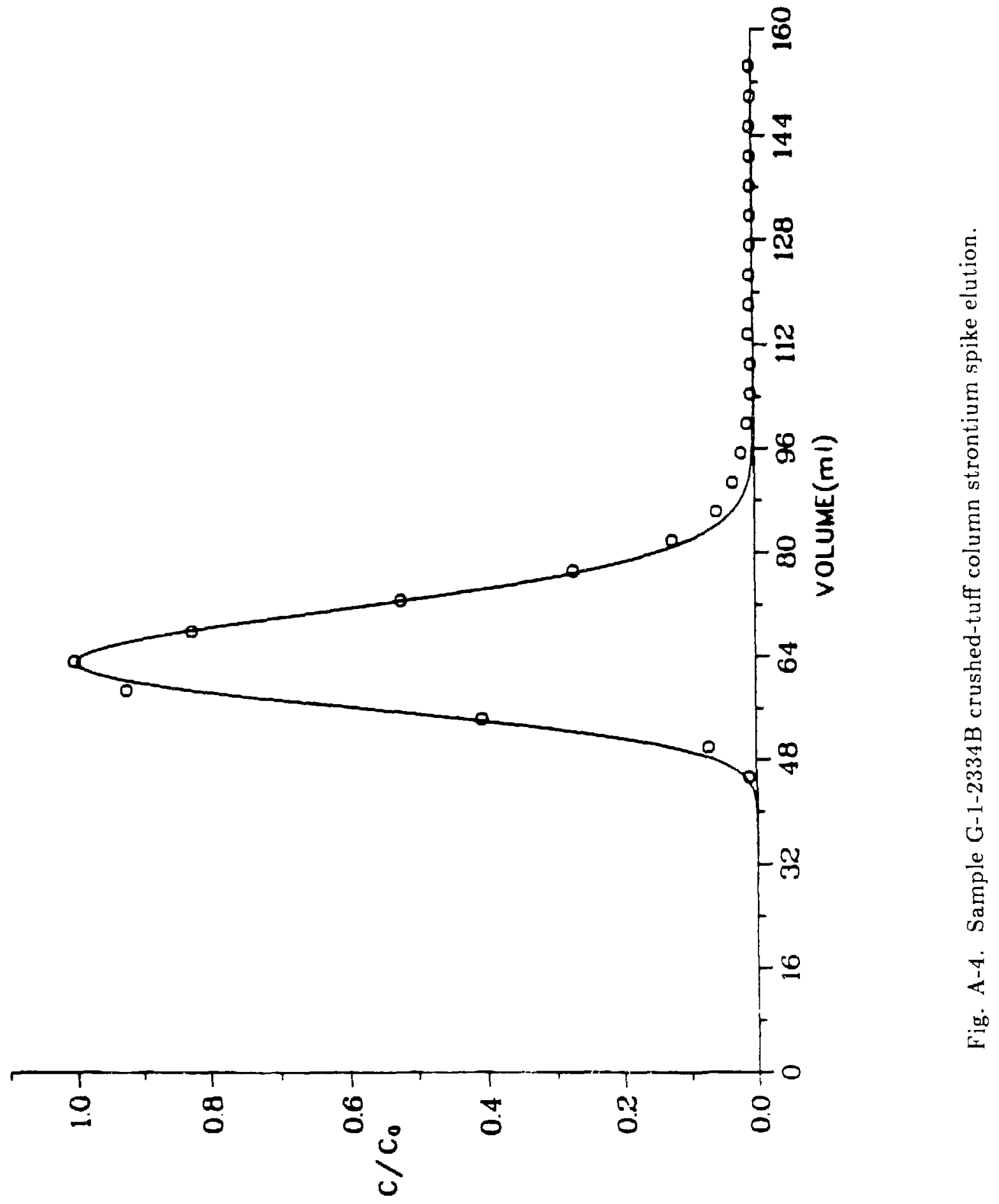


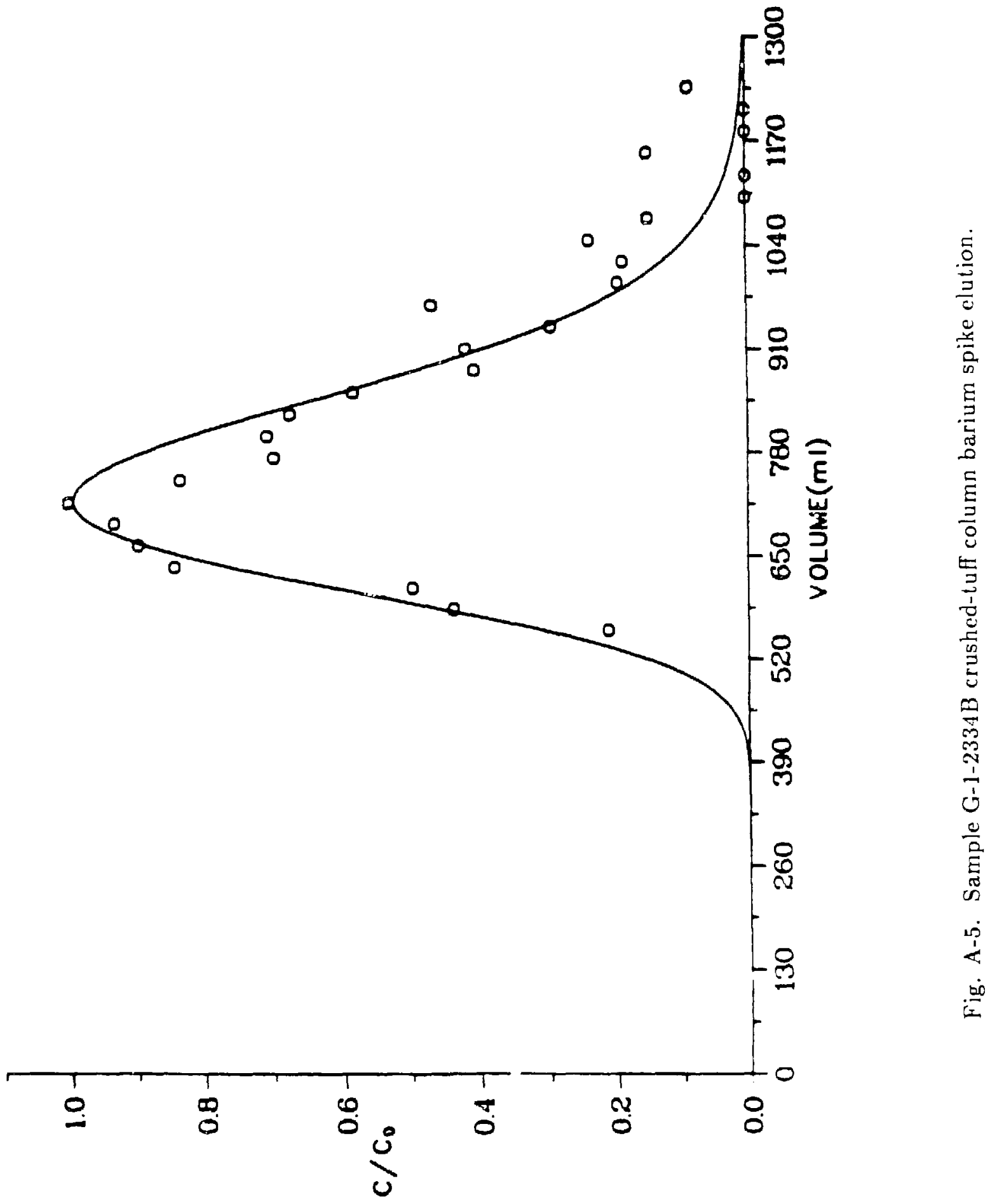




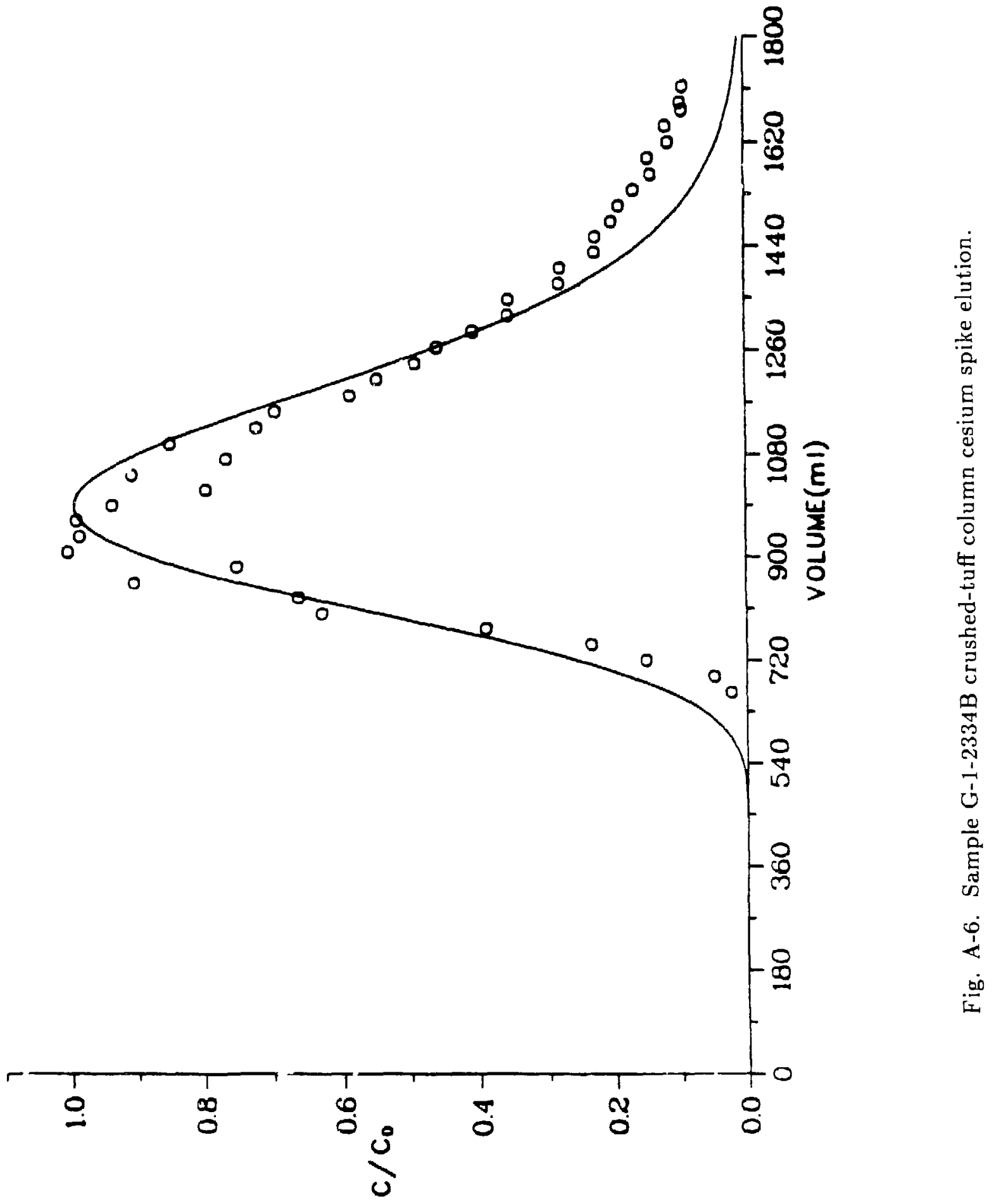




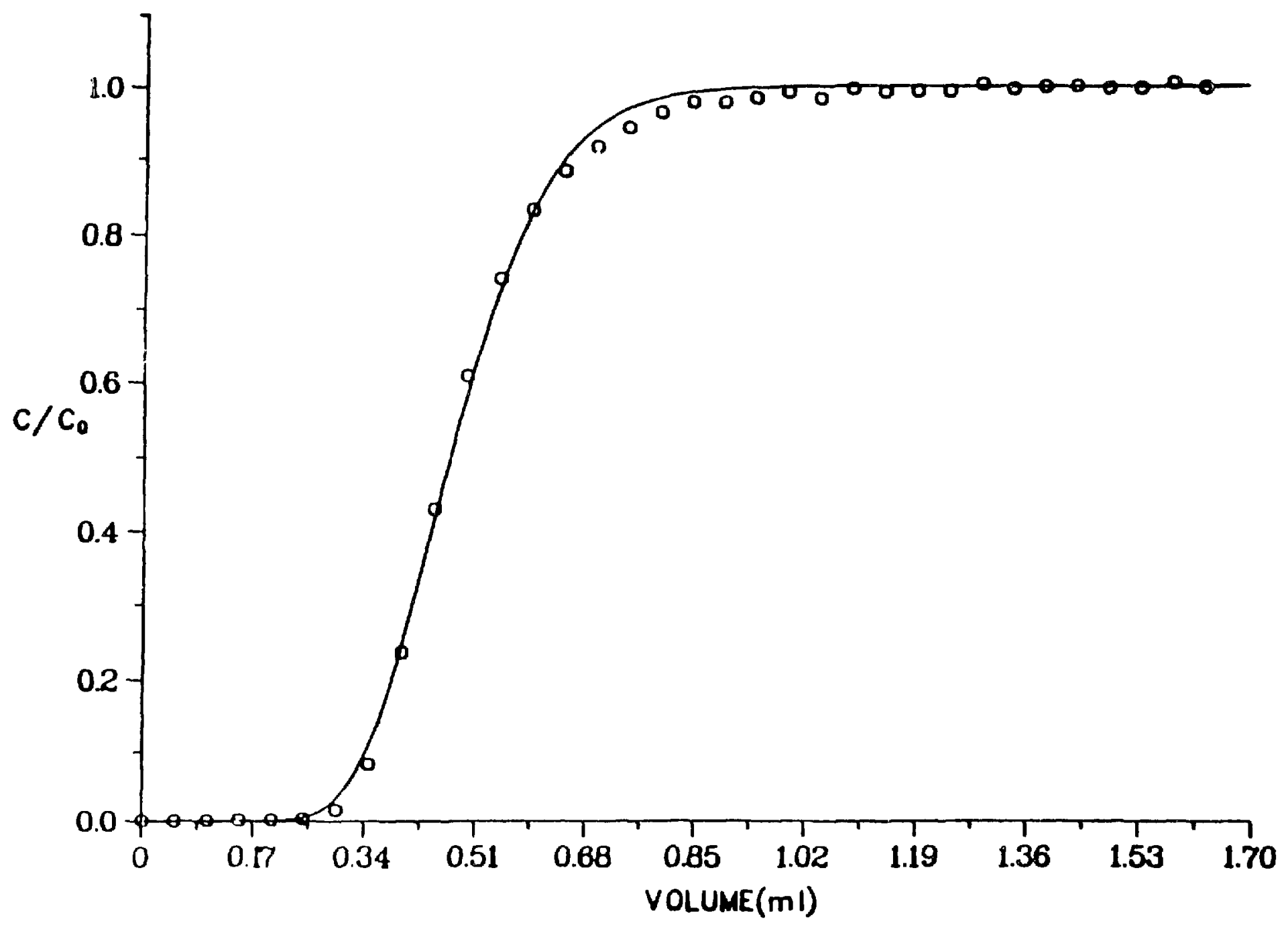

Fig. A-7. Sample G-1-2334C crushed-tuff column one-button continuous feed. 


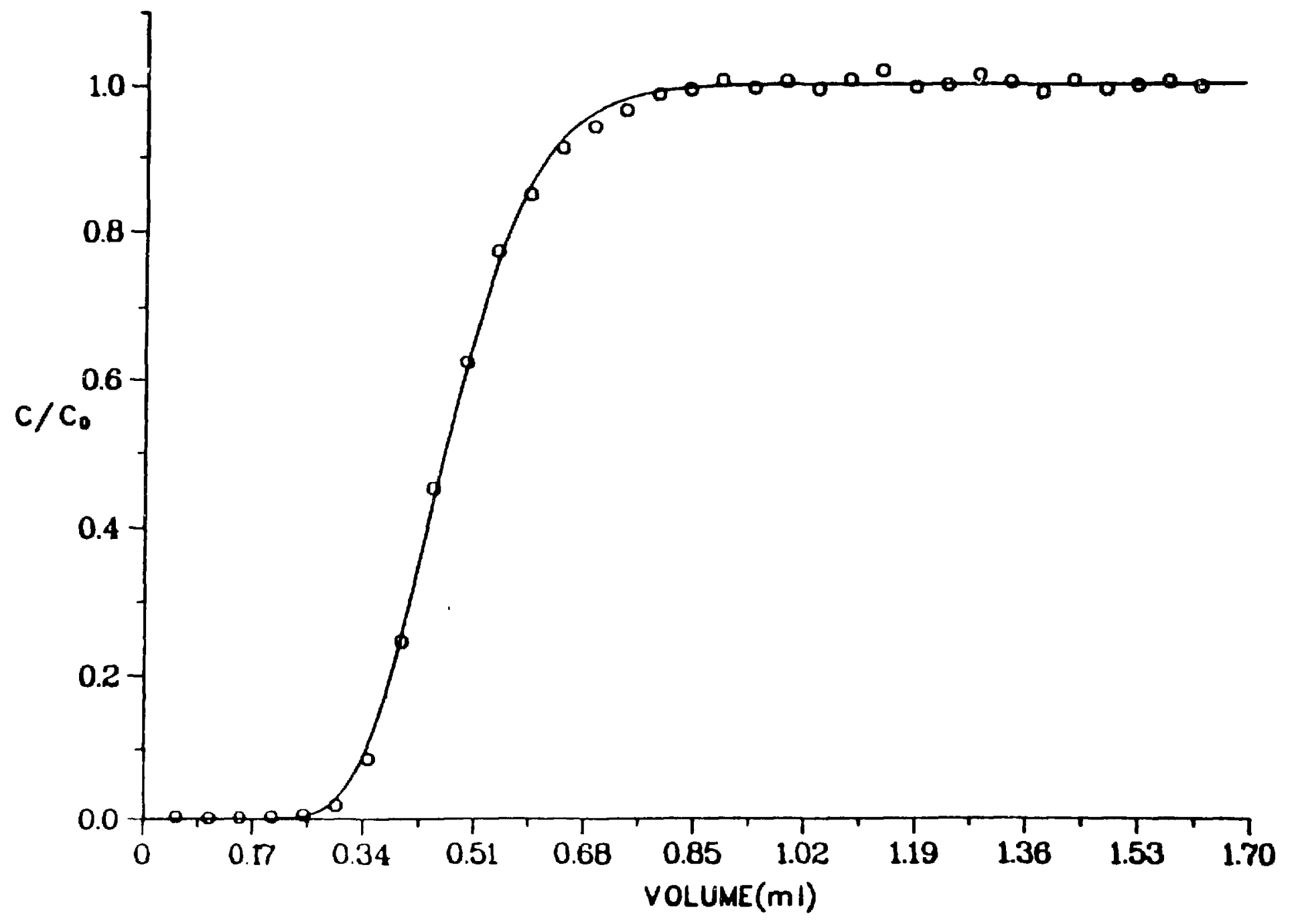




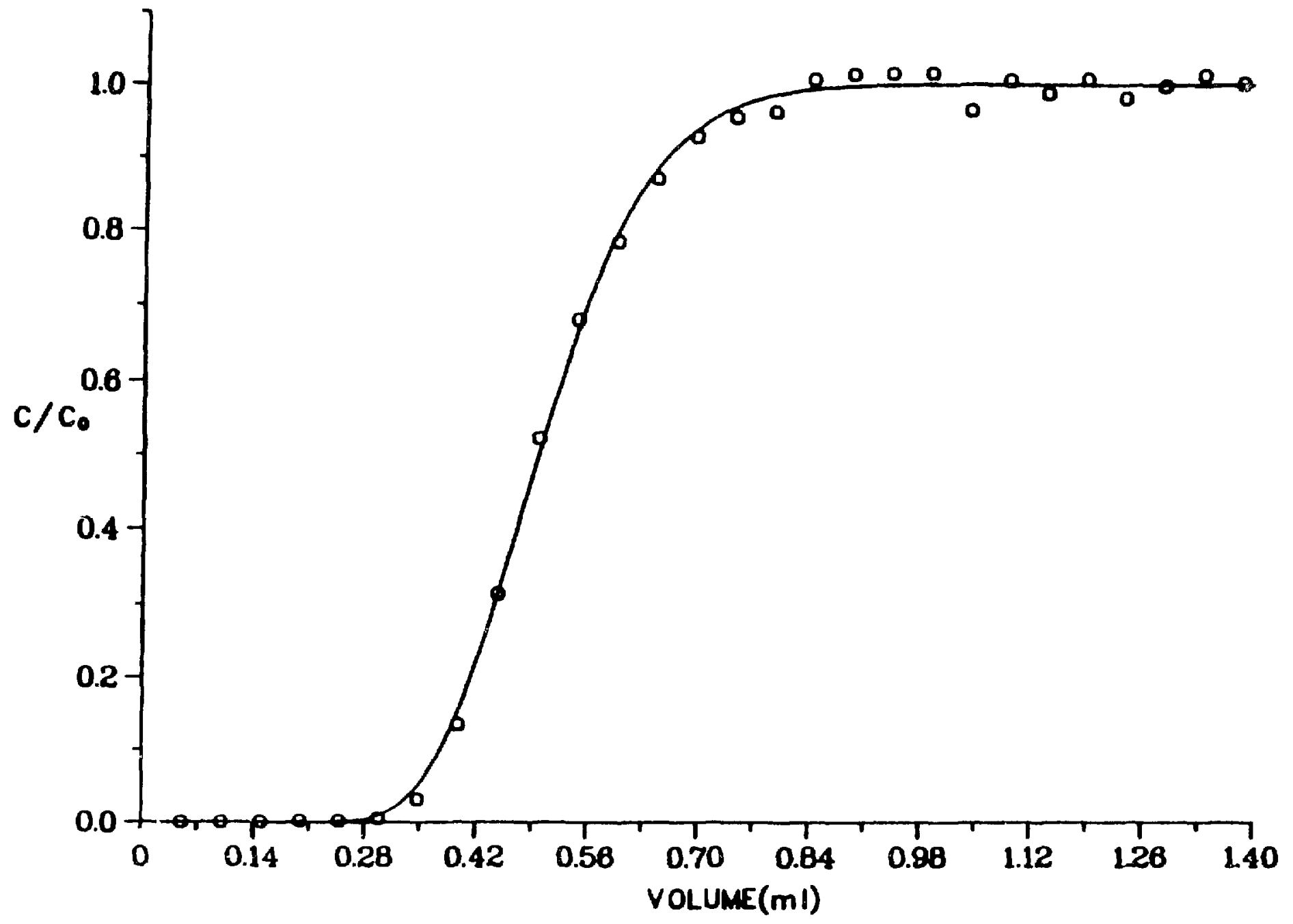

Fig. A-9. Sample G-1-2334C crushed-tuff column HTO elution, continuous feed. 


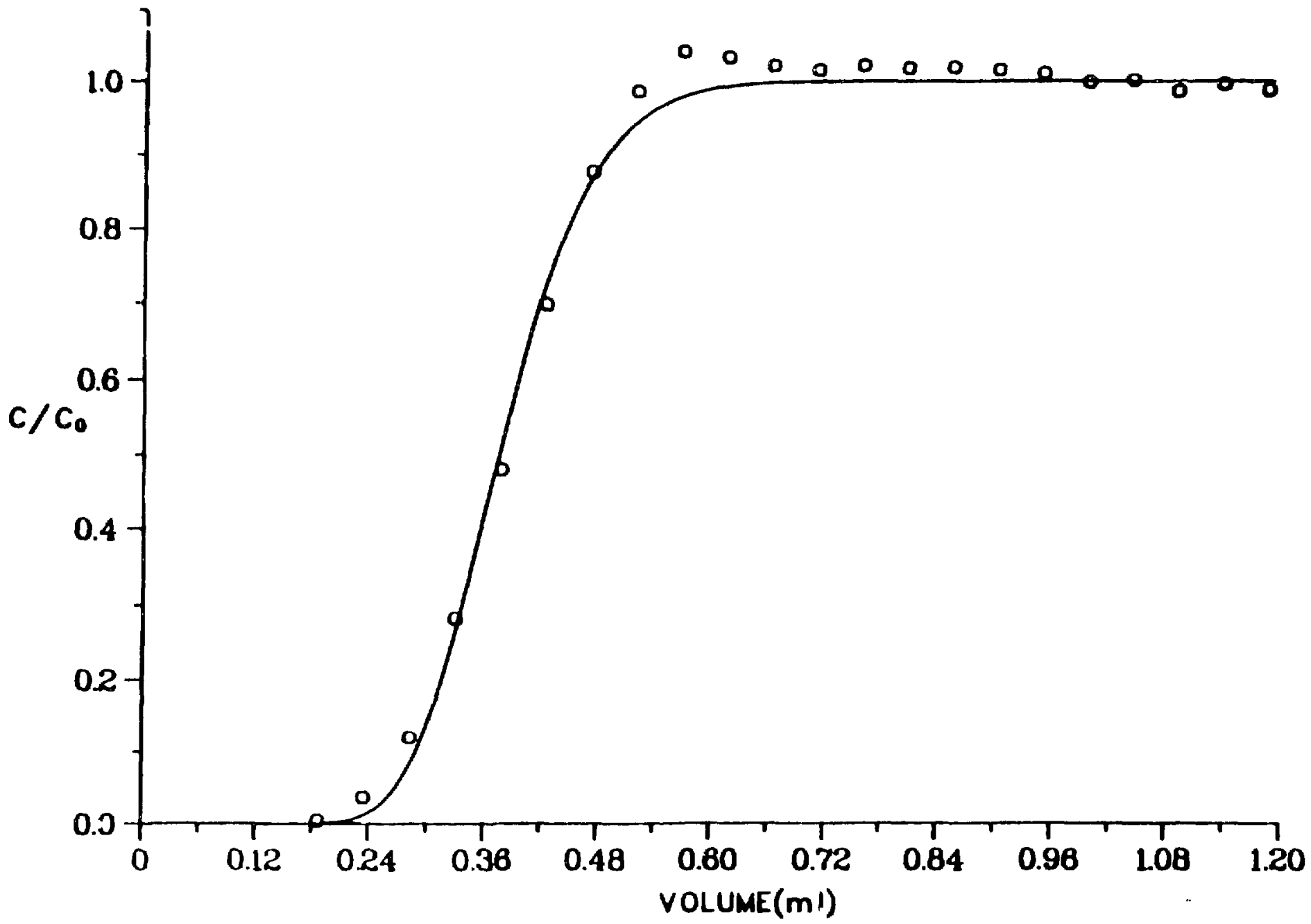

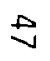

Fig. A-10. Sample G-1-1883 crushed-tuff column I-131 elution, continuous feed. 


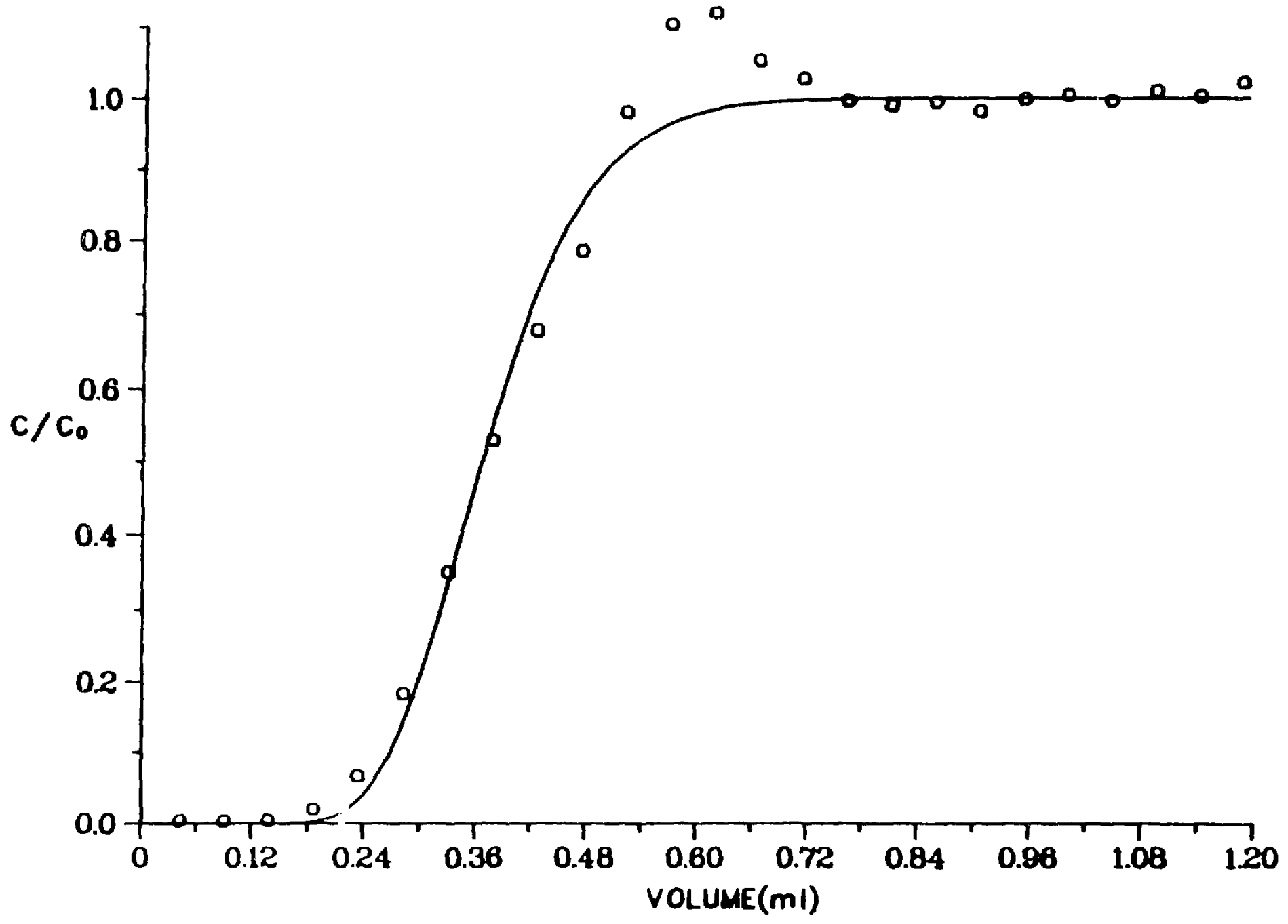

Fig. A-11. Sample G-1-1883 crushed-tuff column second I-131 elution, continuous feed. 


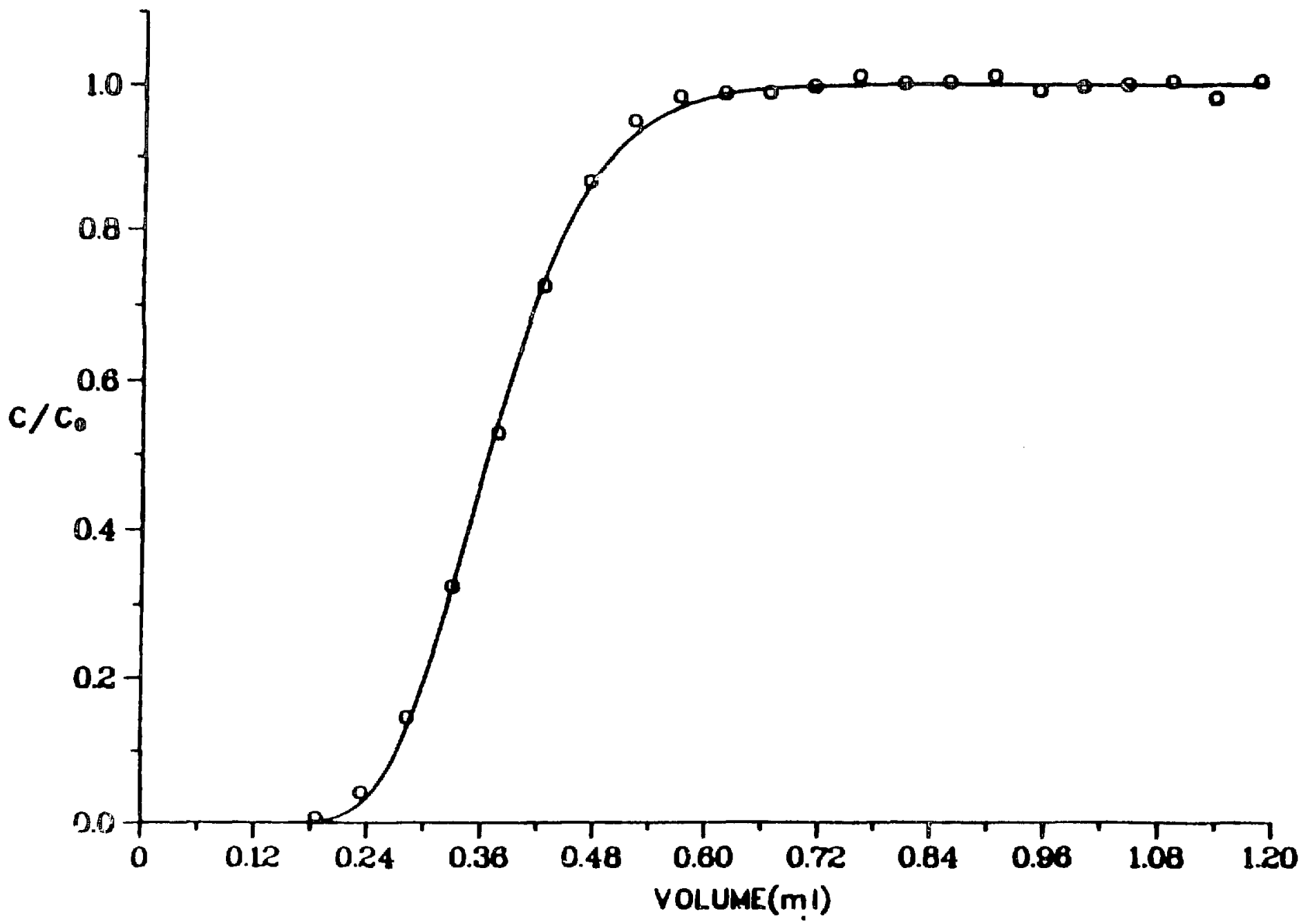

$B$

Fig. A-12. Sample G-1-1883 crushed-tuff column technetium elution, continuous feed. 


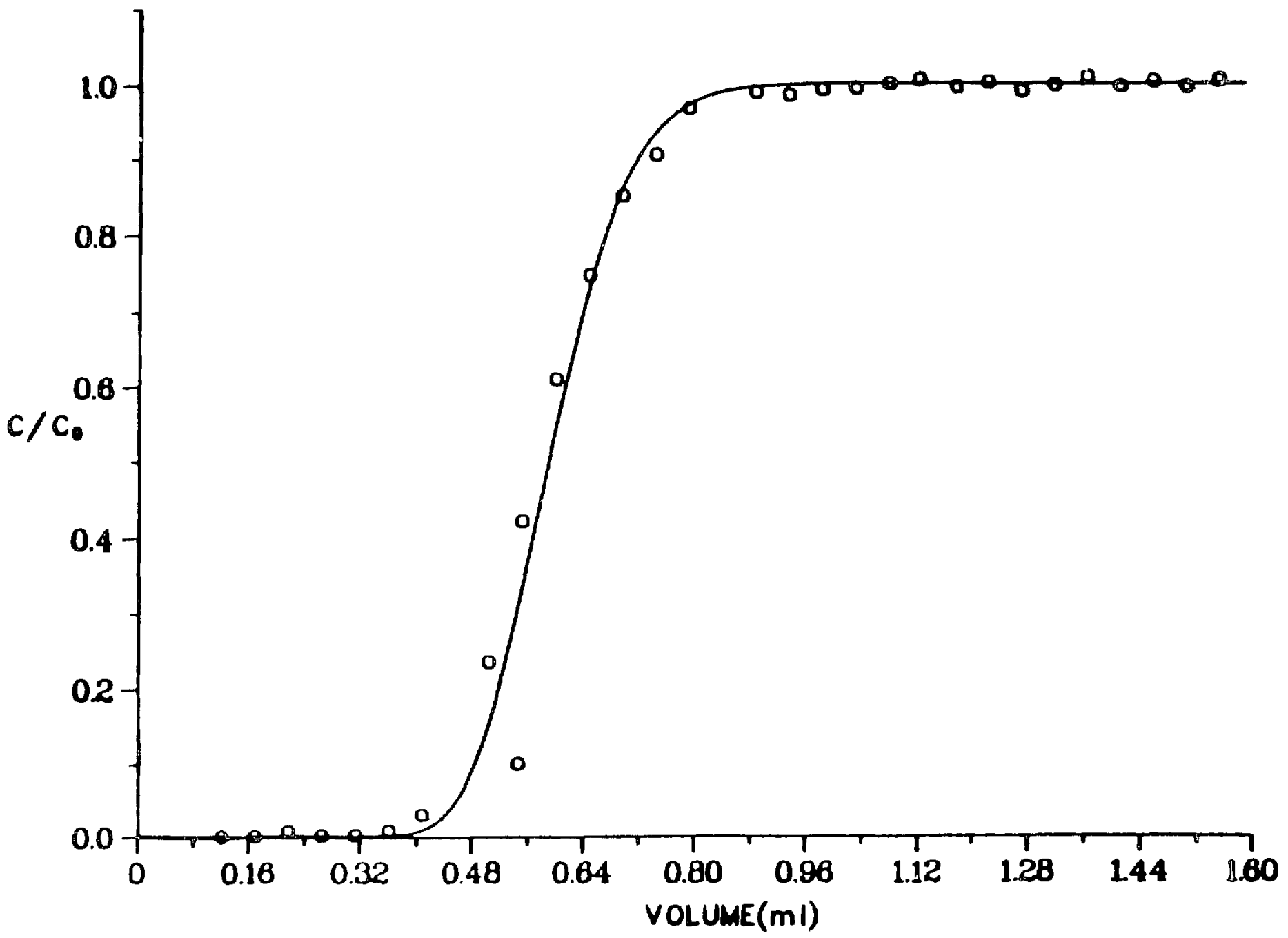

Fig. A-13. Sample G-1-18835 crushed-tuff column iodine elution. 


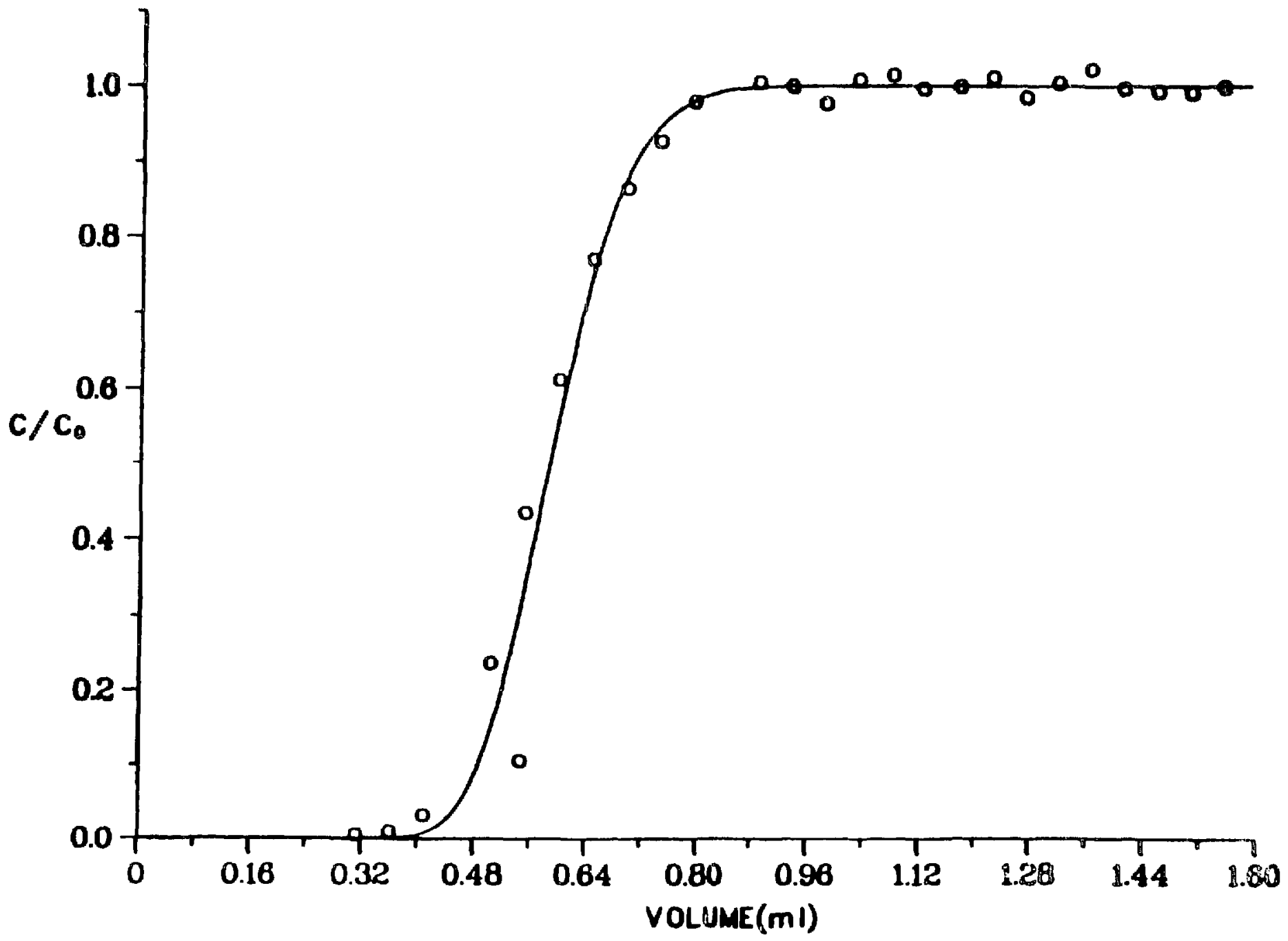

ज

Fig. A-14. Sample G-1-18835 crushed-tuff column technetium elution, continuous feed. 
is

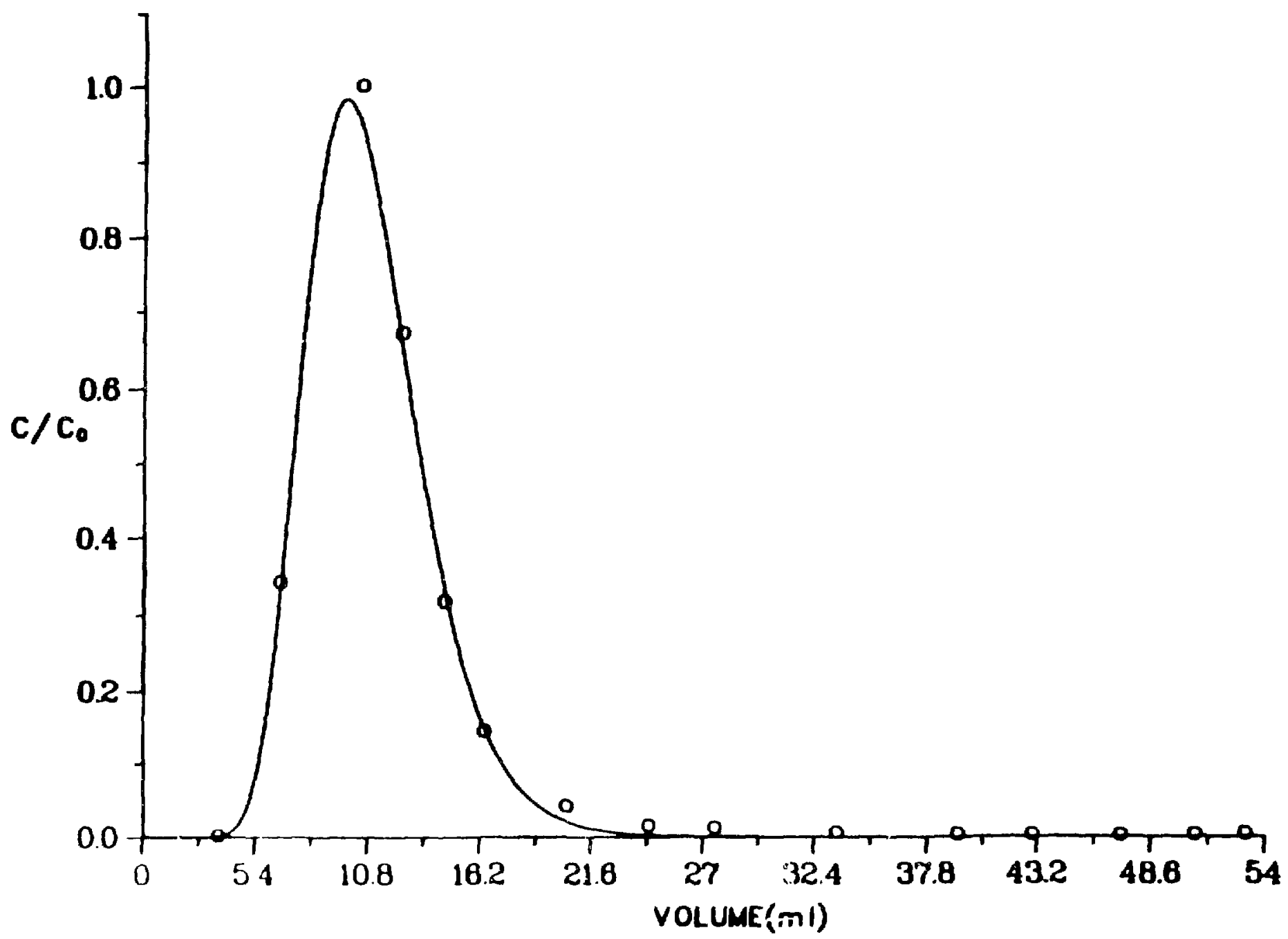

Fig. A-15. Sample YM-22 crushed-tuff column strontium spike elution. 


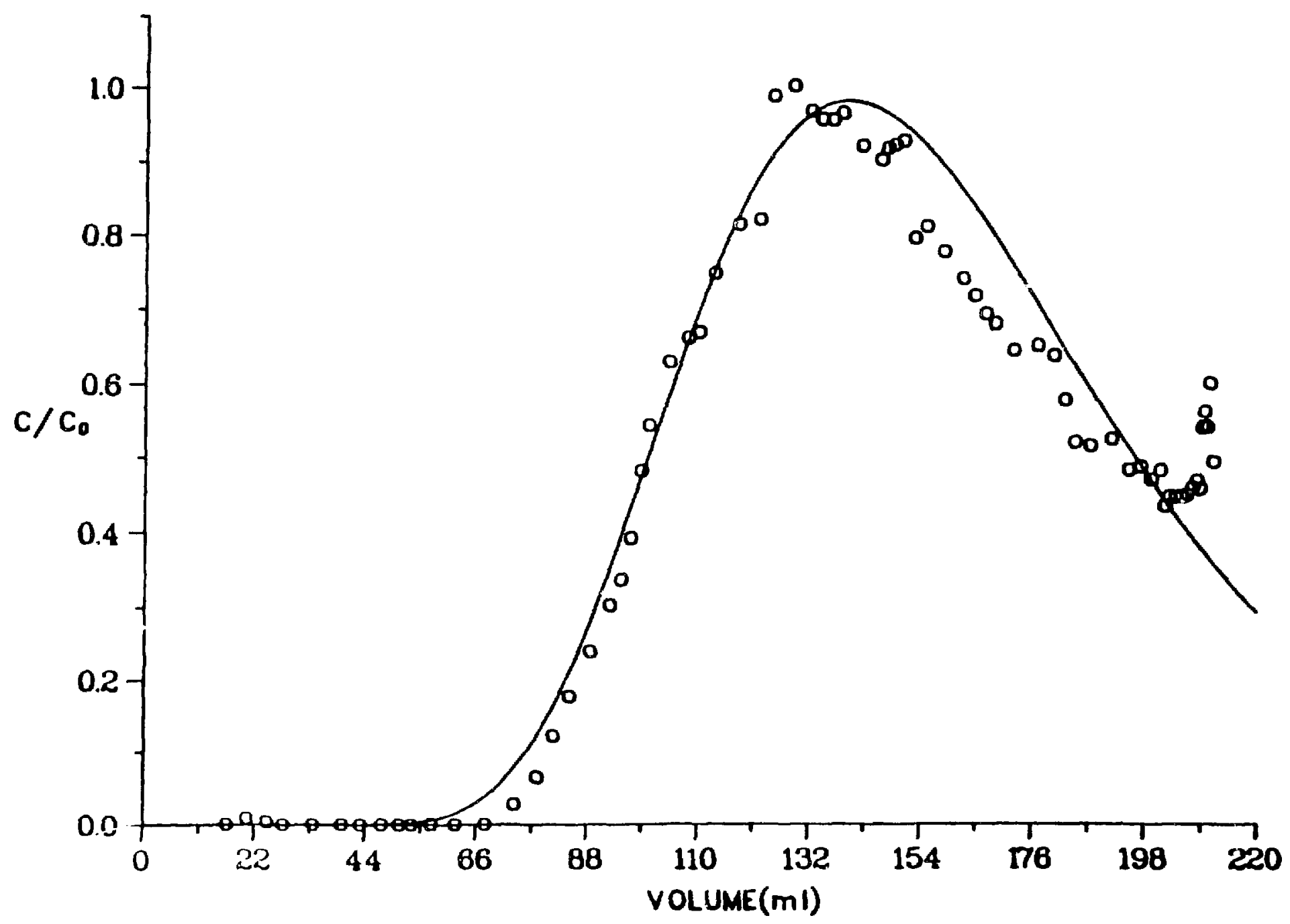




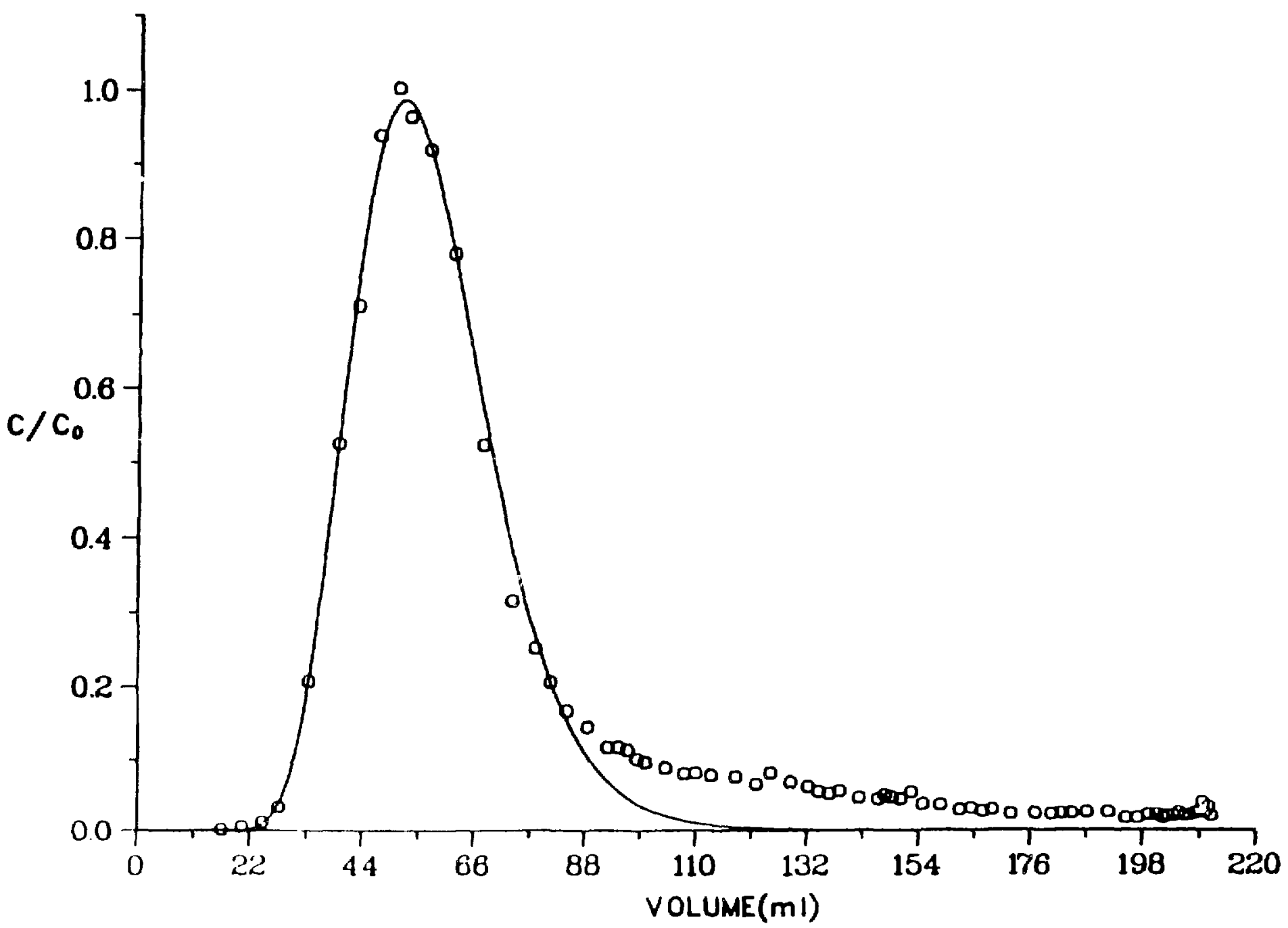

Fig. A-17. Sample YM-22 crushed-tuff column barium spike elution. 


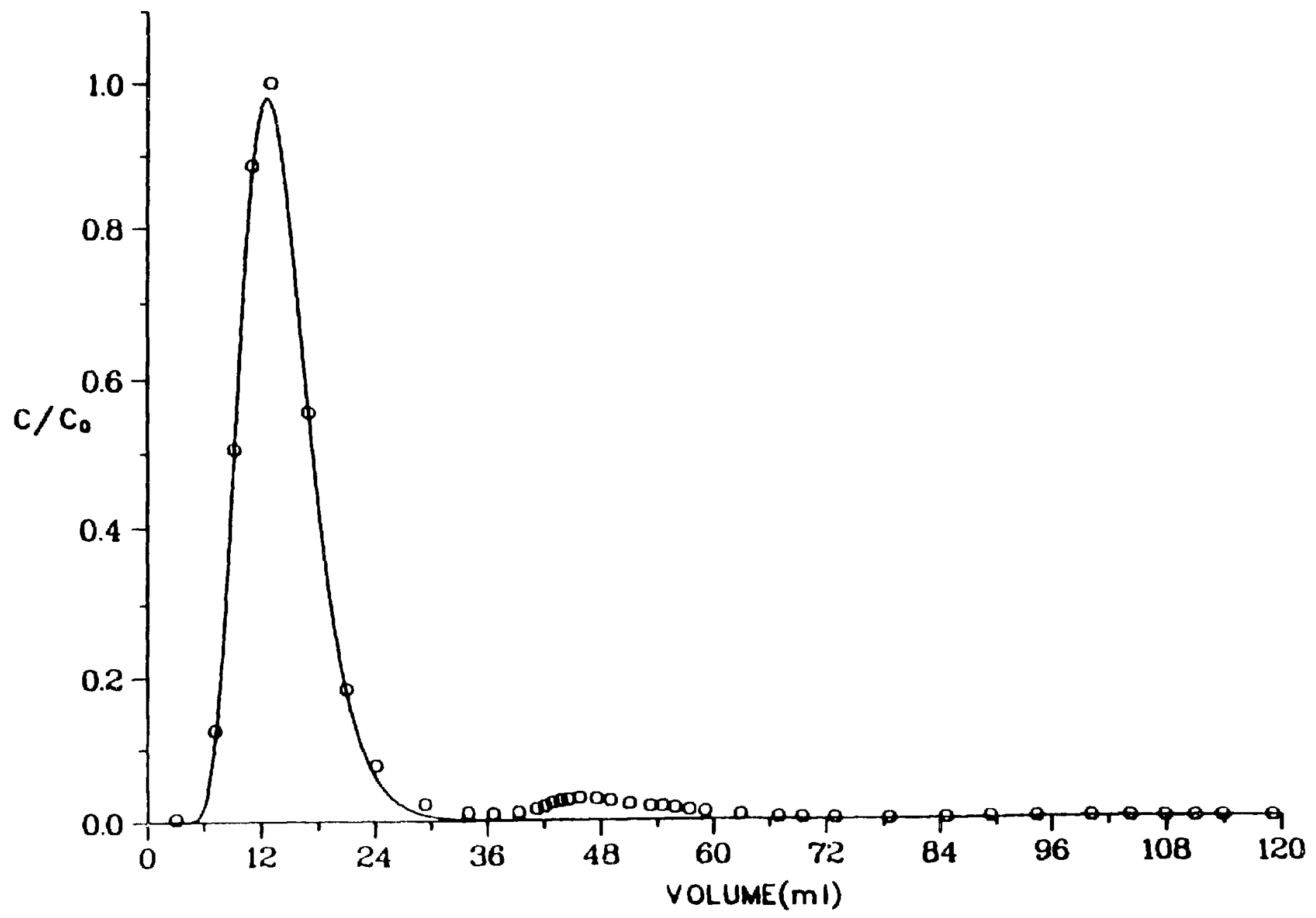




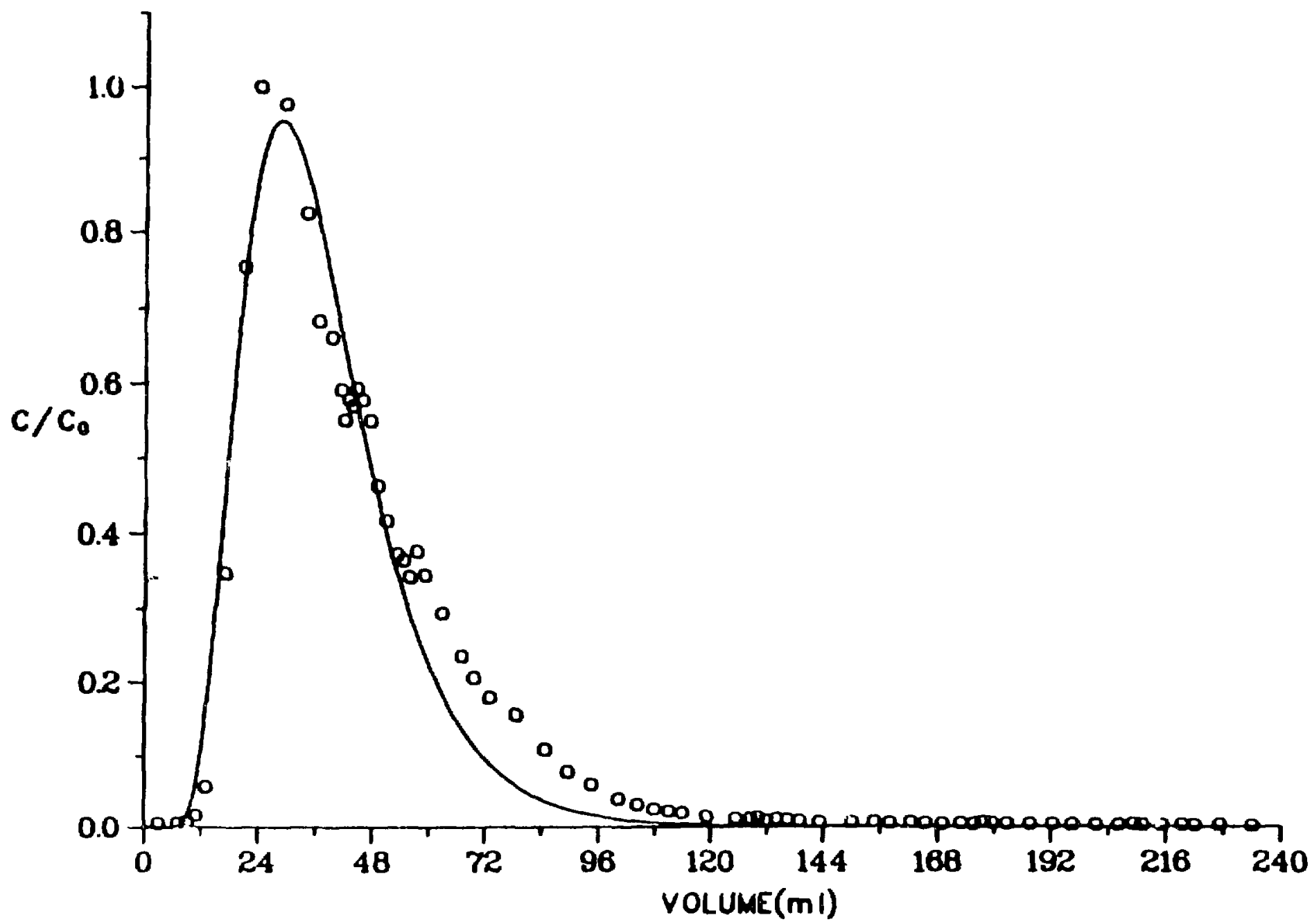

Fig. A-19. Sample YM-54-1 crushed-tuff column cesium spike elution. 


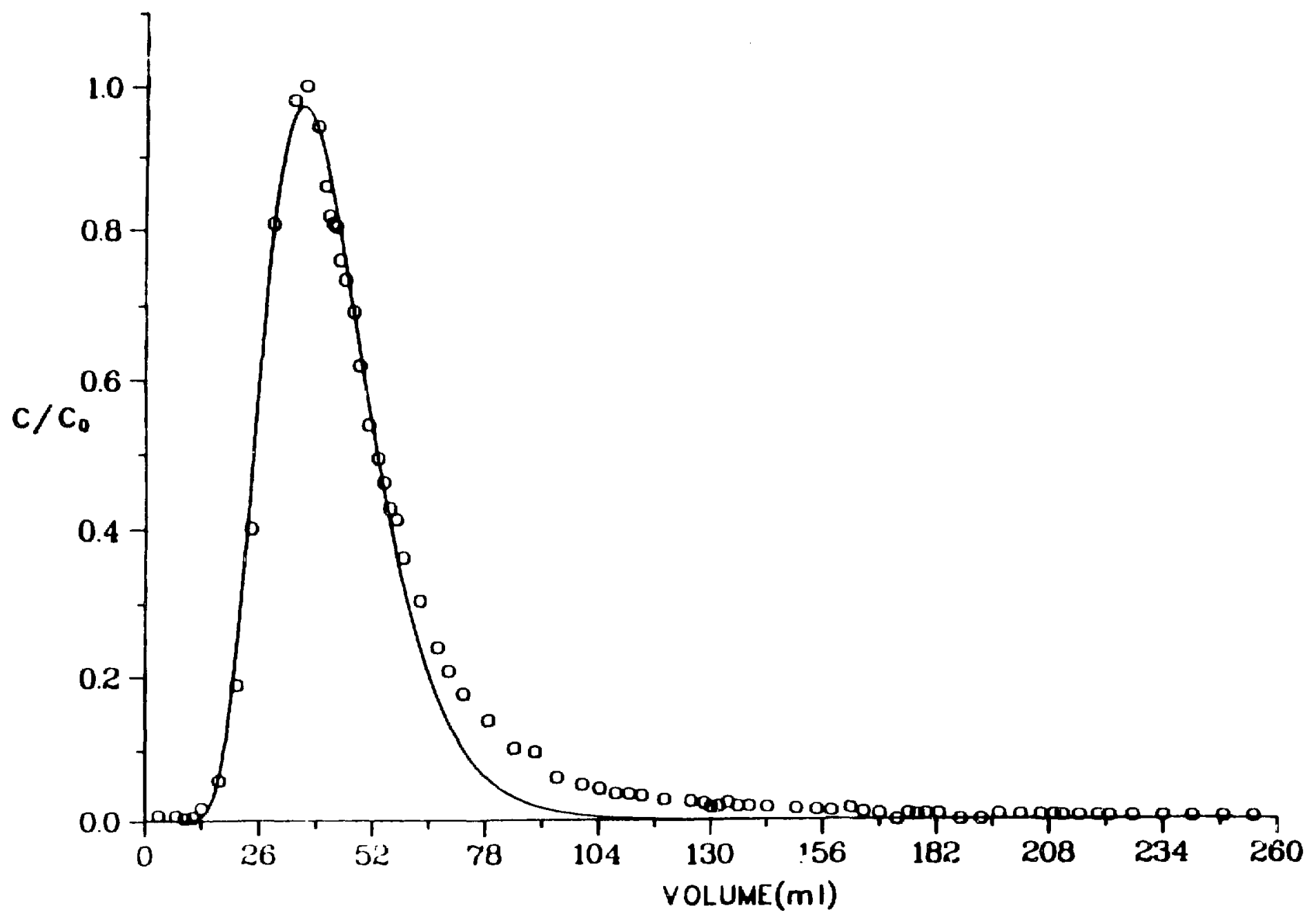




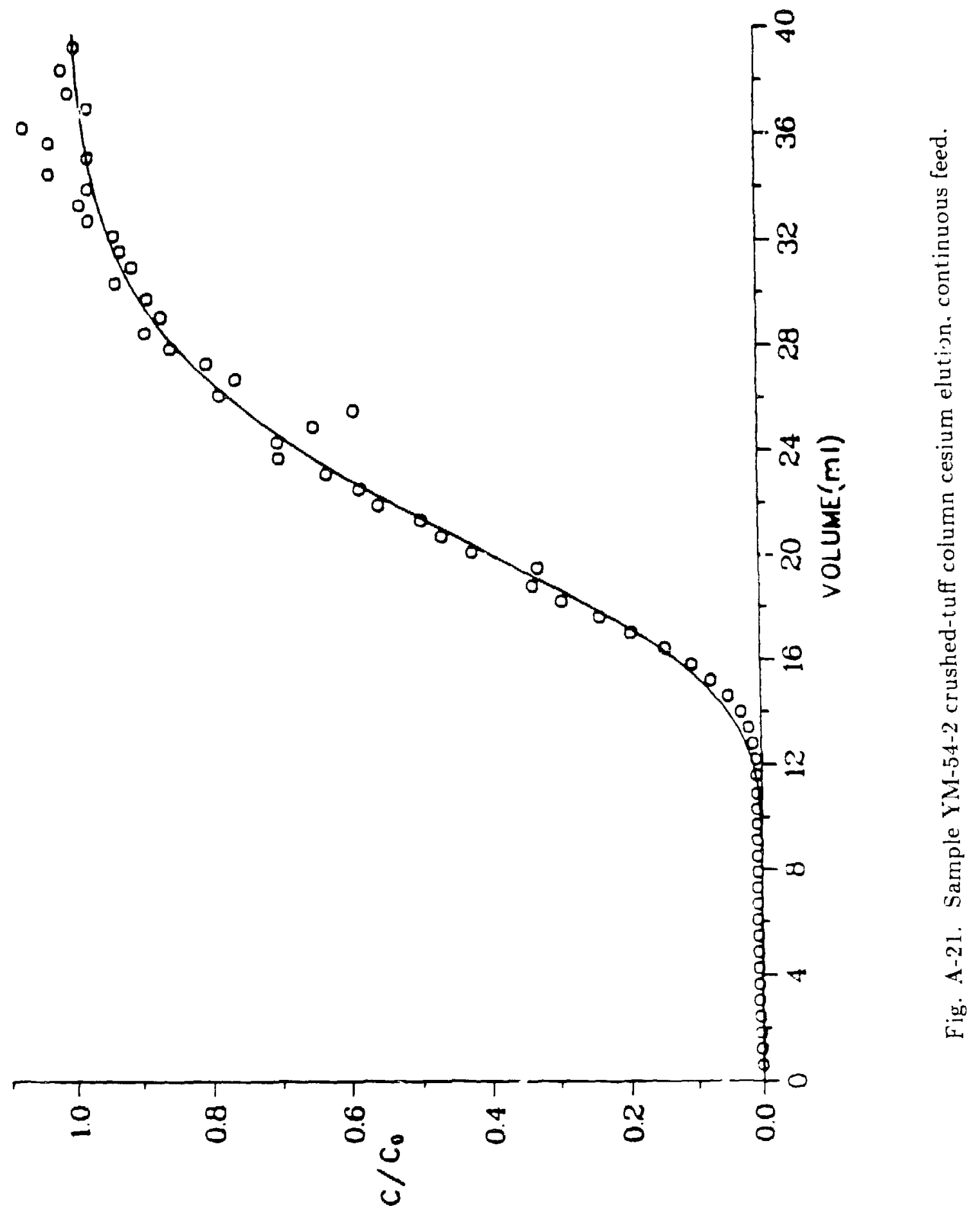




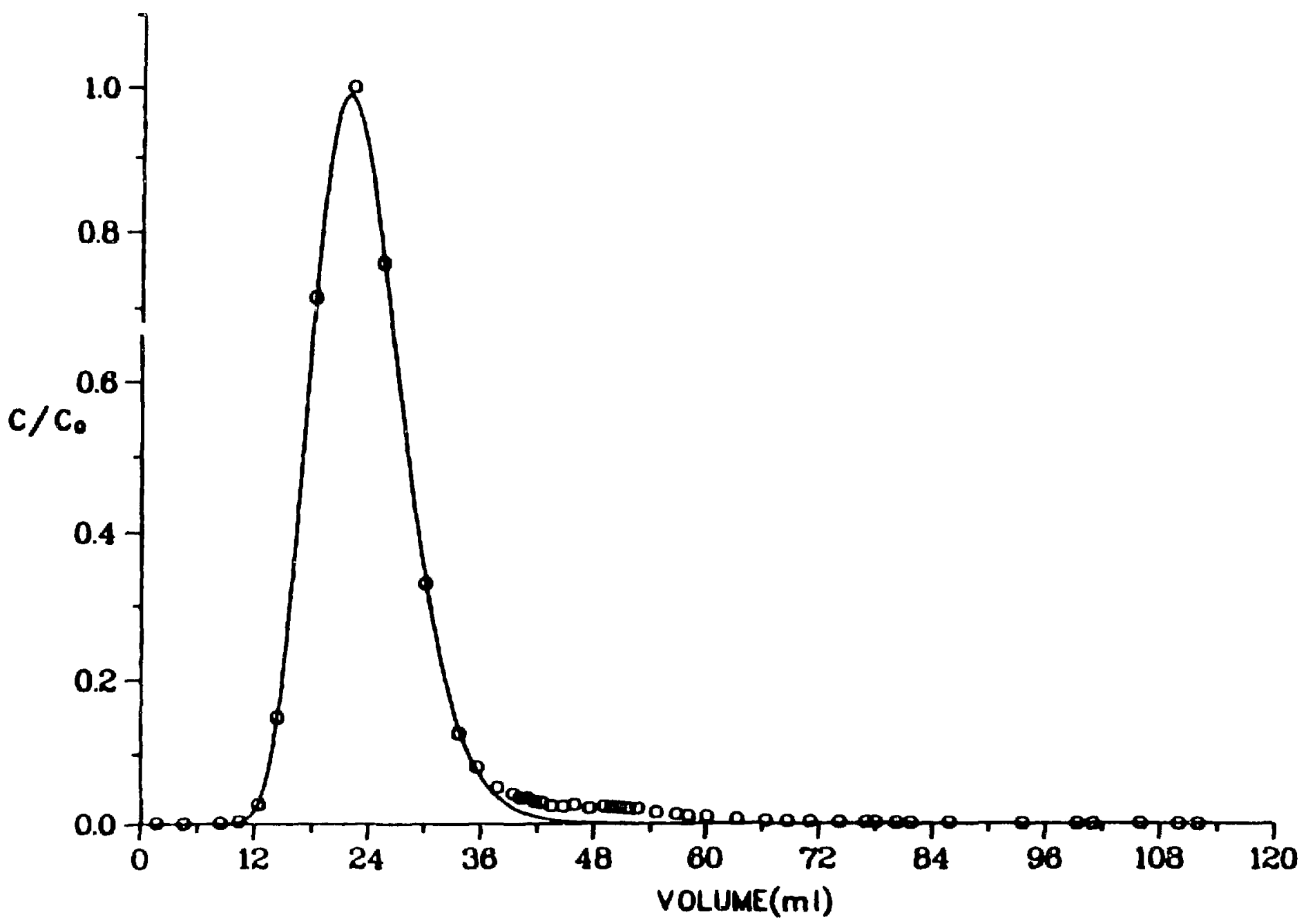

Fig. A-22. Sample YM-54-3 crushed-tuff column strontium spike elution. 


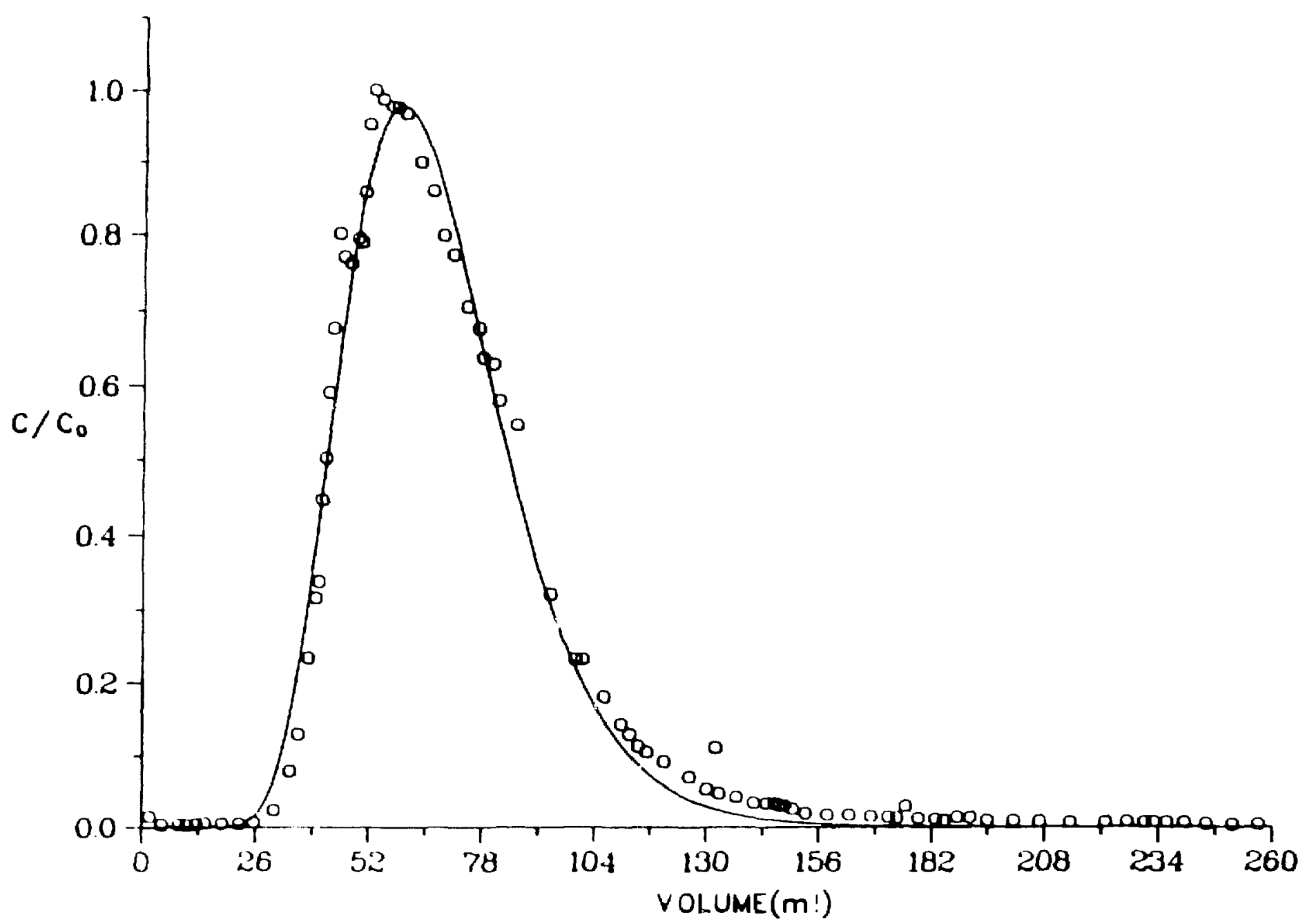

Fig. A-23. Sample YM-54-3 crushed-tuff column cesium spike elution. 


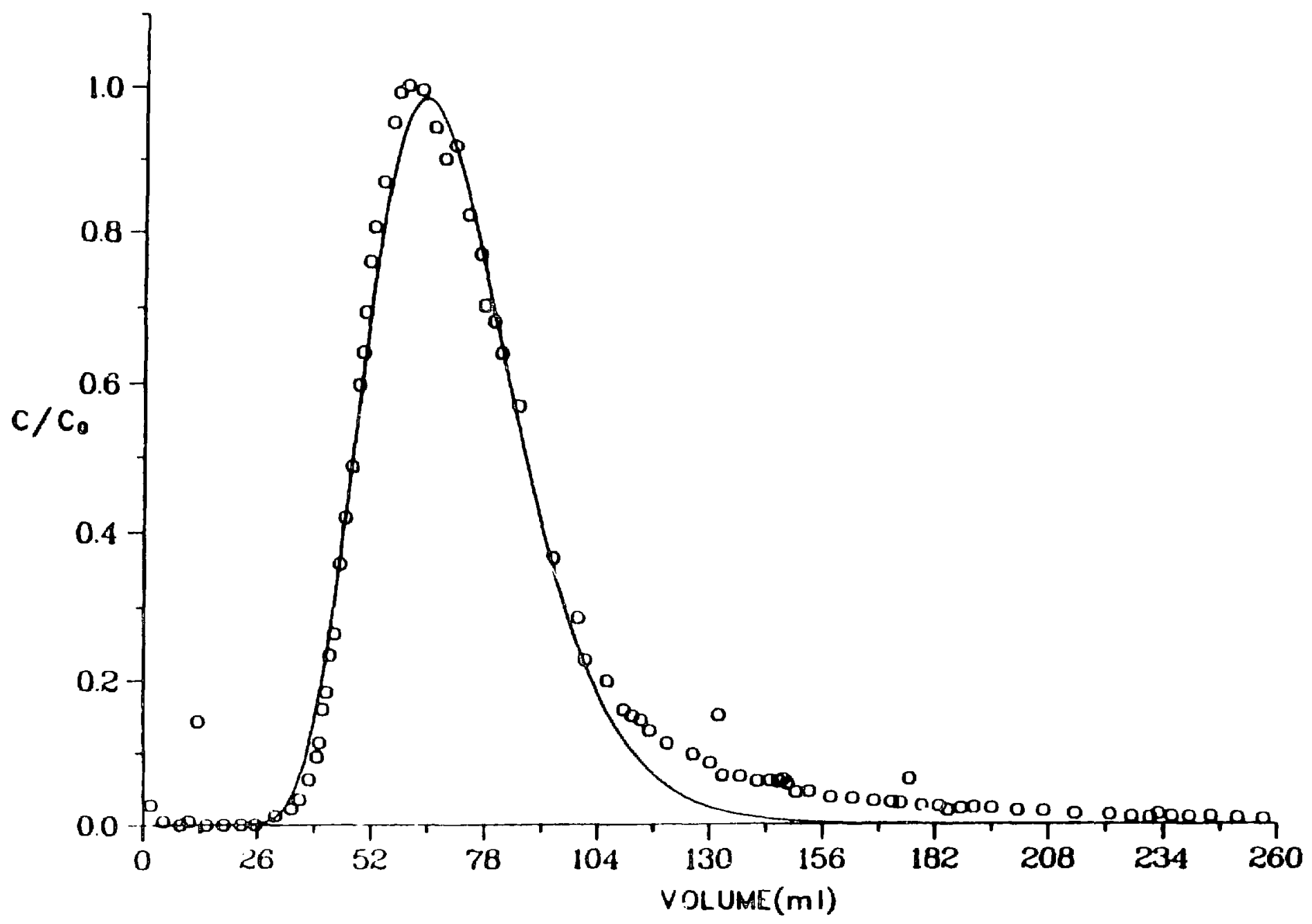

Fig. A-24. Sample YM-54-3 crushed-tuff column barium spike elution. 


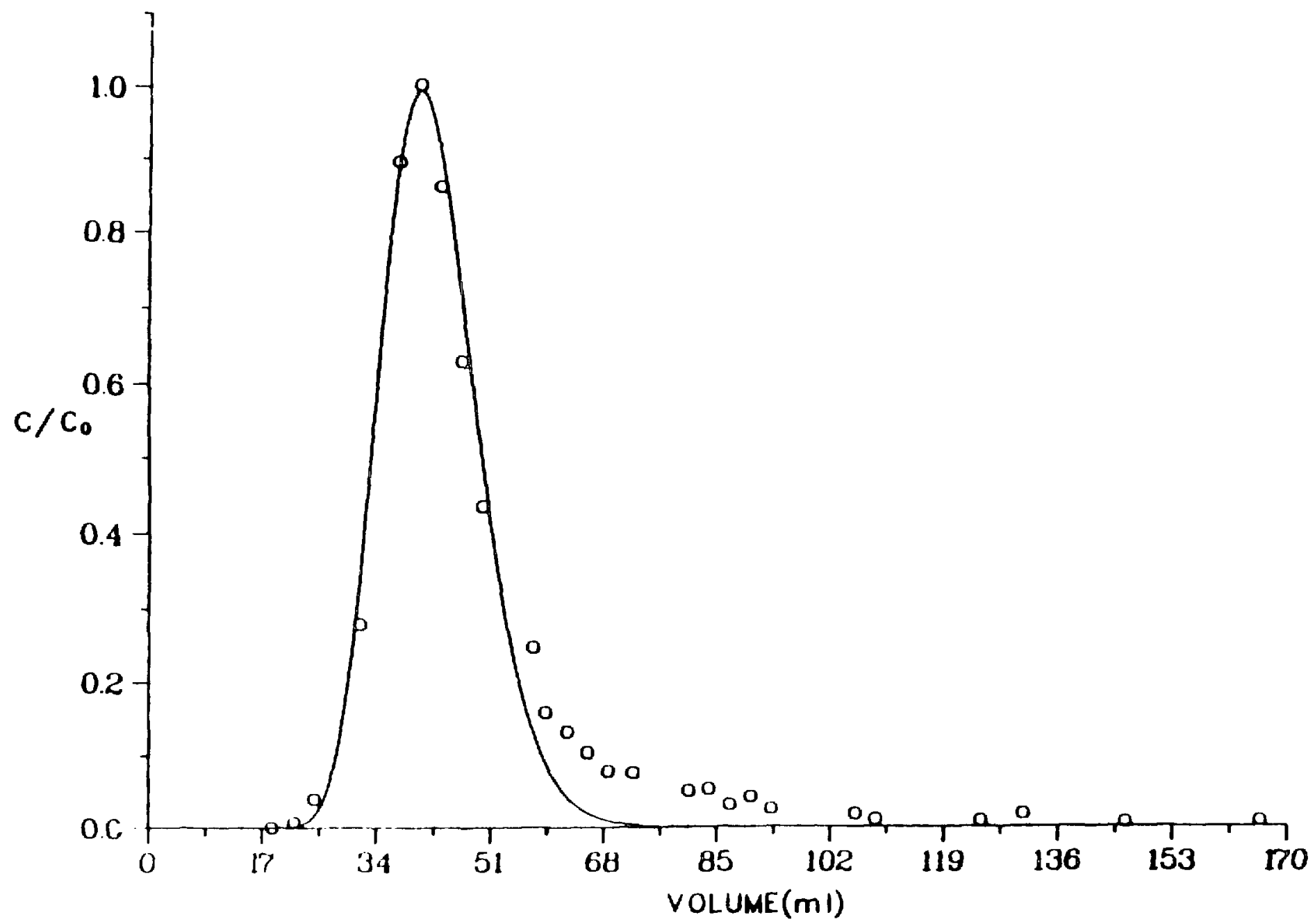

Fig. A-25. Sample J $\Lambda-32-1$ crushed-tuff column strontium spike elution. 


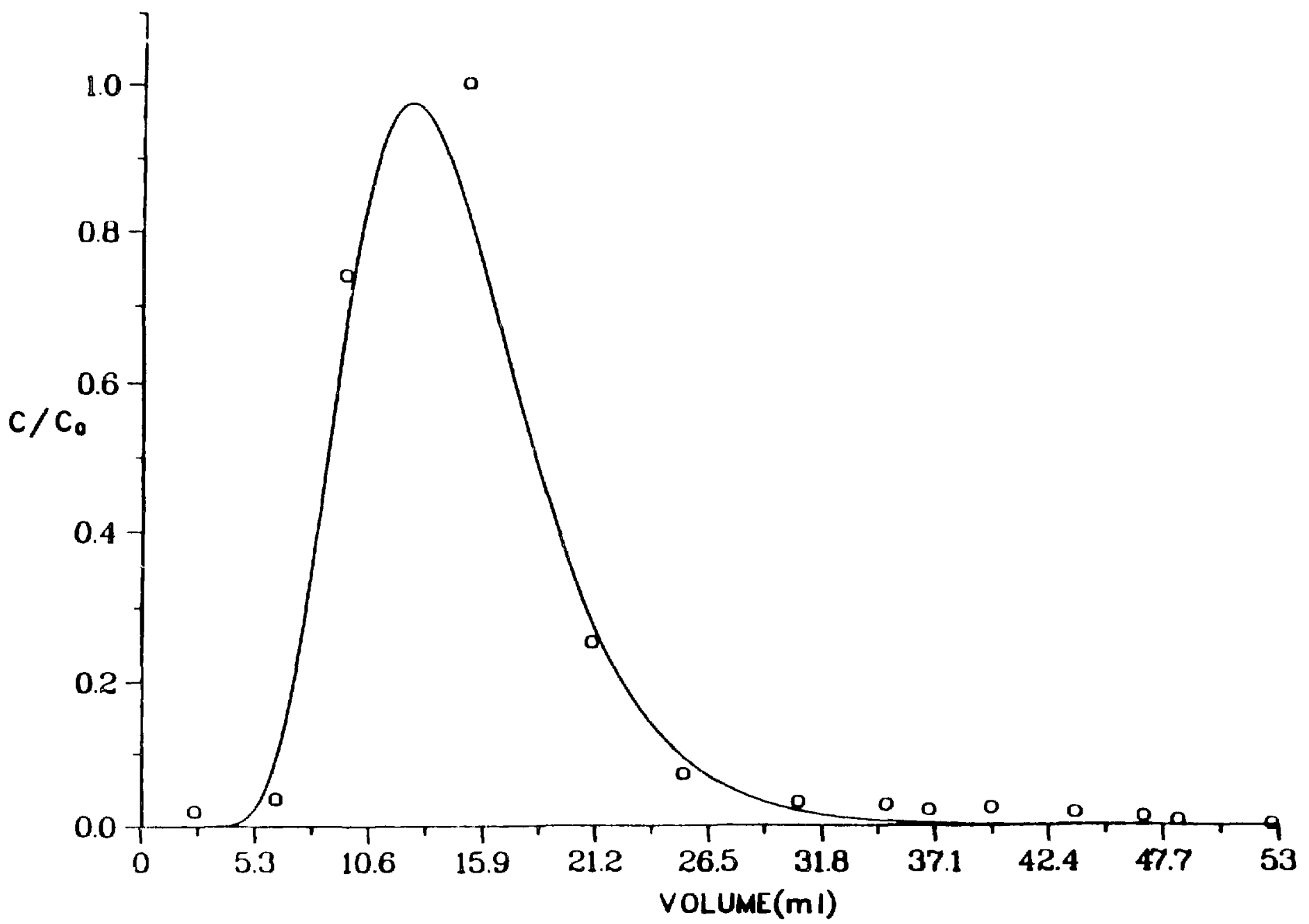




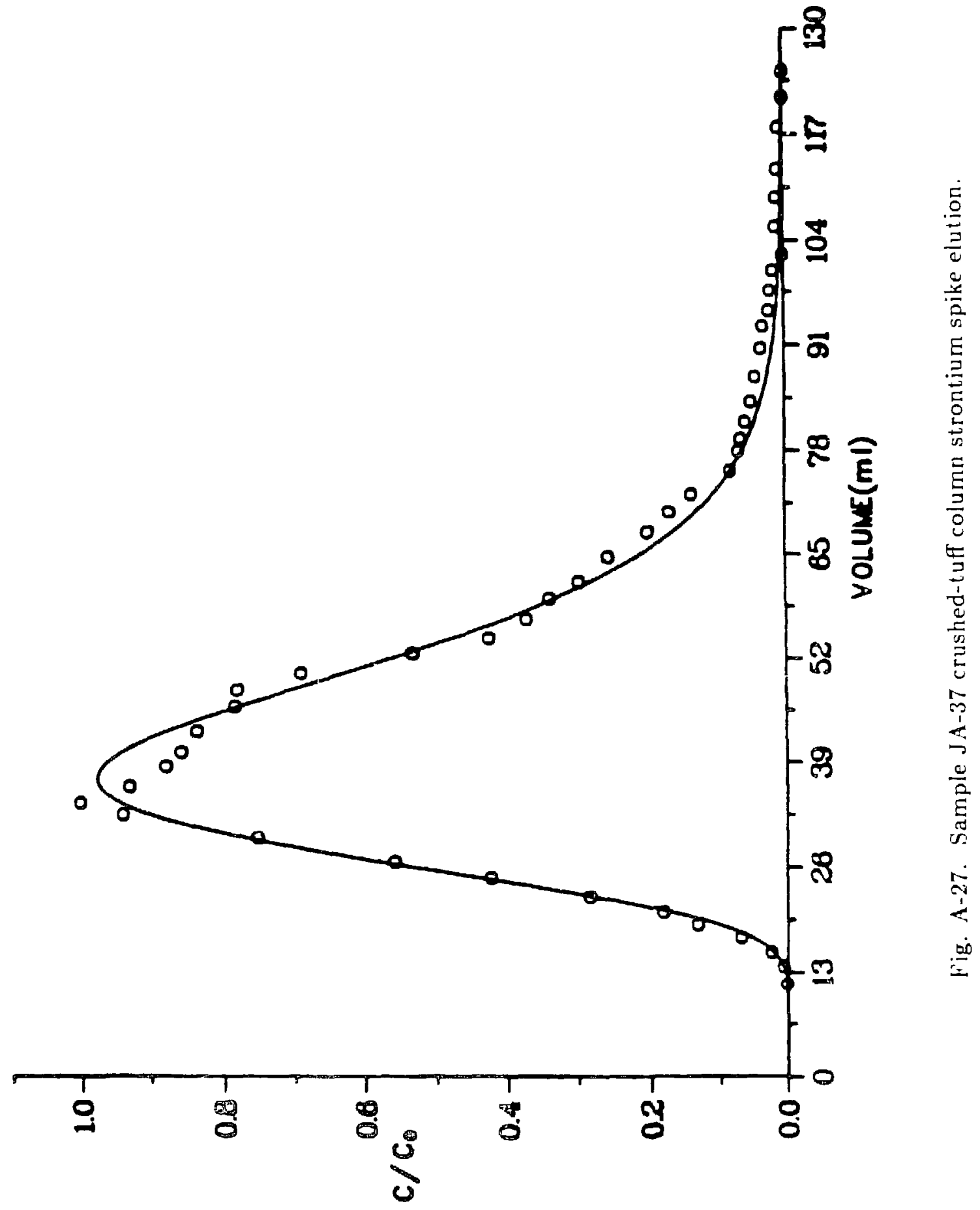




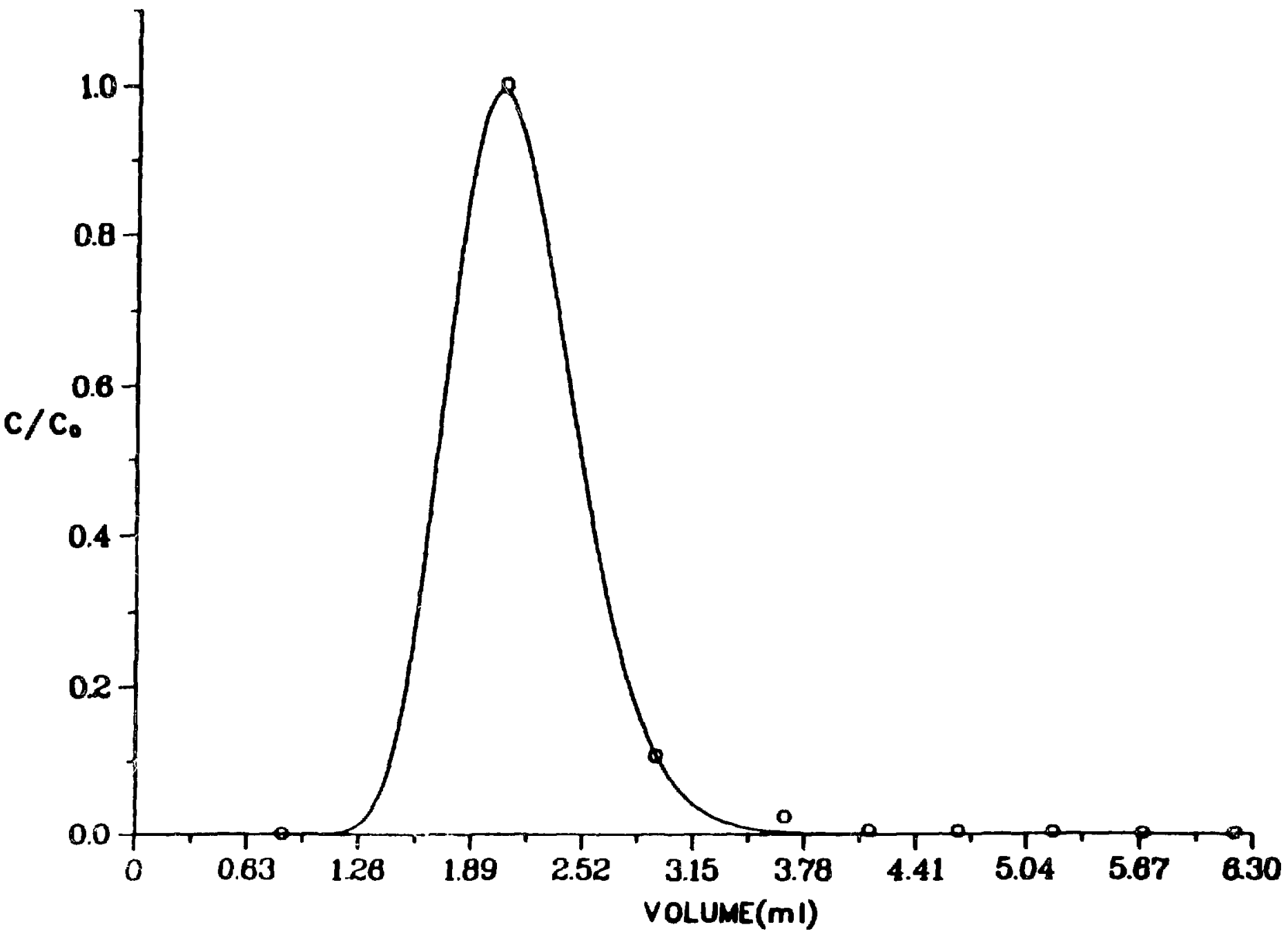

o

Fig. A-28. The G-tunnel crushed-tuff column technetium spike column. 


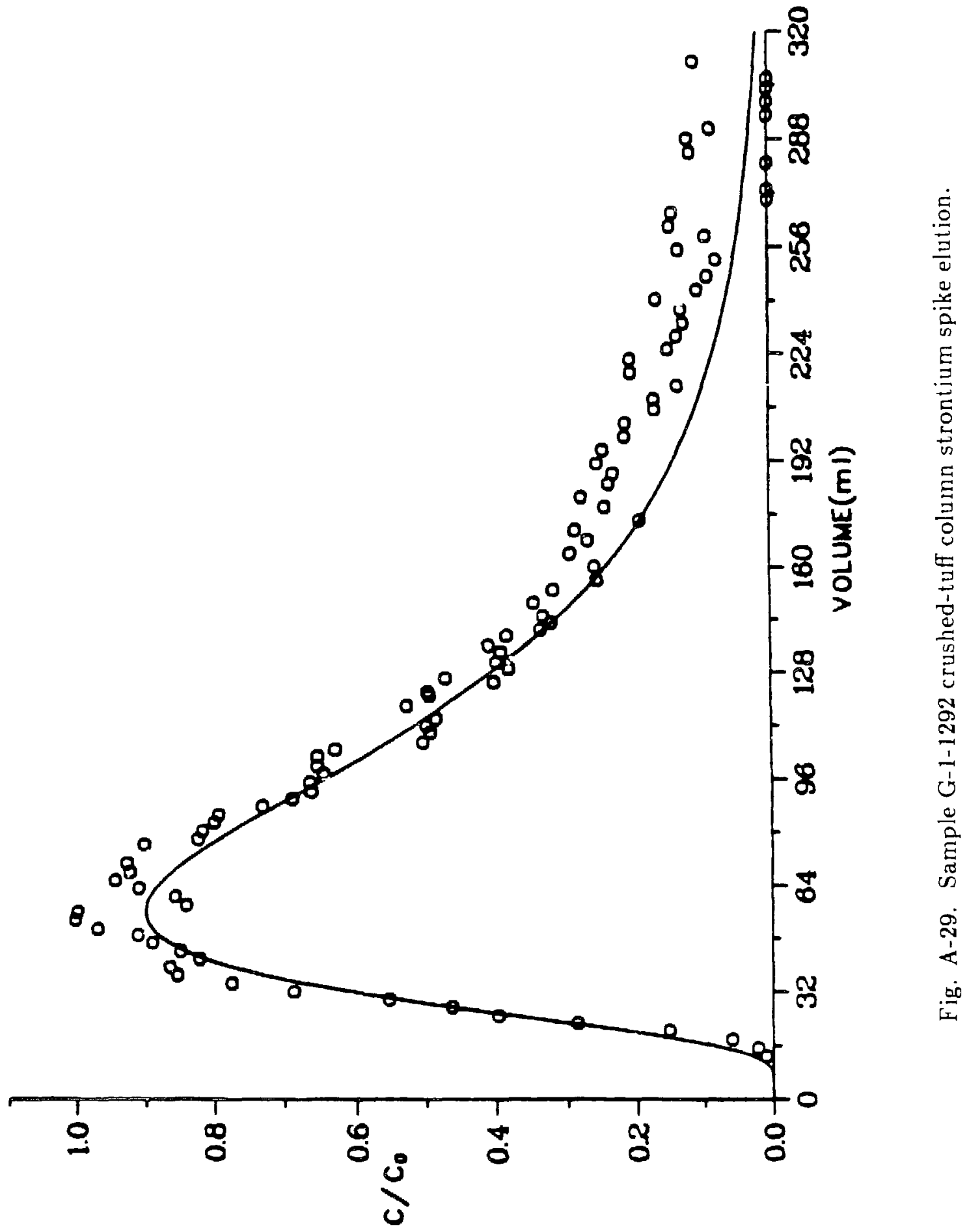




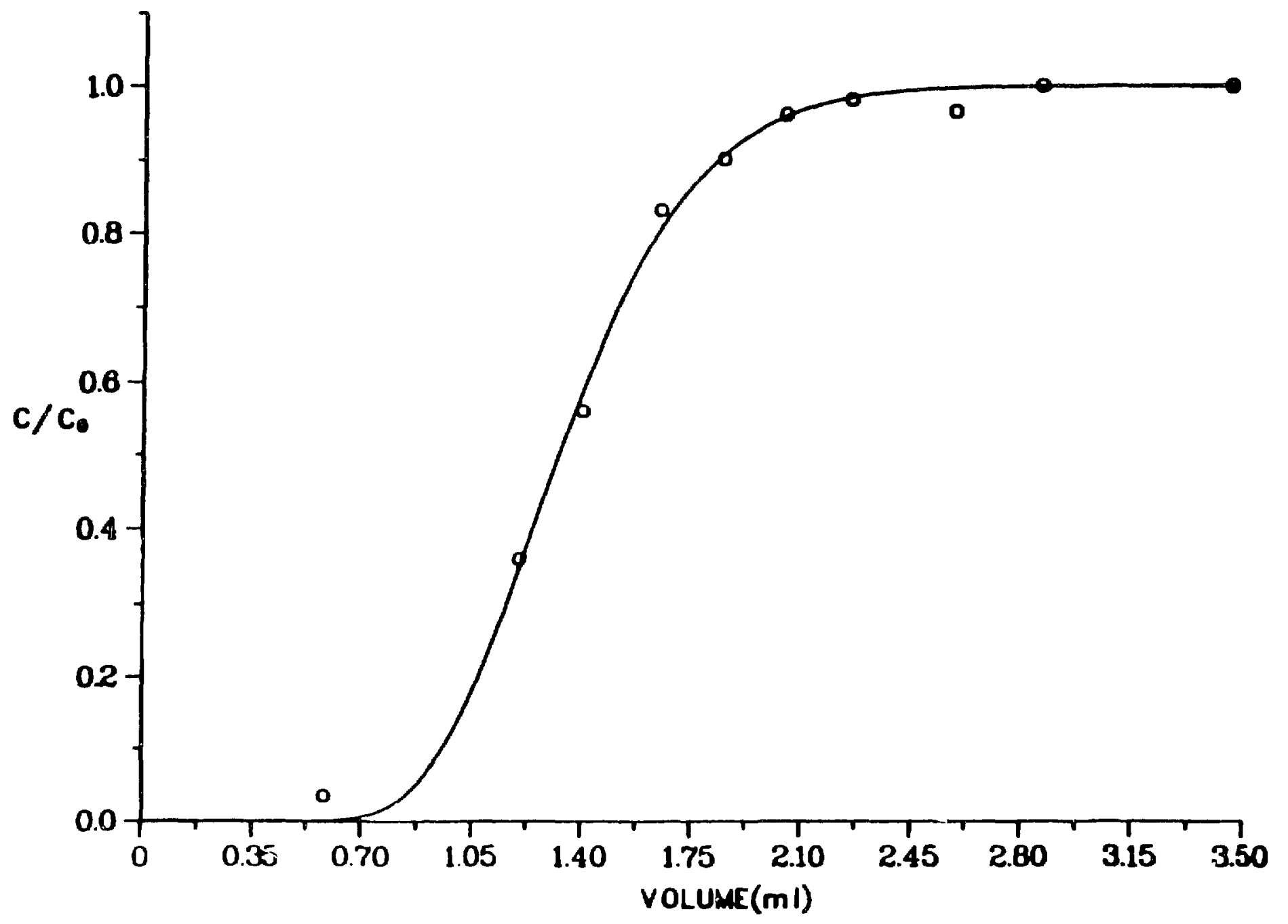




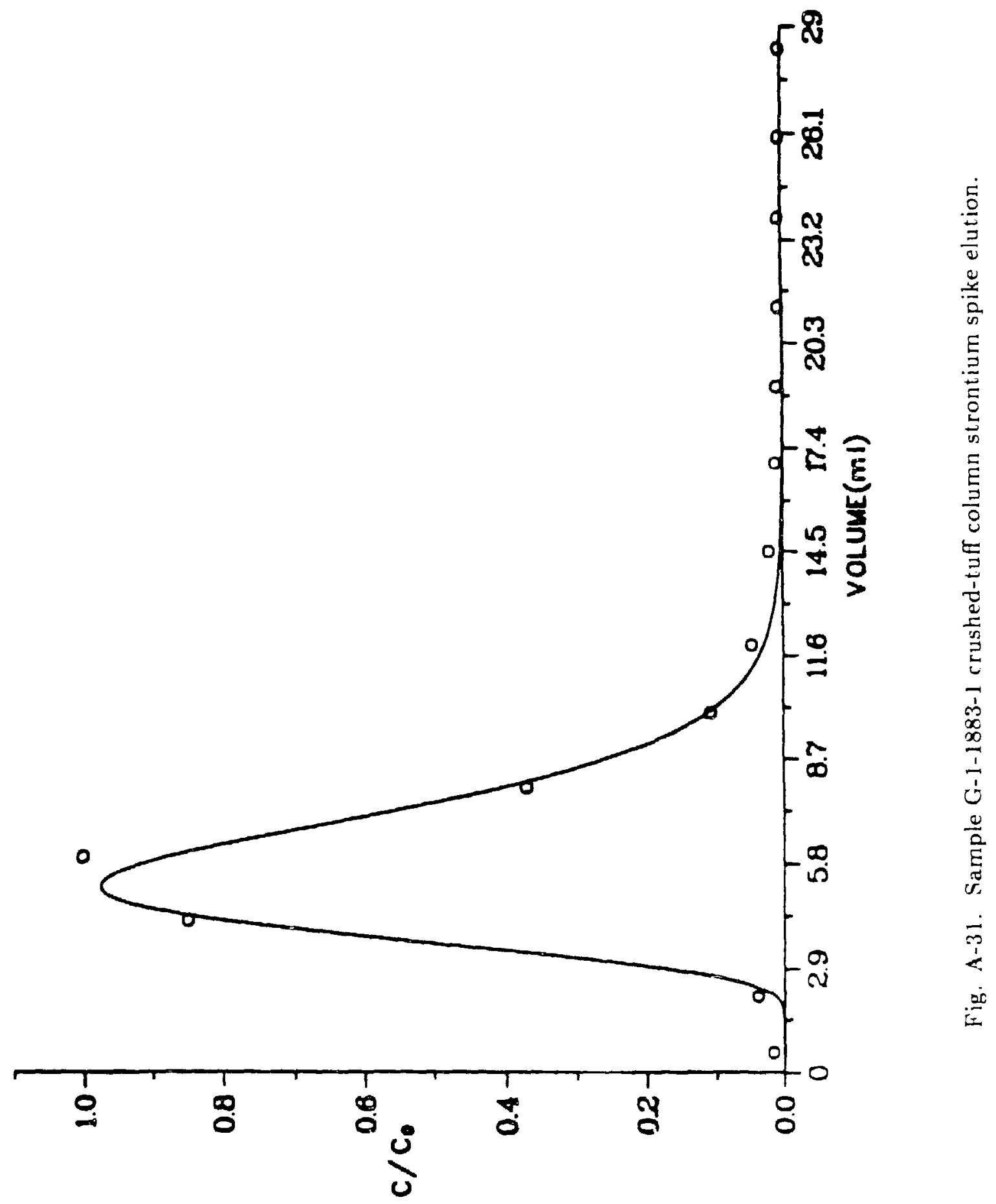




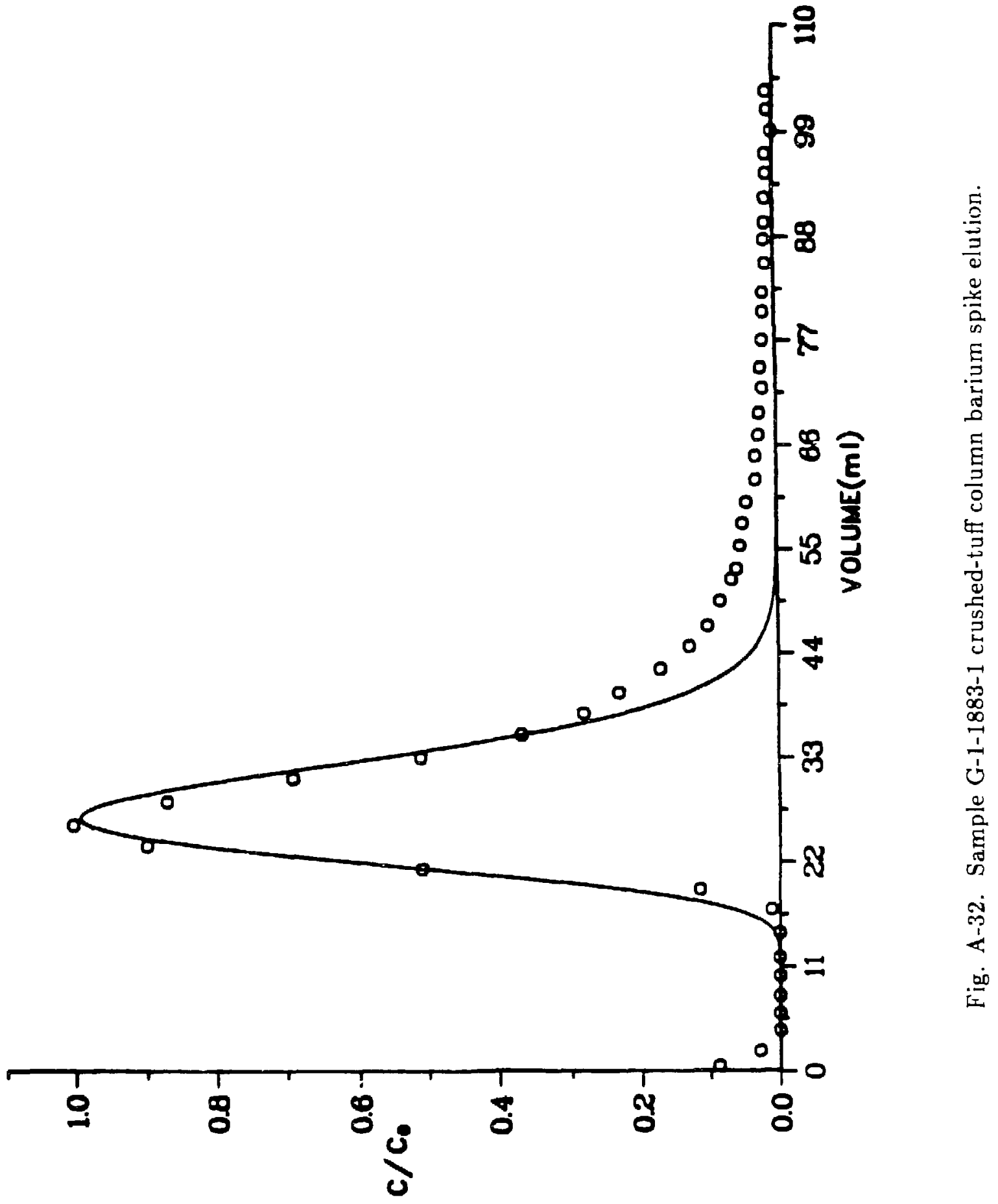




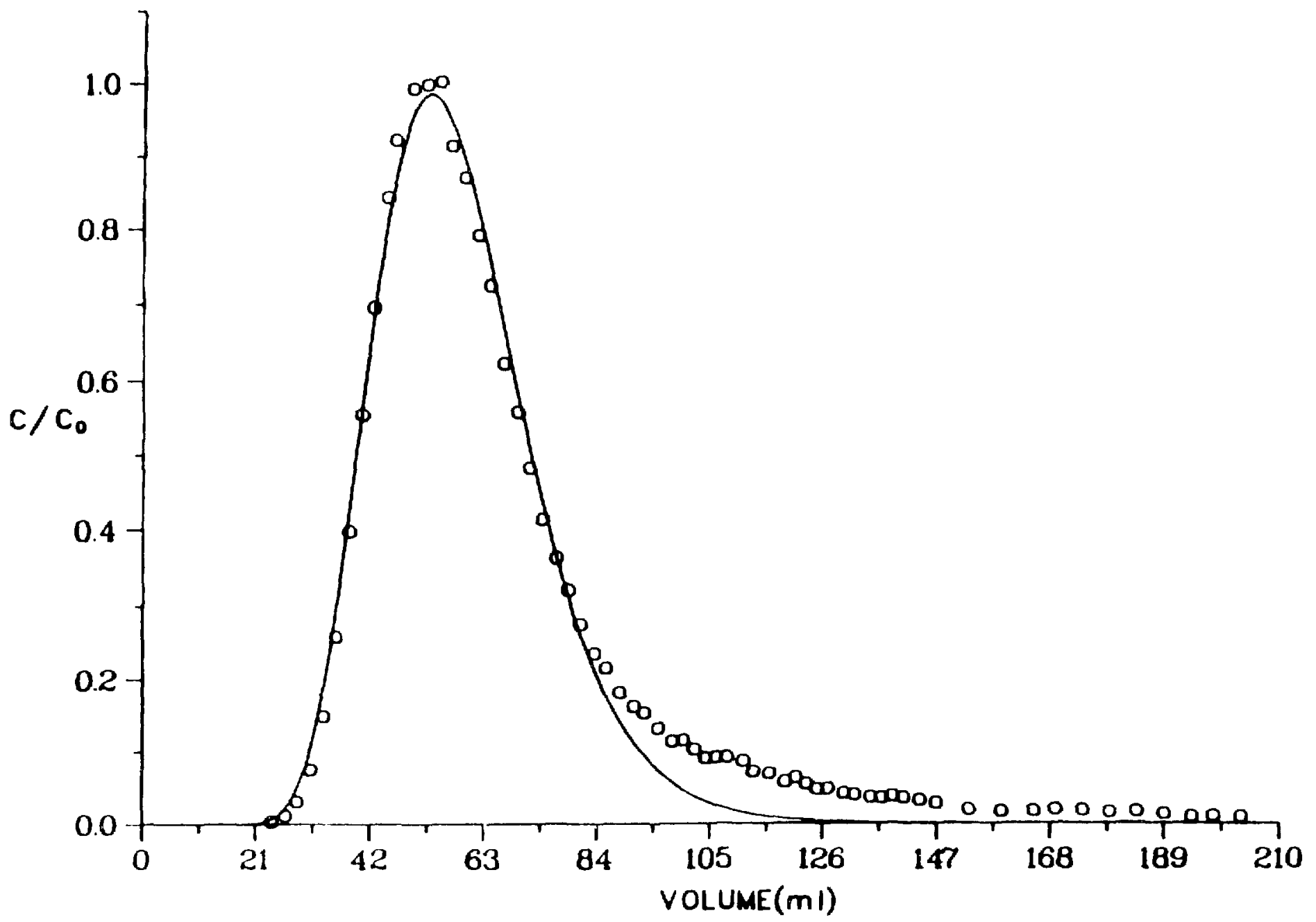

Fig. A-33. Sample (-1-1883-2 crushed-tuff column strontium spike elution. 


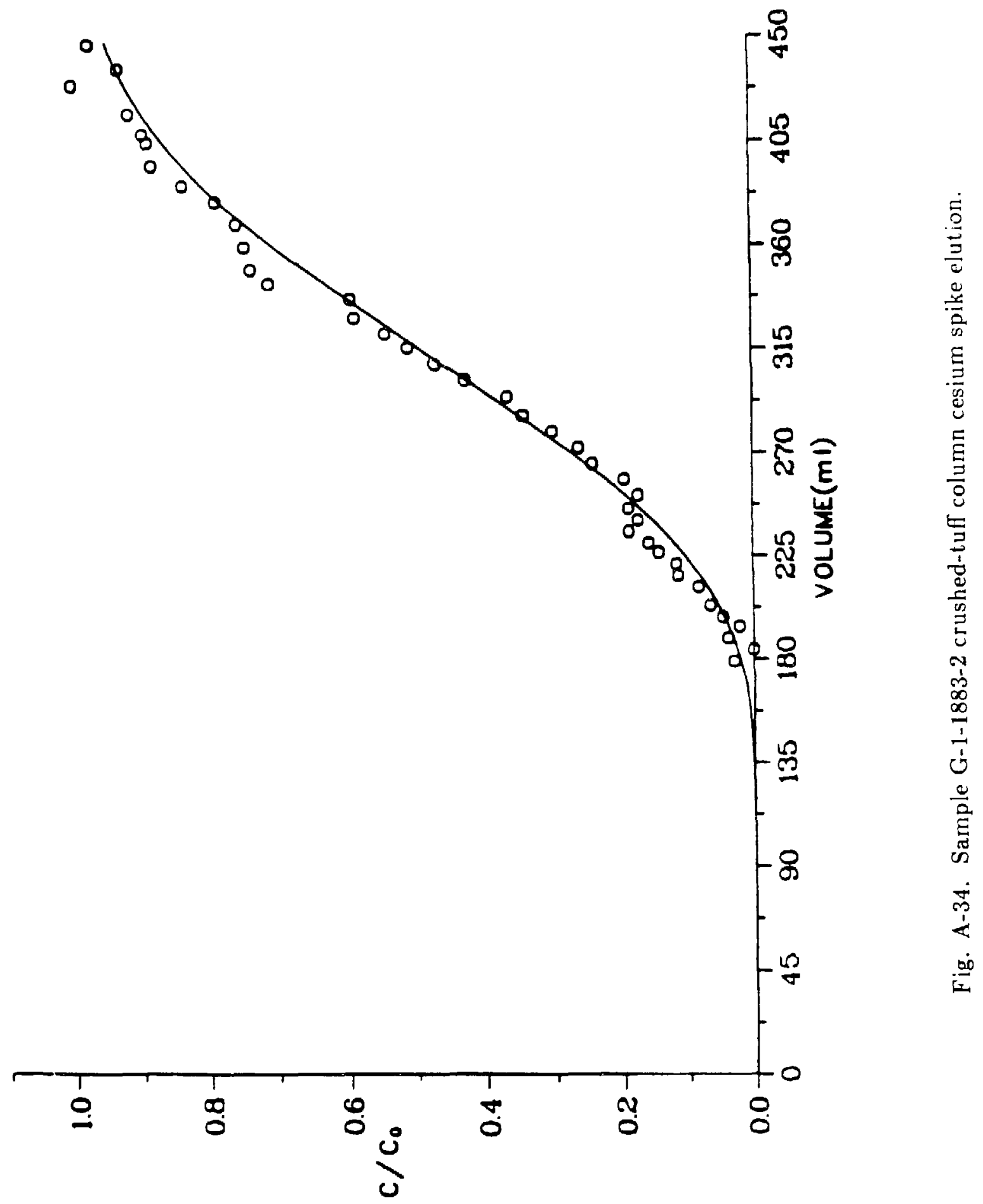




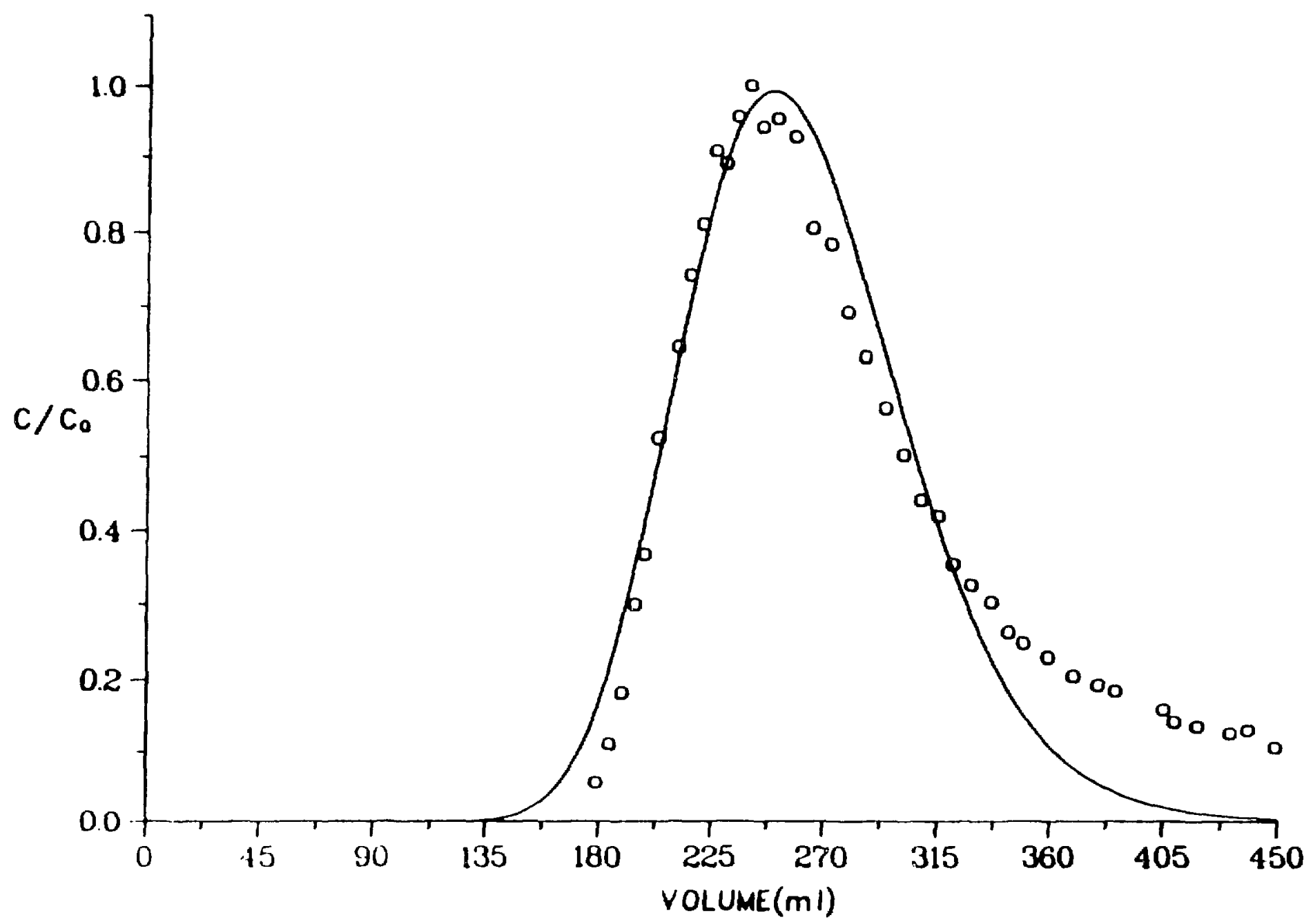

Fig. A-35. Sample G-1-1883-2 crushed-tuff column barium spike elution. 


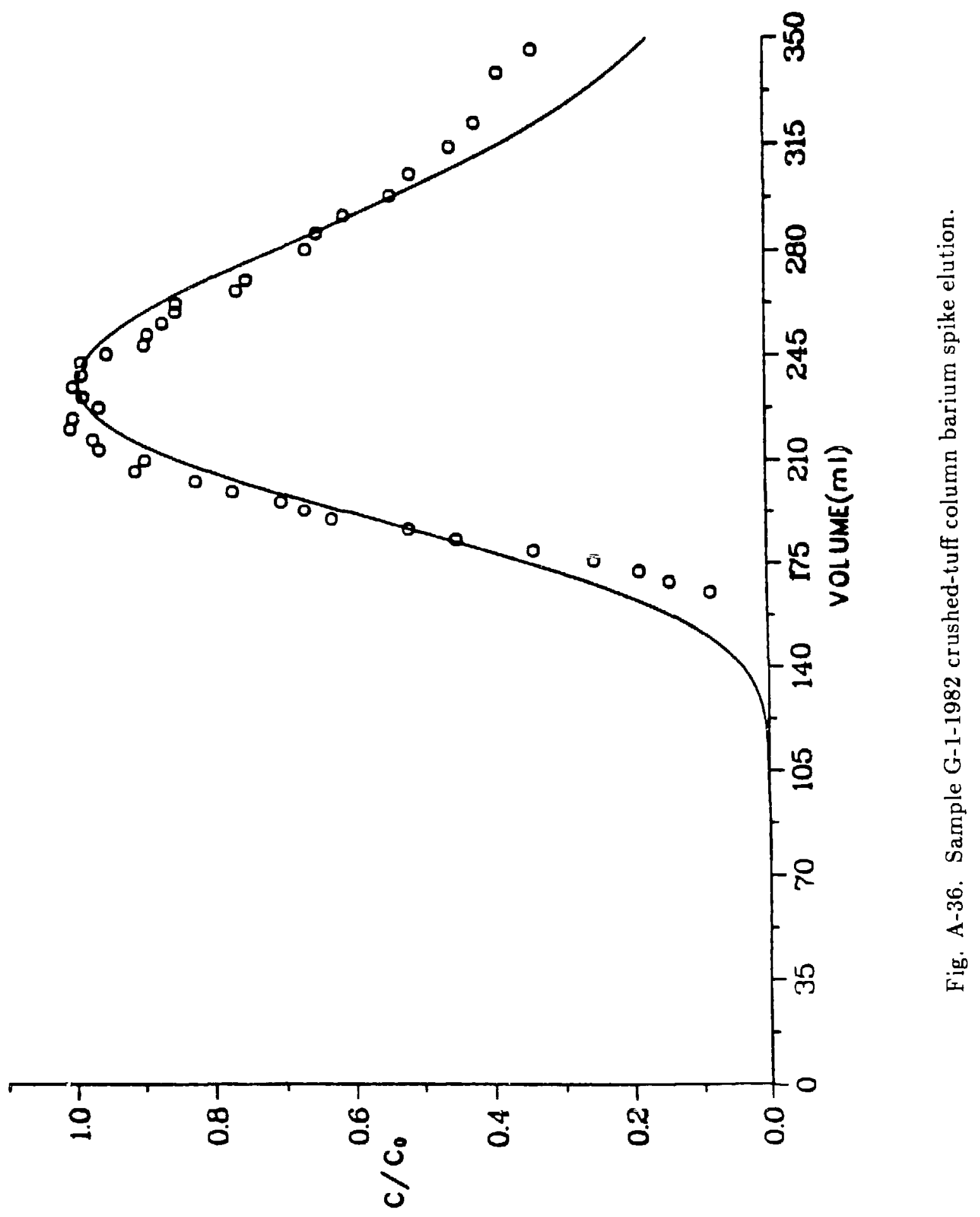




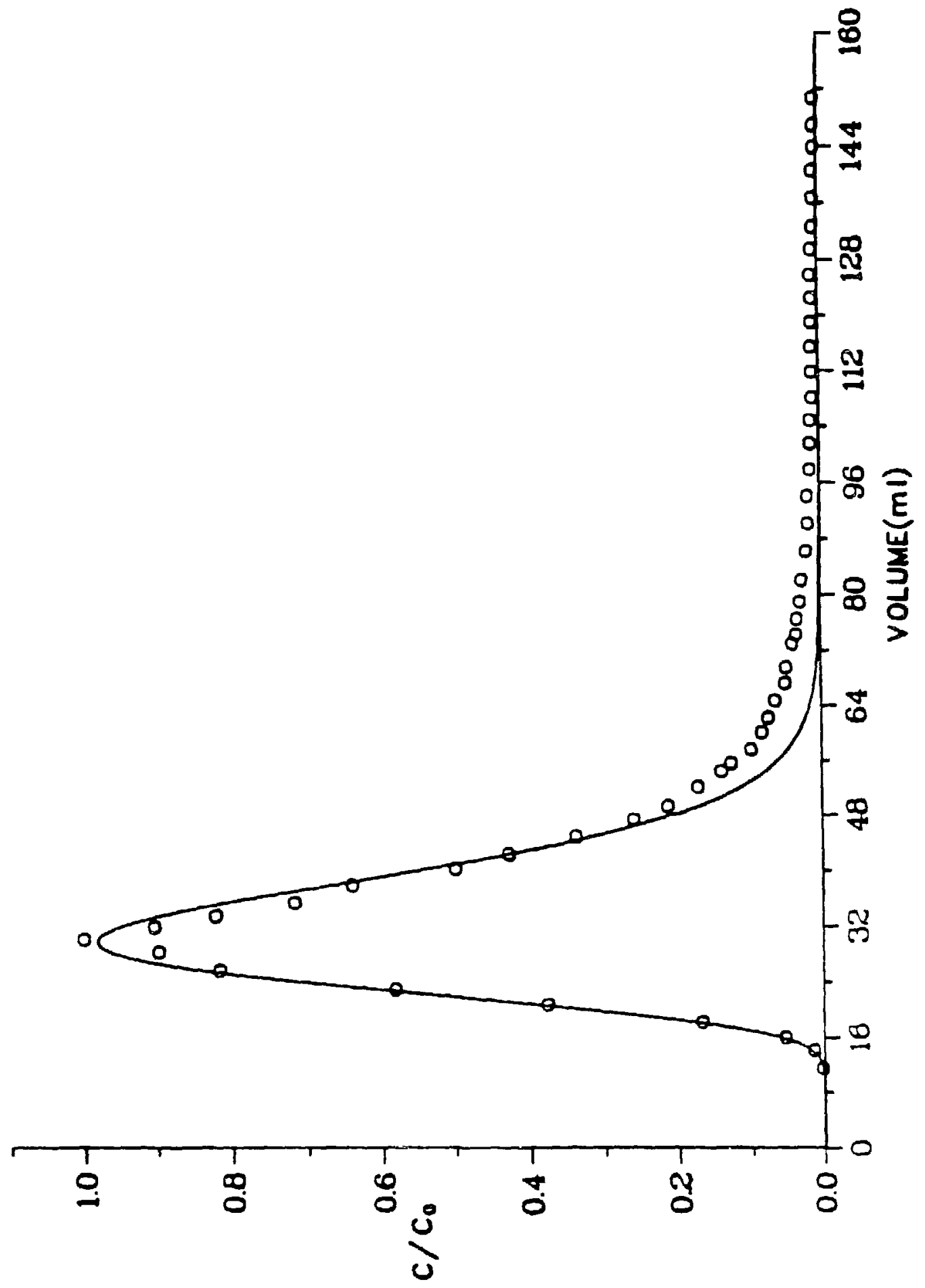




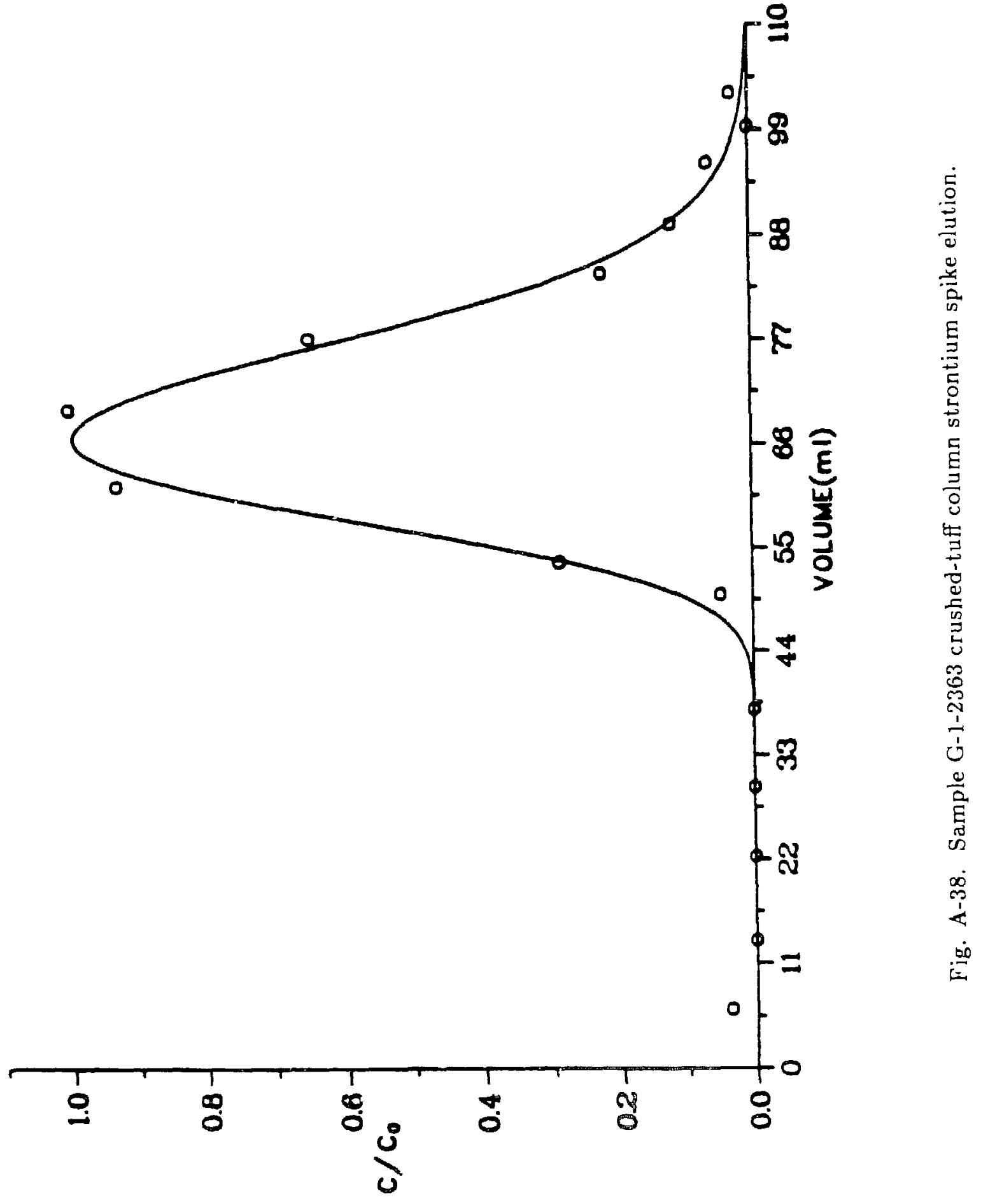




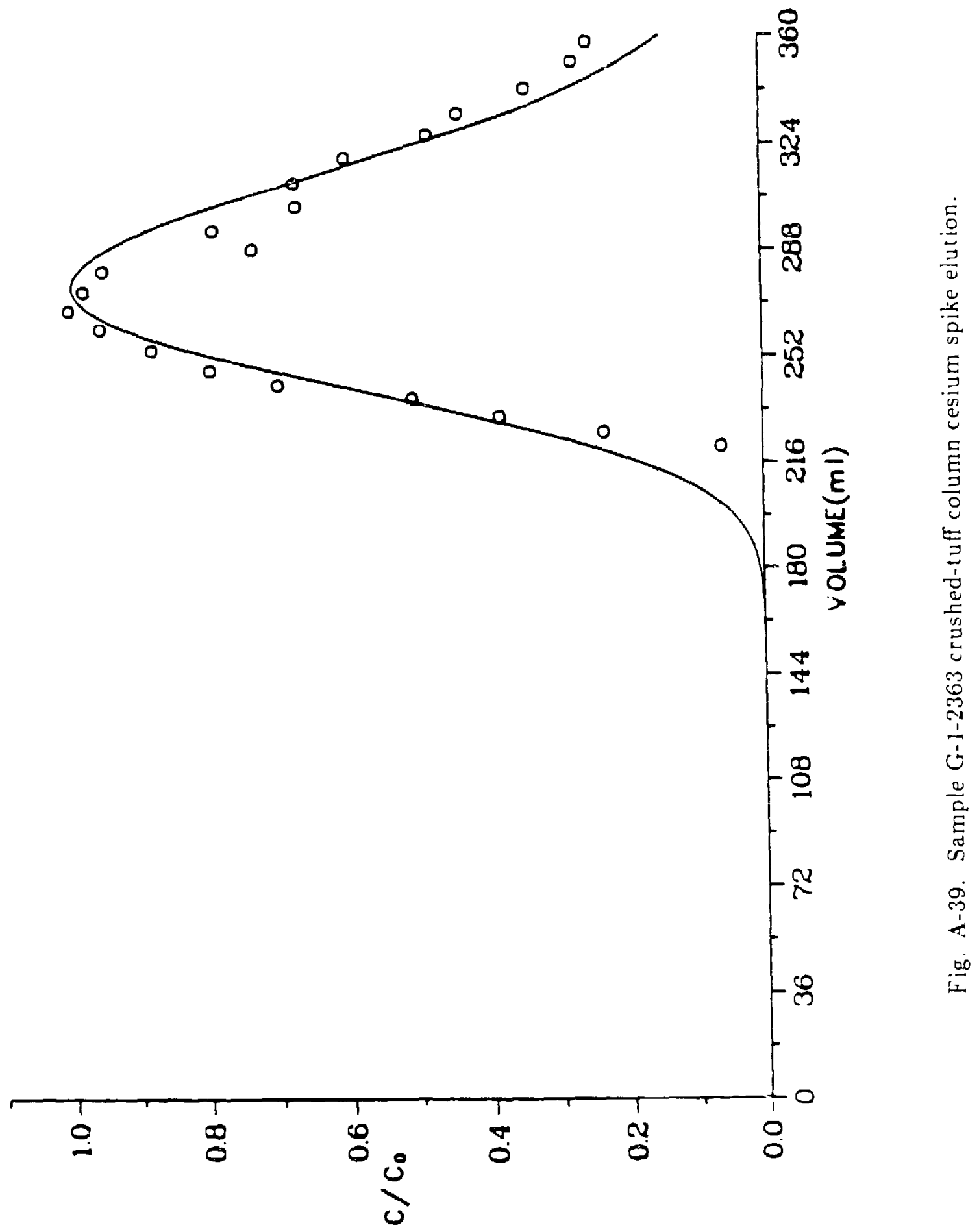




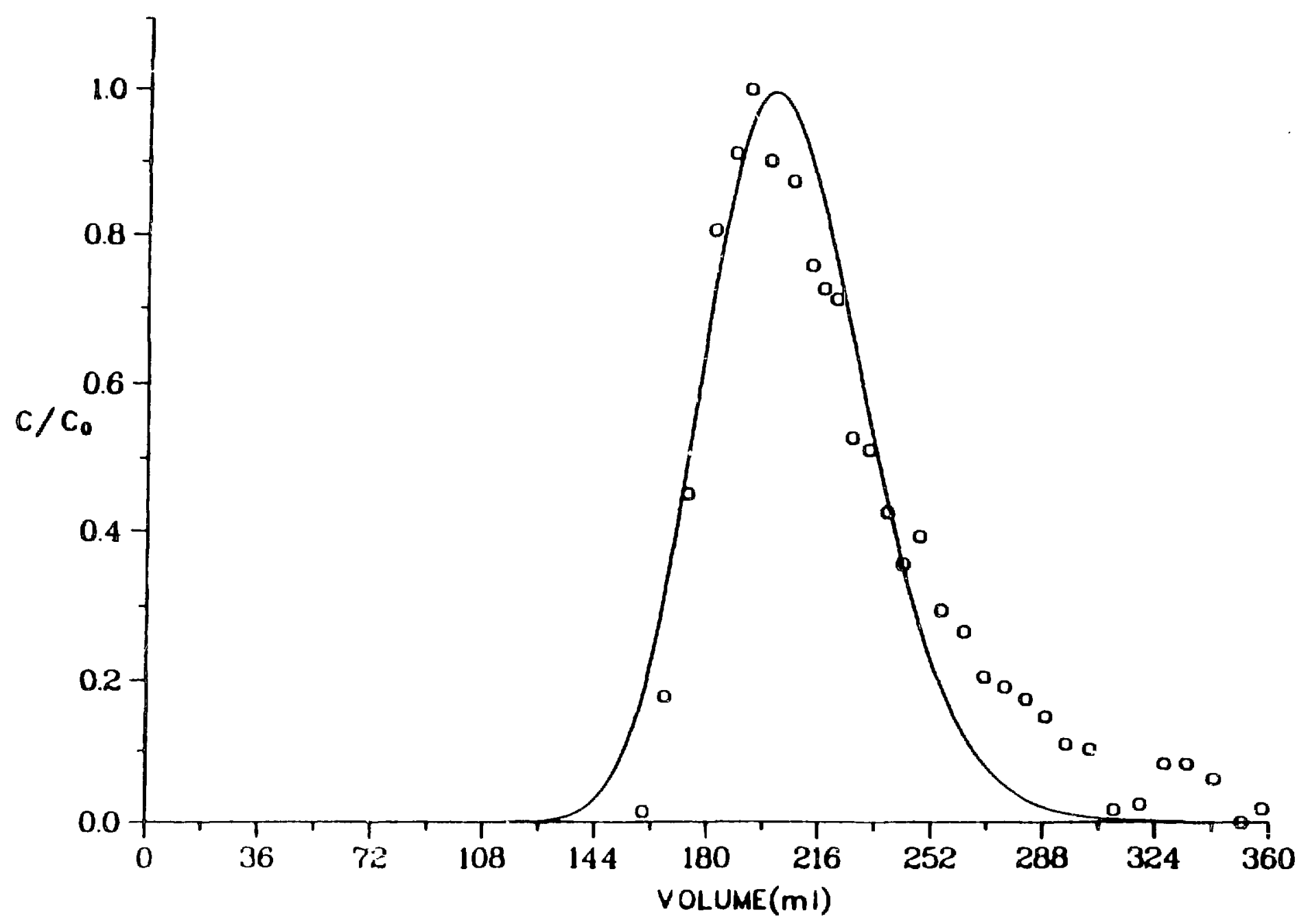

Fig. A-40. Sample G-1-2363 crushed-tuff column barium spike elution. 


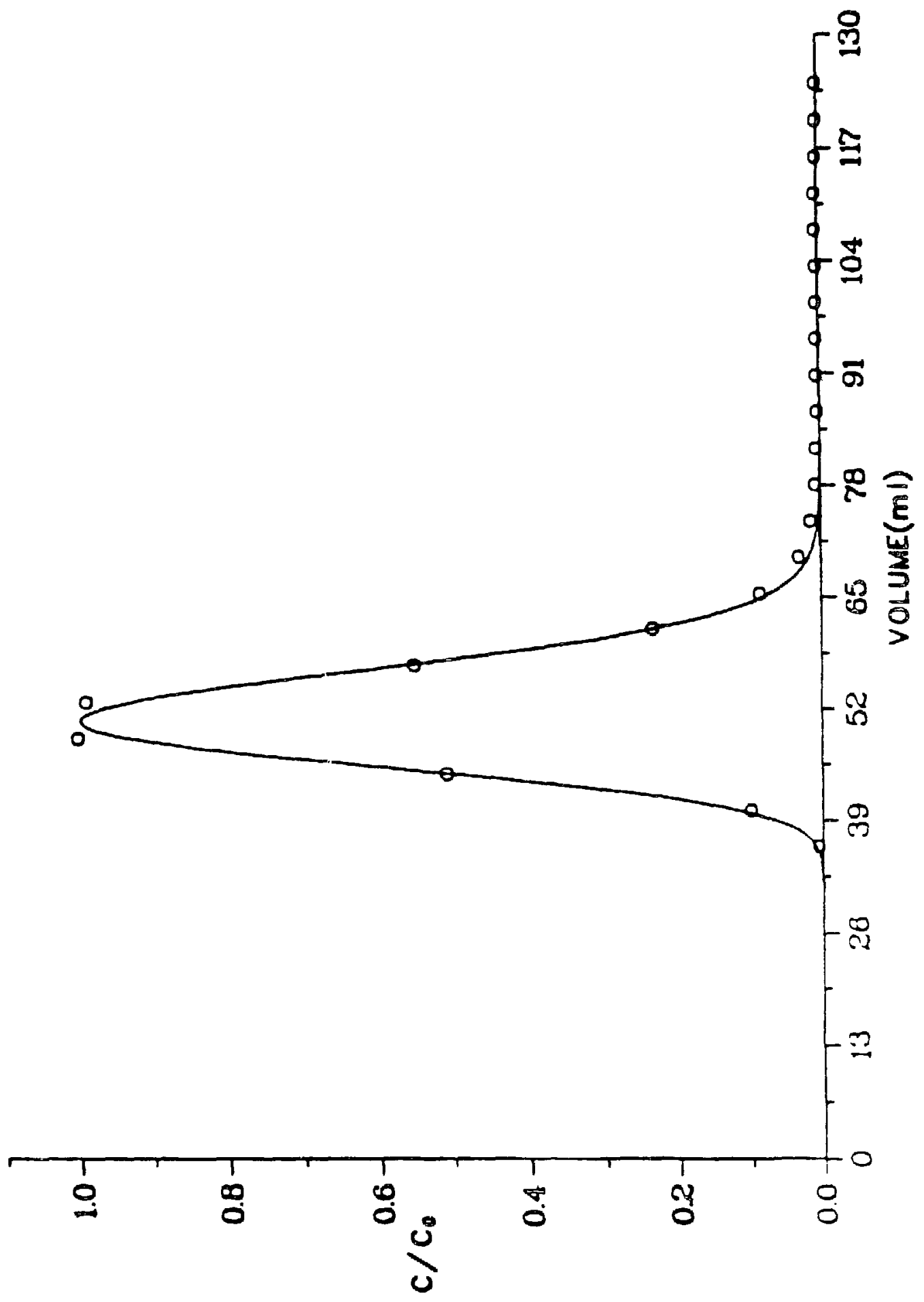




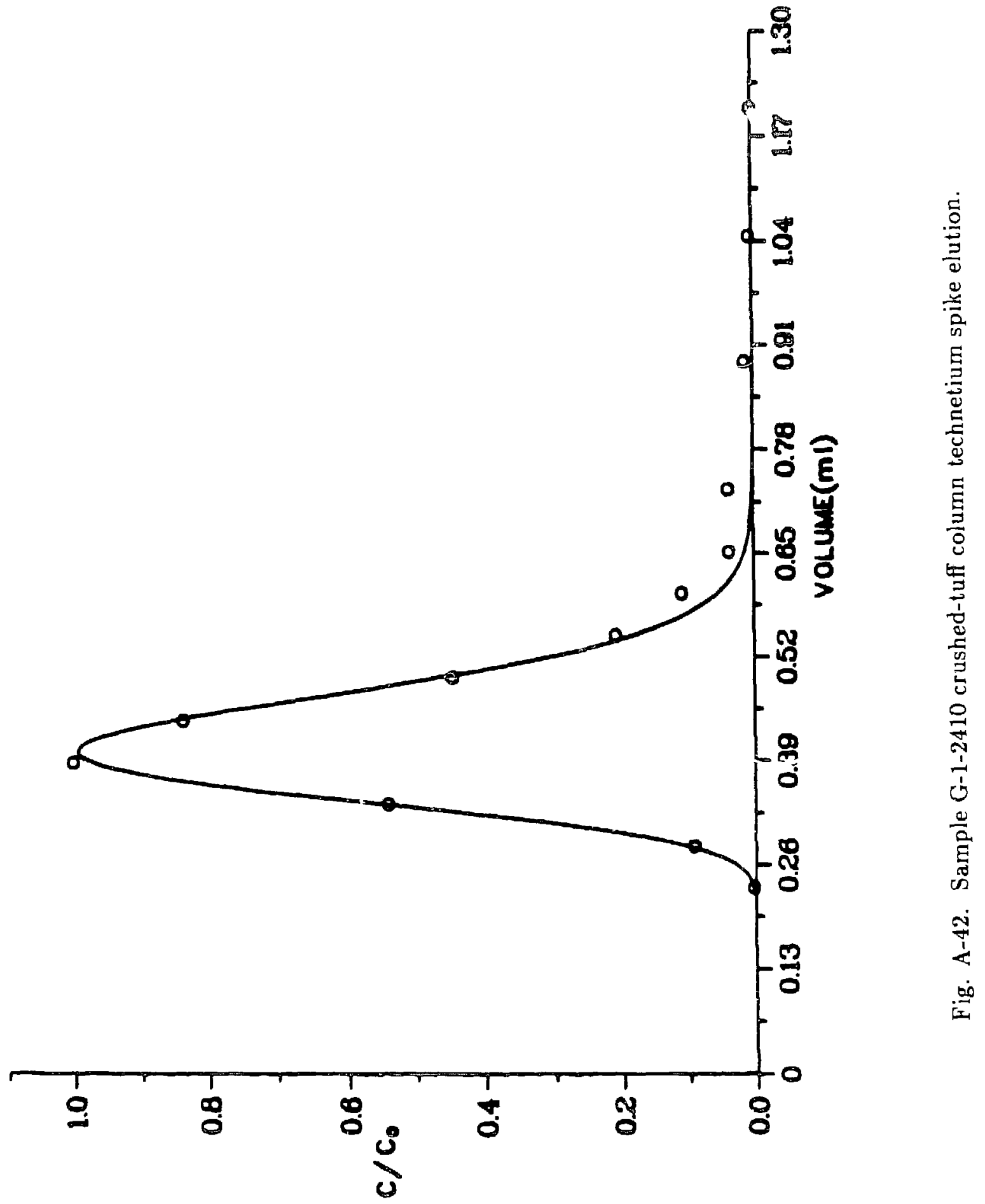


$\stackrel{\infty}{⿶}$

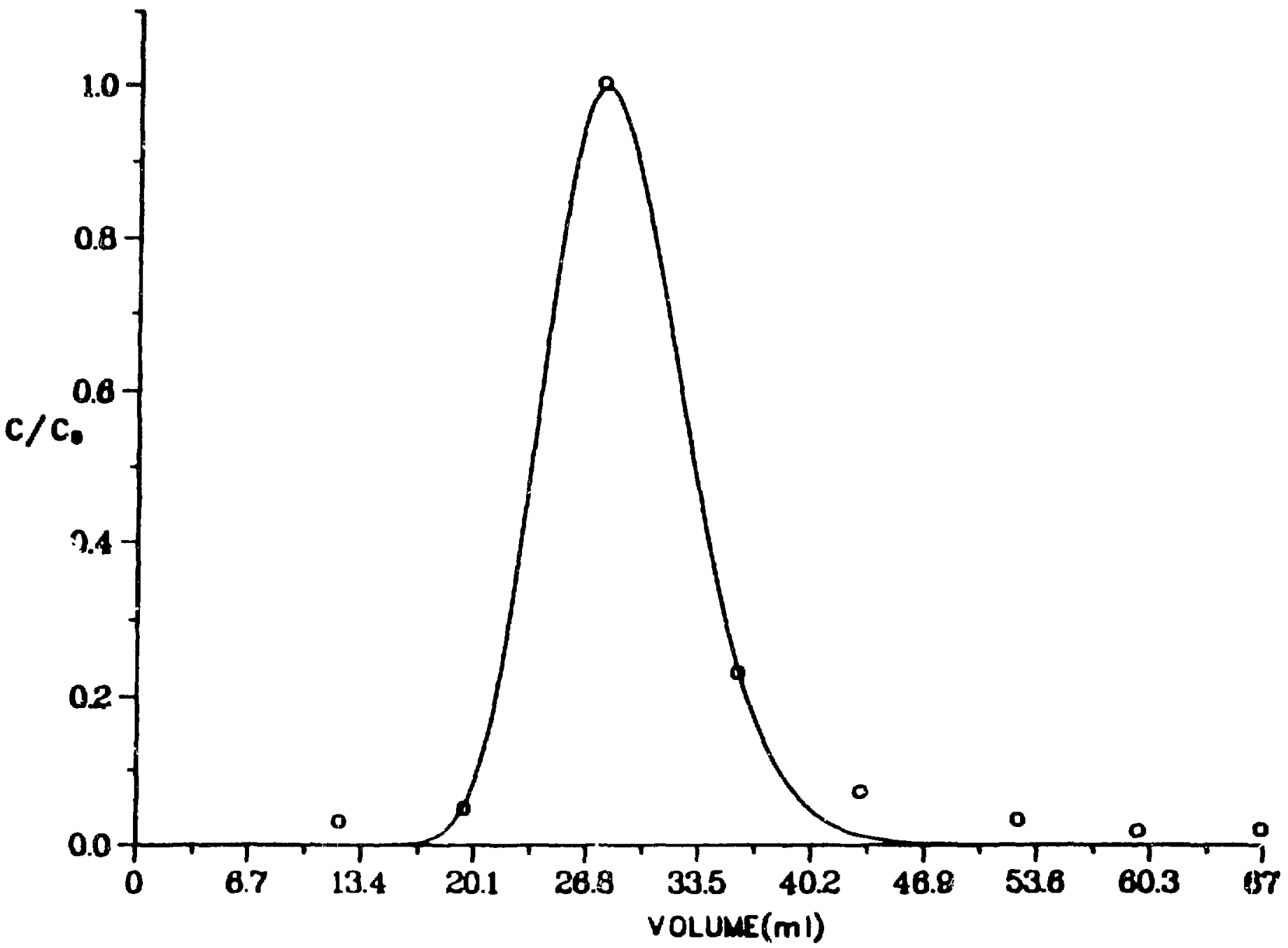

Fig. A-43. Sample (-1-2476 crushed-tuff column strontium spike elution. 


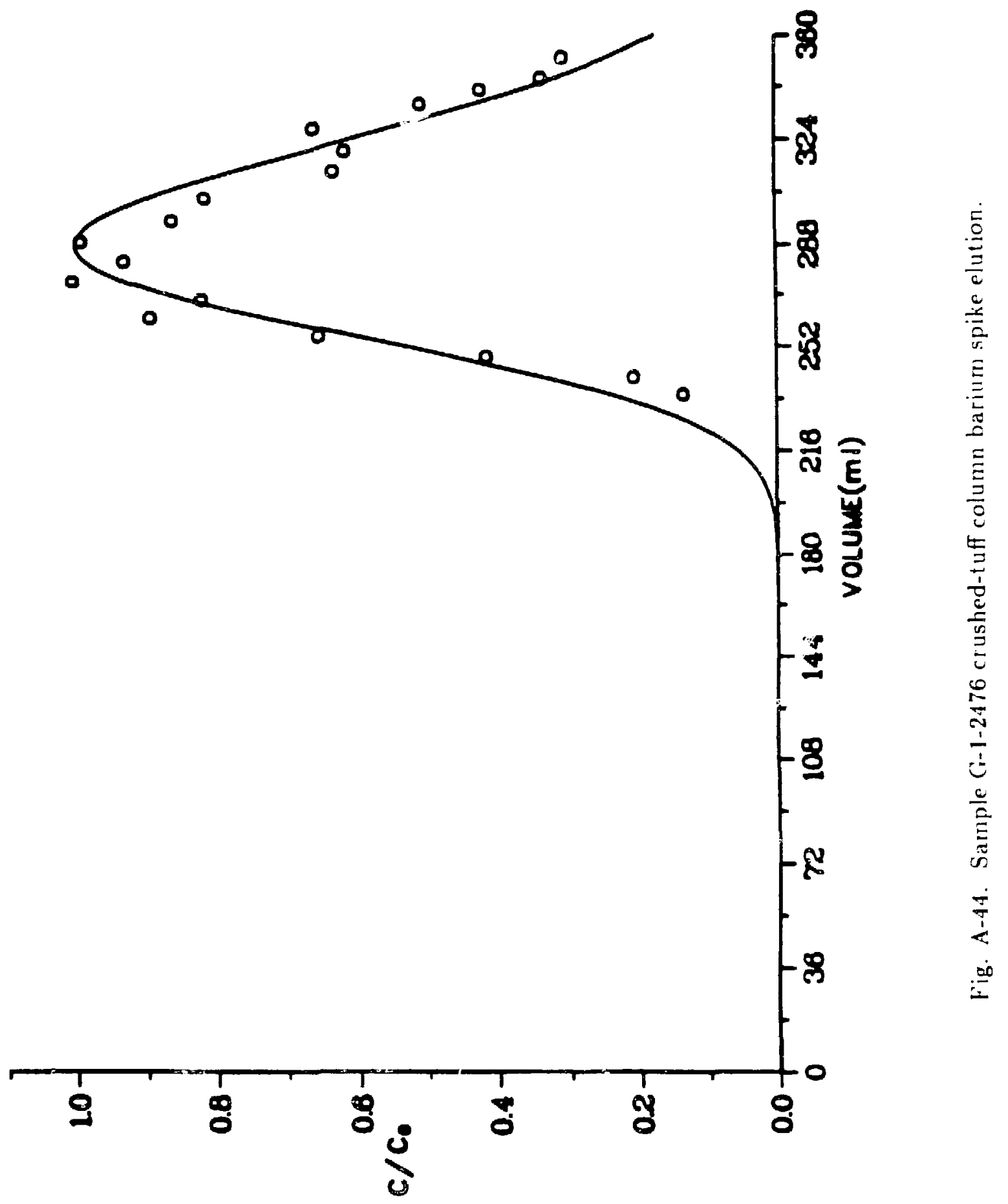




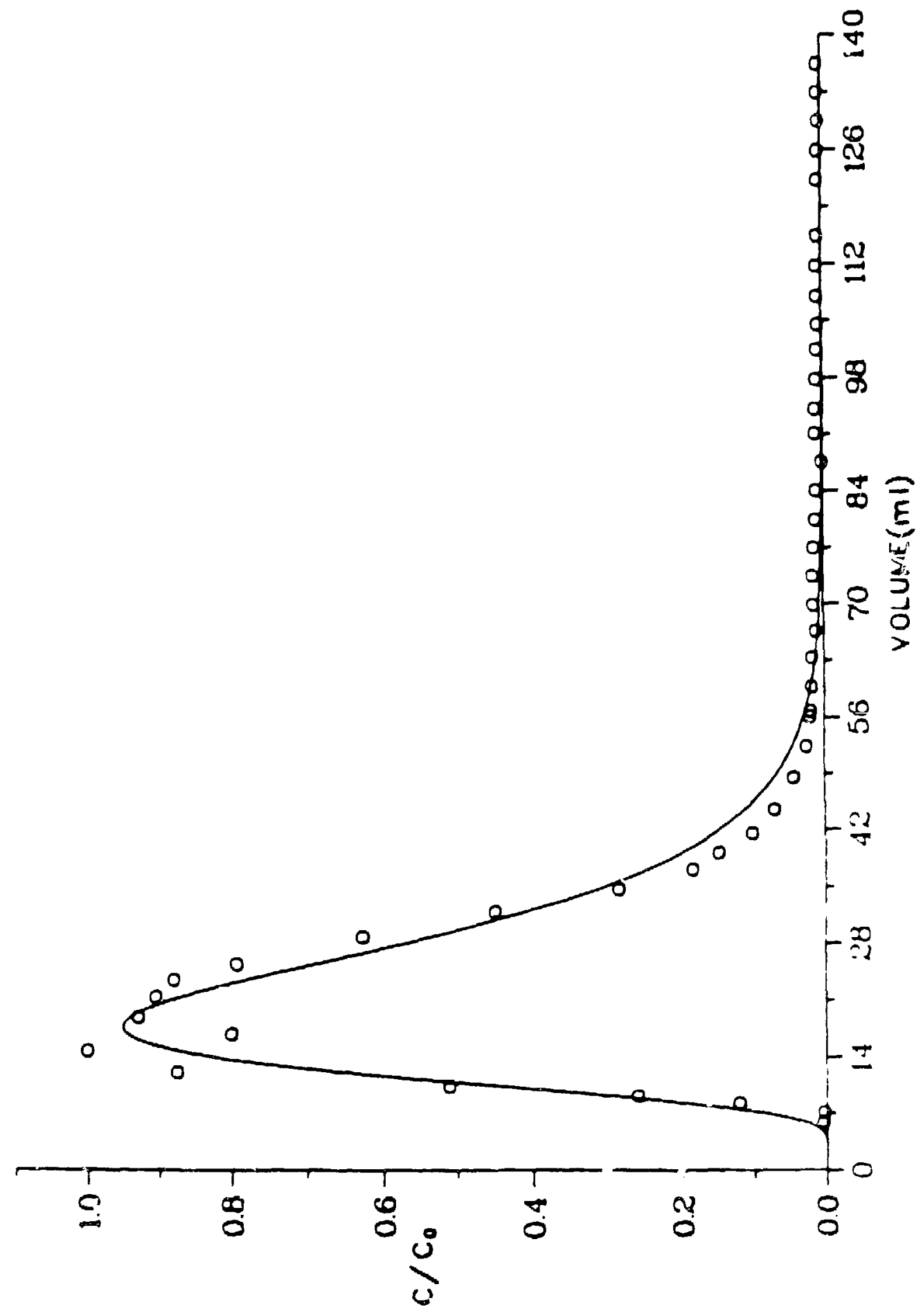




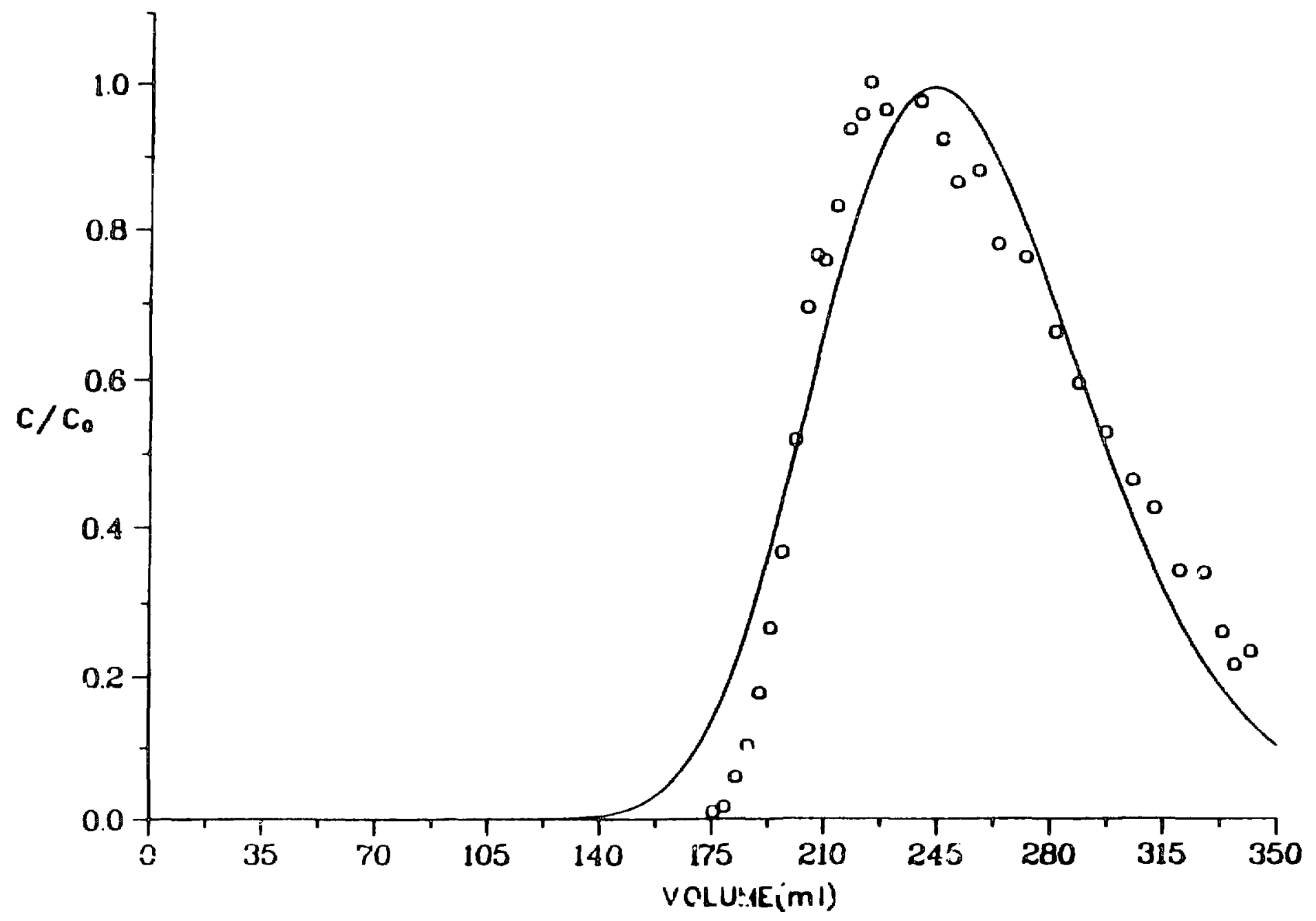


APPENDIX B

FITS OF WAFER UPTAKE TO KINETIC MODEL 


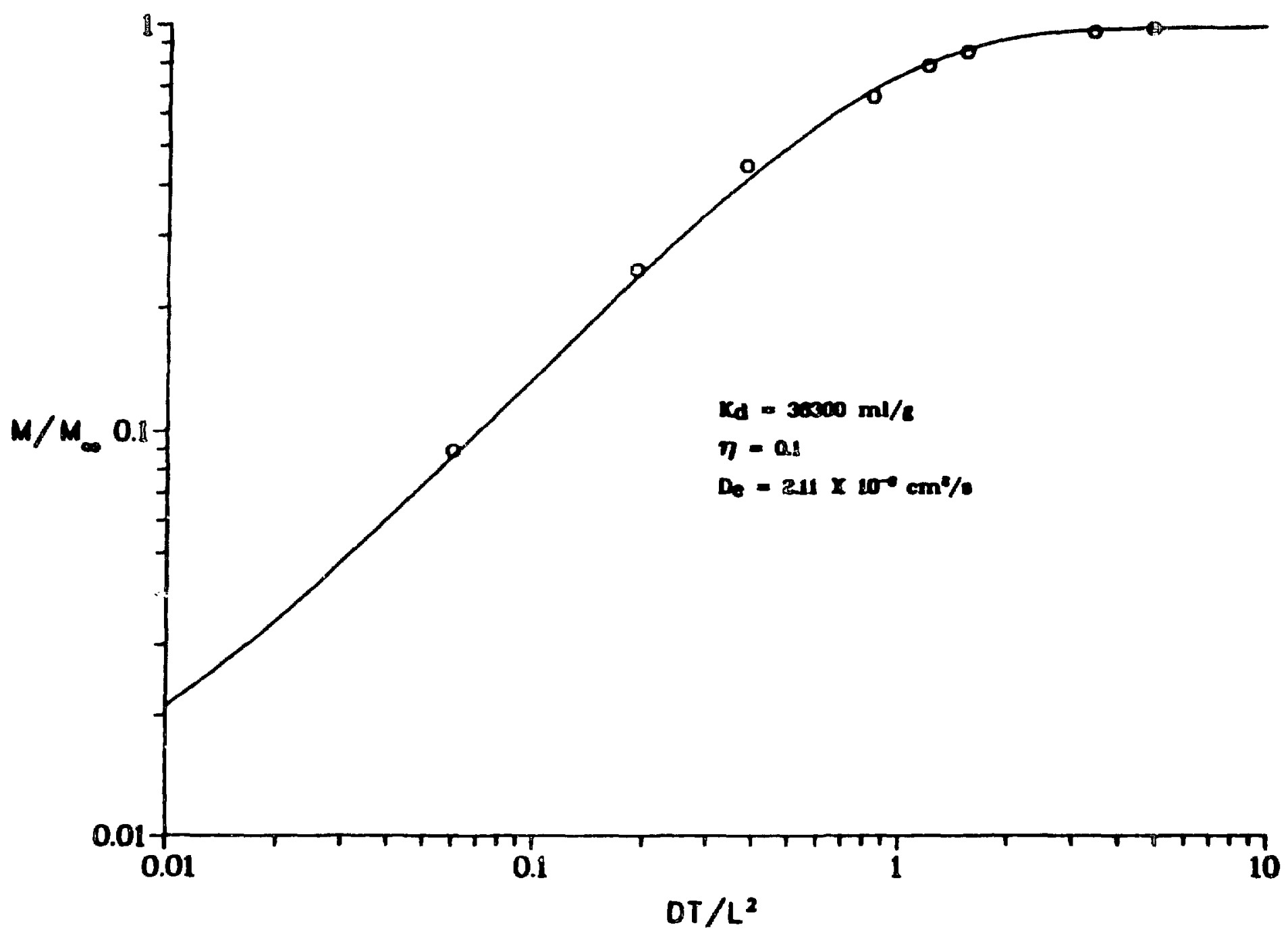




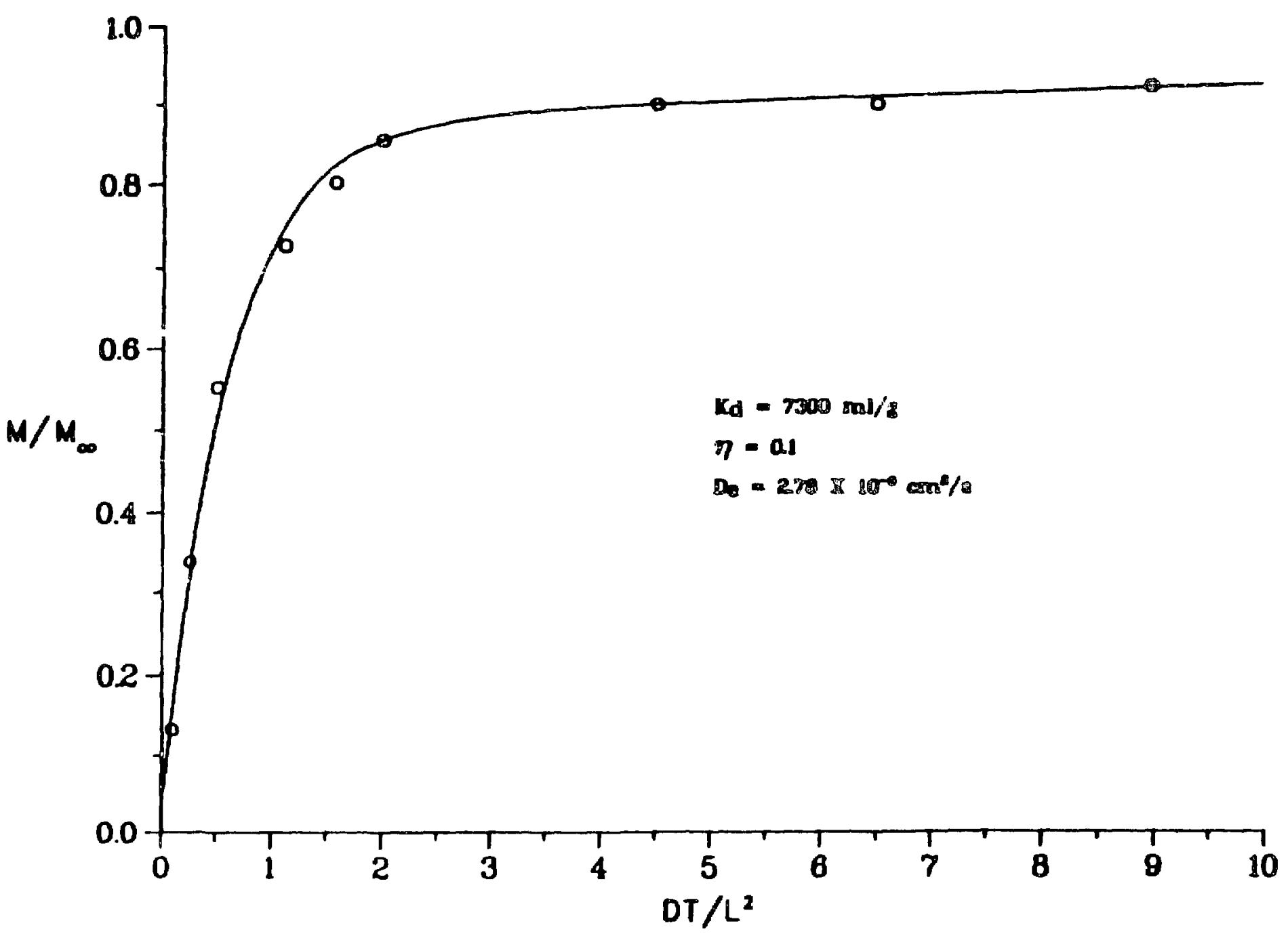

Fig. H-2. Sample G-1-1436 barium diffusion with slow sorption. 


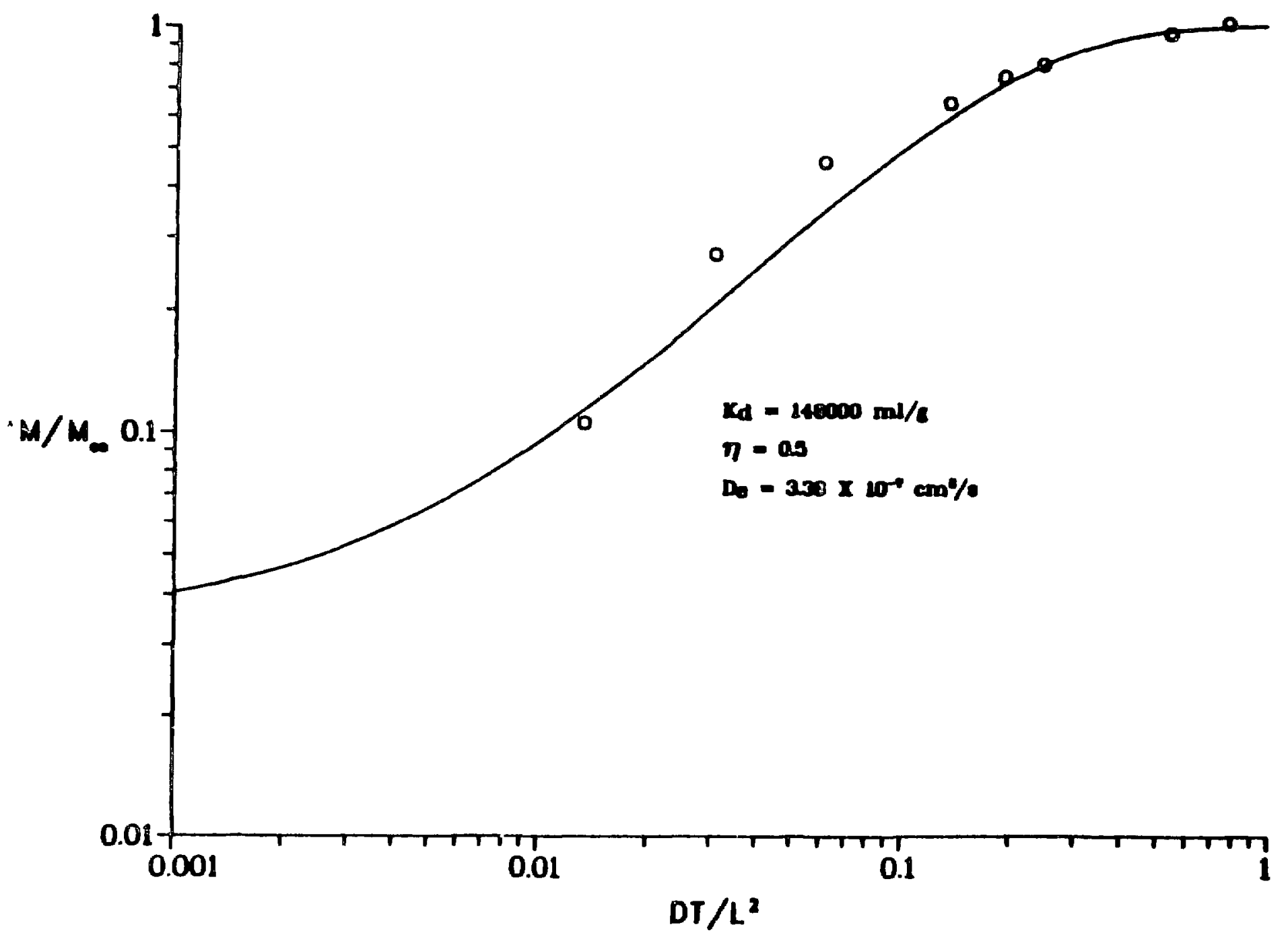




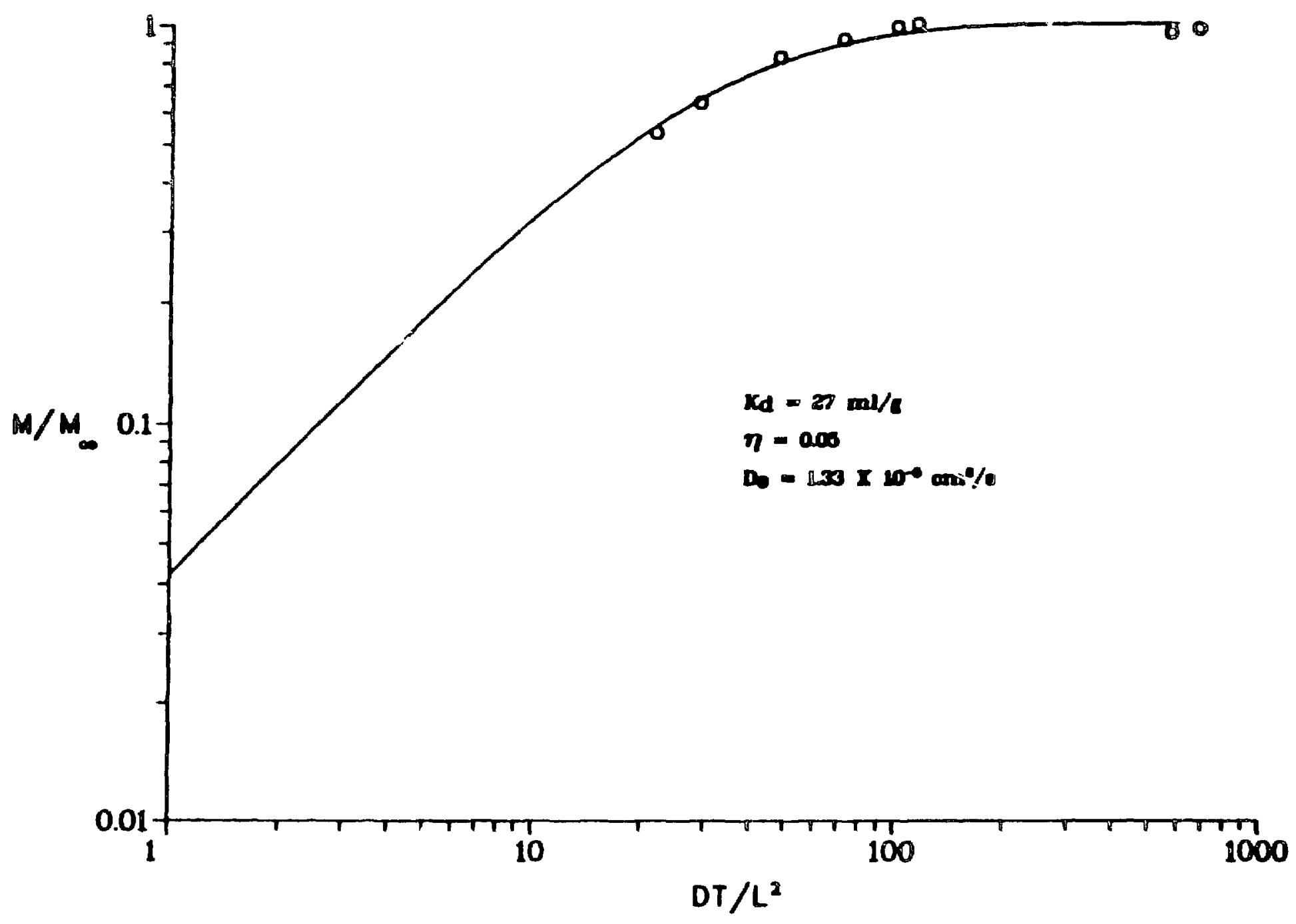

Fig. B-4. Sample (1-1-1883 strontium diffusion with slow sorption. 


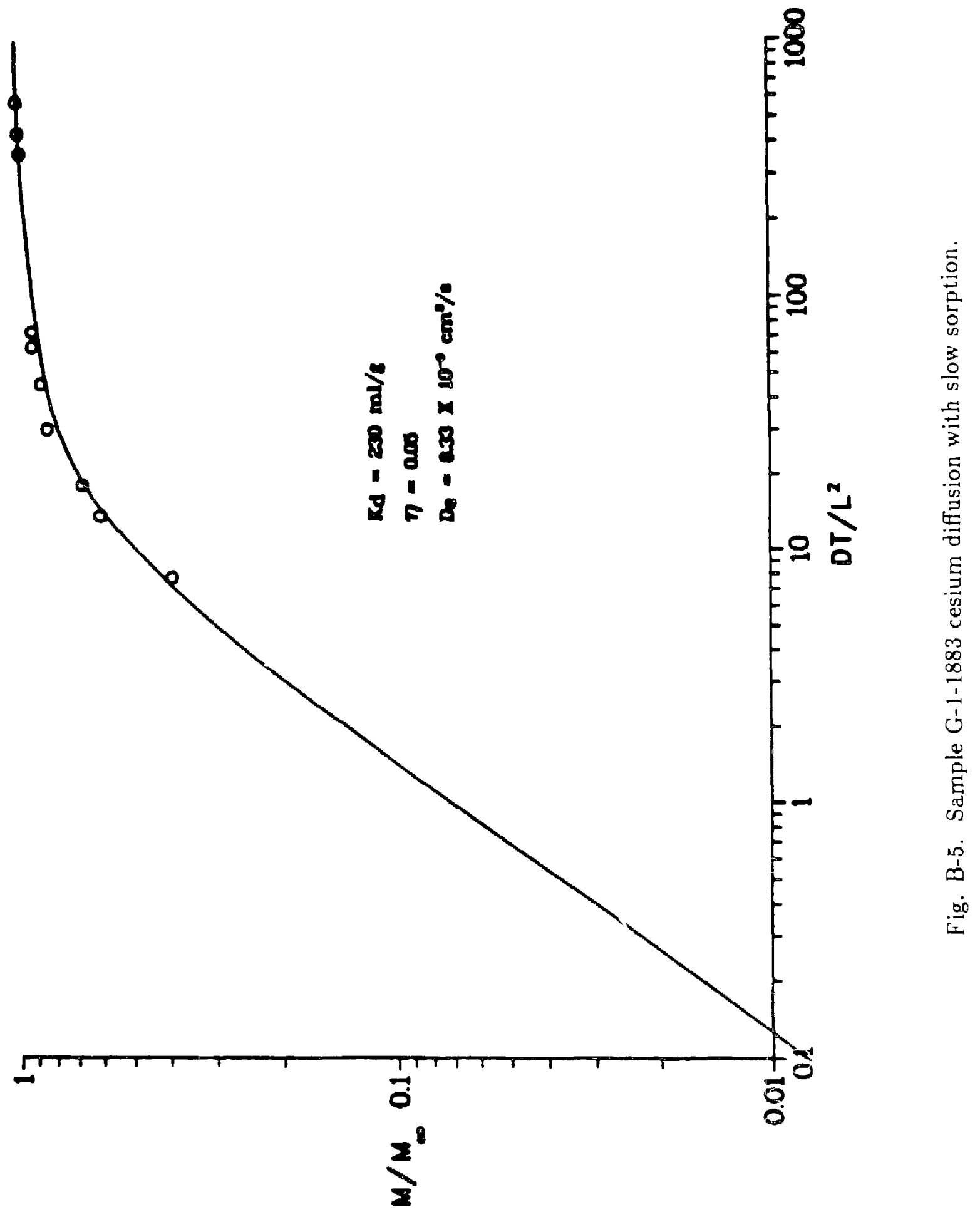




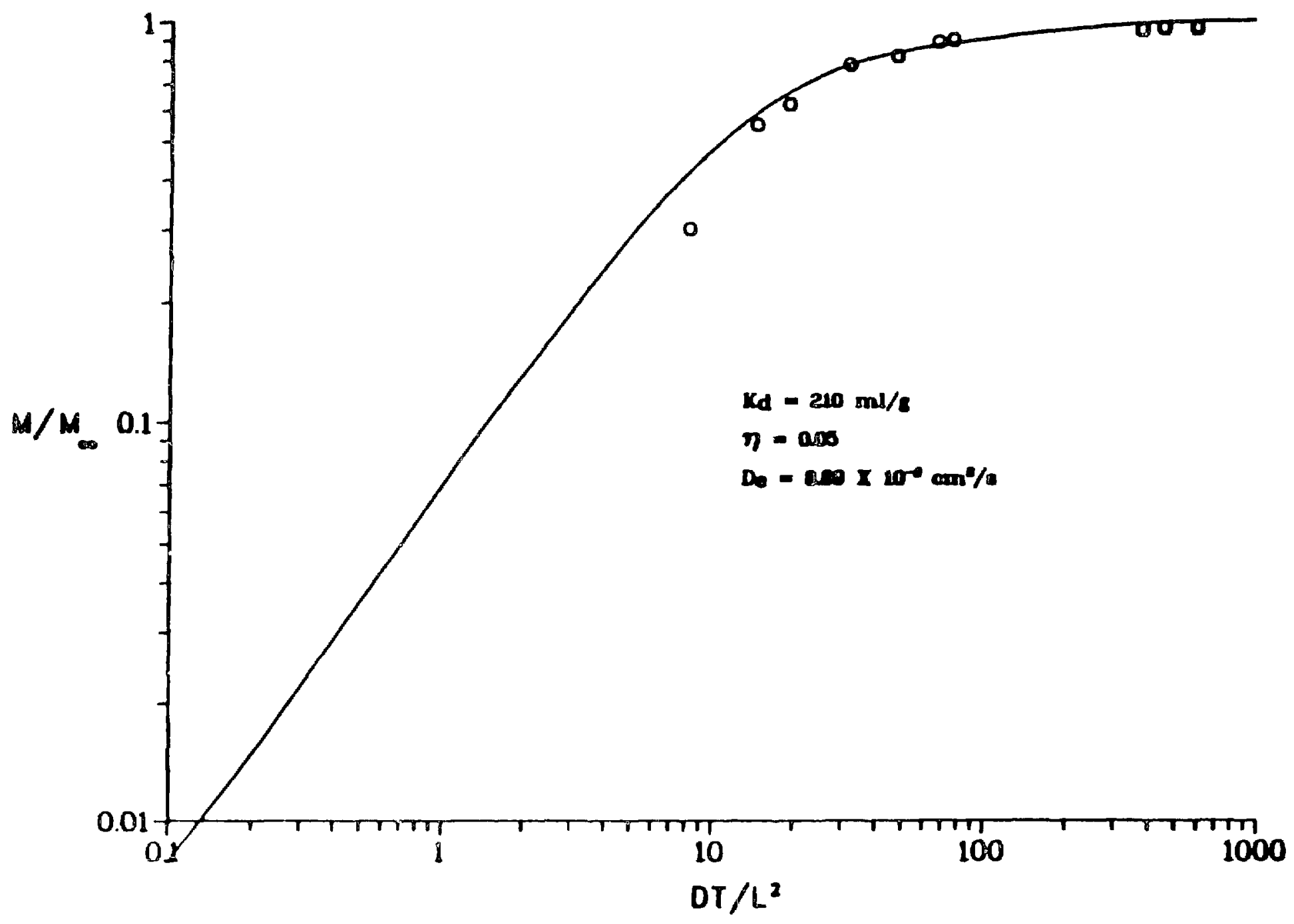

Fig. B-6. Sample G-1-1883 barium diffusion with slow sorption. 


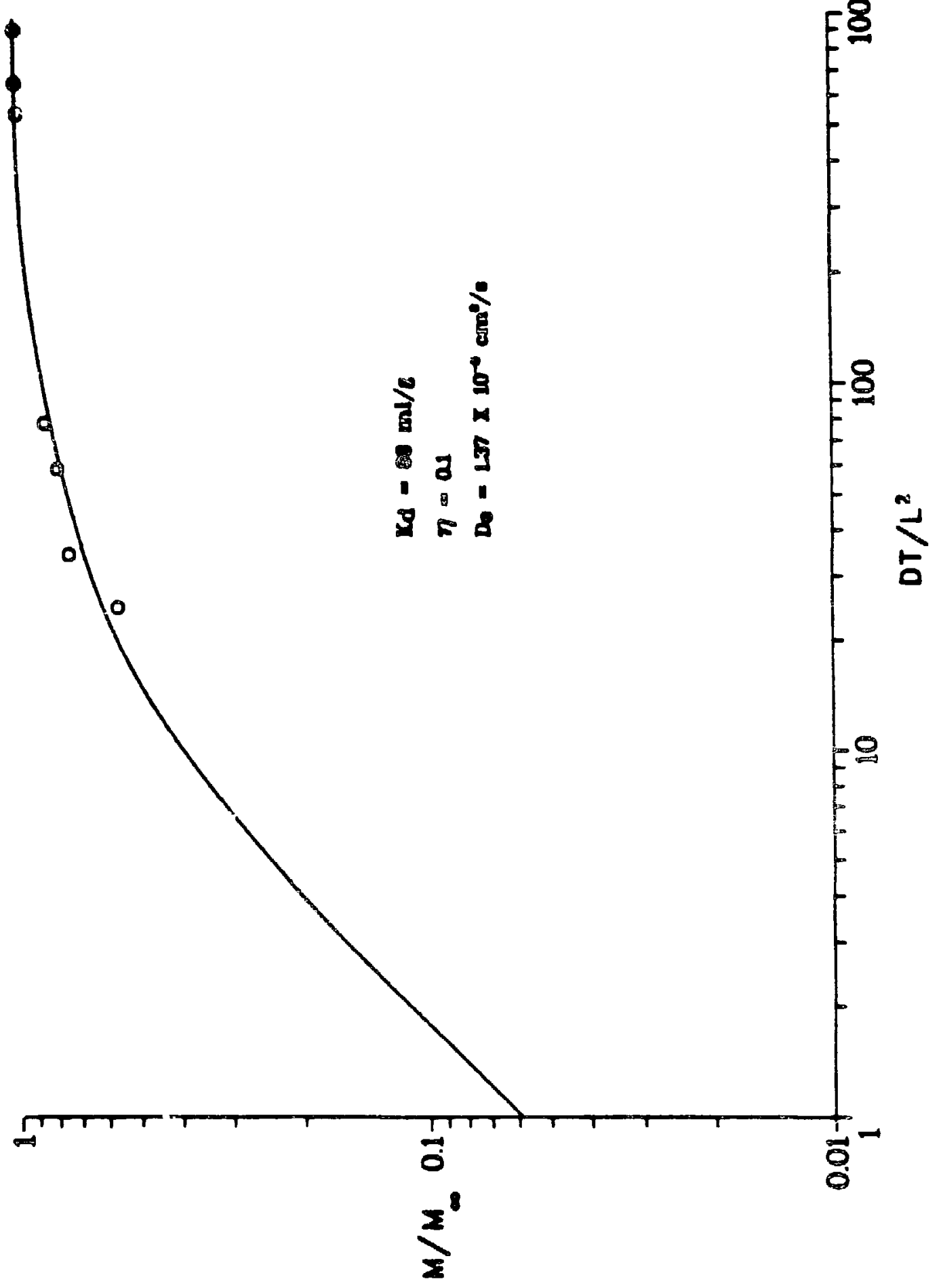

홍

$\frac{3}{5}$

严

돌

$\Xi$

范

$\infty$ 


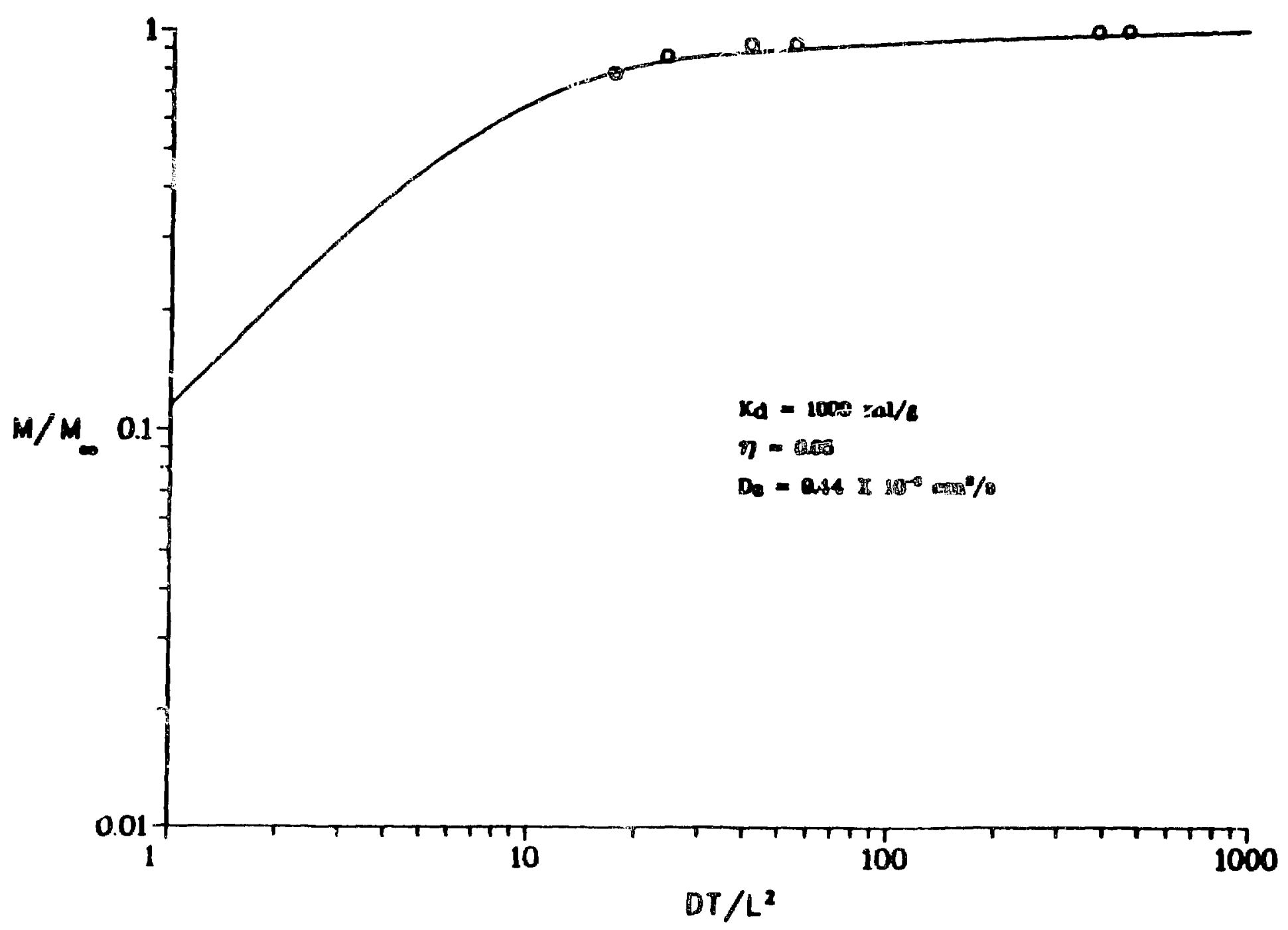

Fig. 3-8. Sample (i-1-1982 cosium diffusion with slow sorption. 


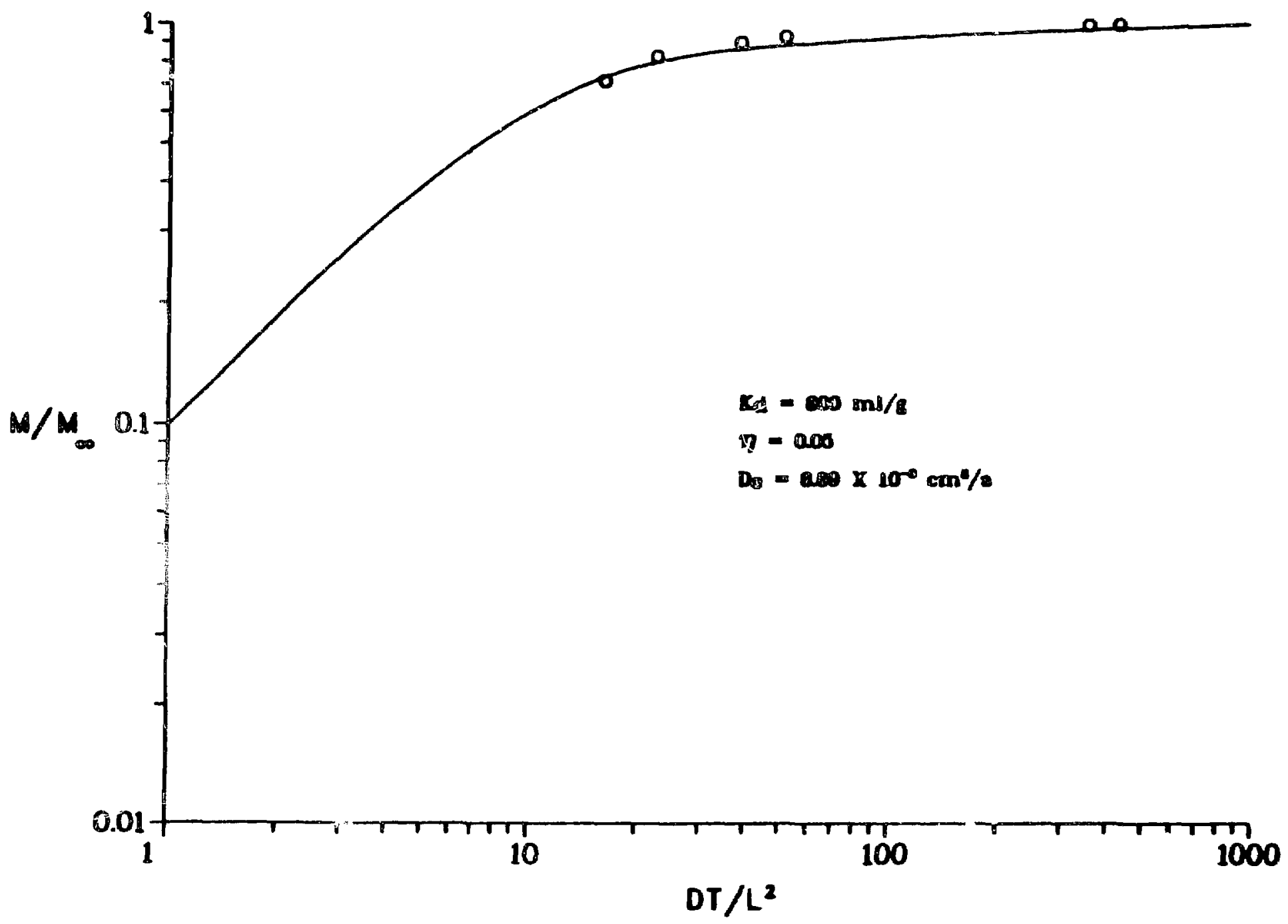

